LA-4946

\author{
Design Study for a \\ Medium-Energy, Intense, \\ Proton-Storage Ring (WNR Ring)
}

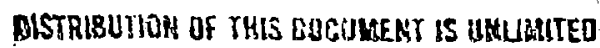


This report was prepared as an account of work sponsored by the United States Government. Neither the United States nor the United States Atomic Energy Commission, nor any of their employees, ner any of their contractors, subcontractors, or their employees, niakes any warranty, express or implied, or assumes any legal liability or responsibility for the ascuracy, completeness or usefulness of any information, apparatus, product or process disclosed, or represents that its use would not infringe privately owned rights.

Printed in the United States of America. Available from National Technical Information Service

U. S. Department of Commerce 5285 Port Royal Road Springfield, Virginia 22151

Price: Printed Copy $\$ 3.00$; Microfiche $\$ 0.95$ 


\title{
Design Study for a Medium-Energy, Intense, Proton-Storage Ring (WNR Ring)
}

\author{
Compiled by
}

Ralph R. Fullwood

NorICE

This report was prepared as an account of work sponsored by the United States Government. Neither the United States nor the United States Atomic Energy Commission, nor any of their employees, nor any of their contractors, subcontractors, or their employees, makes any warranty, express or implied, or assumes any If gal liability or responsibility for the accuracy, com. pleteness or usefulness of any information, appargtus, product or process disclosed, or represents that its use would not infringe privately ownet rights. 


\section{CONRENTS}

FOREWORD $\ldots \ldots \ldots \ldots \ldots \ldots \ldots \ldots \ldots \ldots \ldots \ldots \ldots \ldots \ldots \ldots \ldots \ldots \ldots \ldots \ldots \ldots \ldots \ldots \ldots$

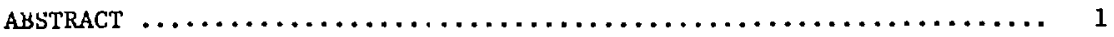

I. SUMMARY AND BACKGROUND $\ldots \ldots \ldots \ldots \ldots \ldots \ldots \ldots \ldots \ldots \ldots \ldots \ldots \ldots$

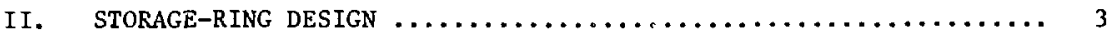

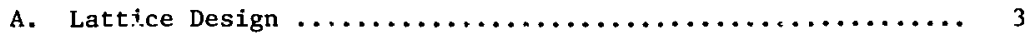

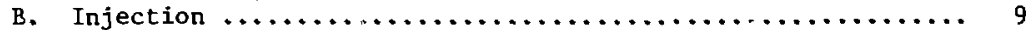

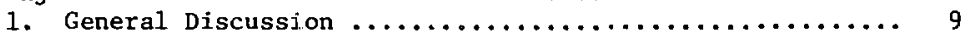

2. Charge-Exchange Injection ..................... 10

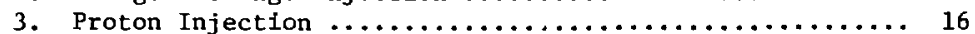

C. Extraction ................................... 19

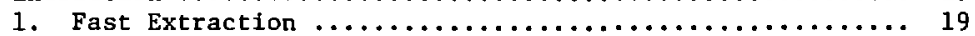

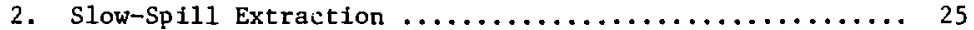

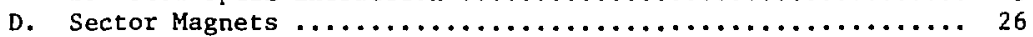

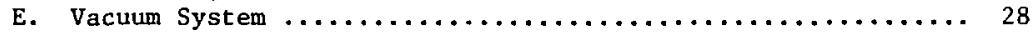

F. Alignment, Geodetics, and Errors ................ 35

III. BEAM STABILITY $\ldots \ldots \ldots \ldots \ldots \ldots \ldots \ldots \ldots \ldots \ldots \ldots \ldots \ldots \ldots$

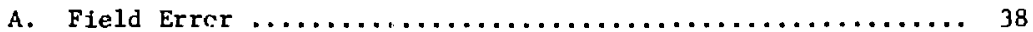

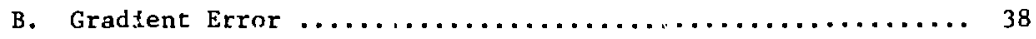

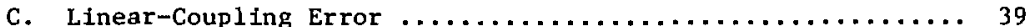

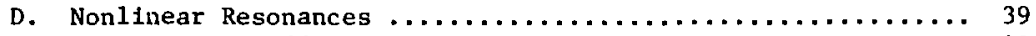

E. Space-Charge Effects .......................... 39

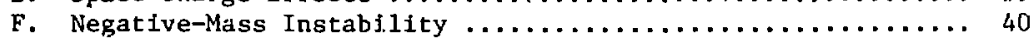

G. Longitudinai Resistive-Wall Eftect .................. 40

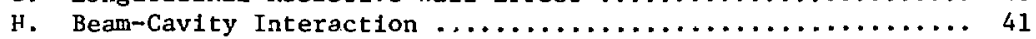

I. Transverse Resistive-Wall Instability $\ldots \ldots \ldots \ldots \ldots \ldots \ldots \ldots, 41$

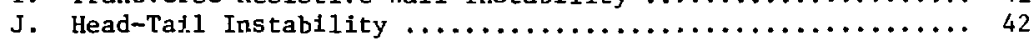

K. Resistive-Wall Effect for a Bunched Beam .............. 43

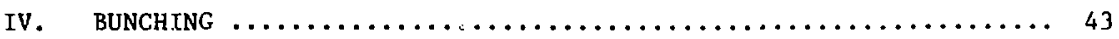

A. Capture and Adiabatic Debunching $\ldots \ldots \ldots \ldots \ldots \ldots \ldots \ldots \ldots$

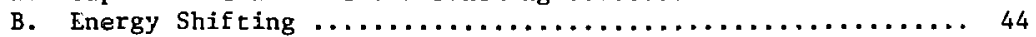

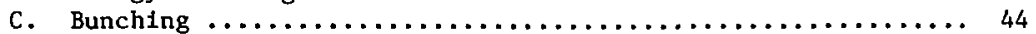

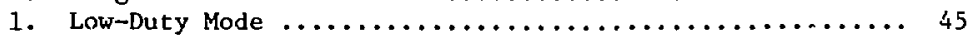

2. High-Duty Mode ......................... 45

D. An Alternative to Debunching $\ldots \ldots \ldots \ldots \ldots \ldots \ldots \ldots \ldots \ldots \ldots \ldots$

V. MEDIUM-ENERGY PROTON-STORAGE RING APPI ICATIONS $\ldots \ldots \ldots \ldots \ldots \ldots . . \ldots 5$

A. Defense Applications $\ldots \ldots \ldots \ldots \ldots \ldots \ldots \ldots \ldots \ldots \ldots \ldots \ldots$

B. Neutron-Pulse Radiolysis . . . . . . . . . . . . . . . . 46

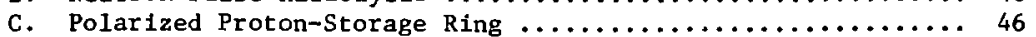

D. Counting Experiments ......................... 47

E. Pulsed Source for an Unstable Particle-Storage Ring ....... 47

1. Muon-Storage Ring ........................ 47

2. Colliding Unstable-Particle Storage Ring ............ 47

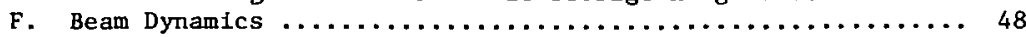

G. Neutron Time-of-Flight Spectrometer $\ldots \ldots \ldots \ldots \ldots \ldots \ldots \ldots \ldots, 48$

VI. GLOSSARY OF SPECIALIZED TERMS $\ldots \ldots \ldots \ldots \ldots \ldots \ldots \ldots \ldots \ldots \ldots \ldots$

REFERENCES $\ldots \ldots \ldots \ldots \ldots \ldots \ldots \ldots \ldots \ldots \ldots \ldots \ldots \ldots \ldots \ldots \ldots \ldots \ldots \ldots \ldots \ldots \ldots$ 


\section{FOREWORD}

This report represents an overall view of the design of a medium-energy proton-storage ring for use at the Los Alamos Meson Physics Facility (LAMPF). It is not, by any means, a design report but does serve to point out areas of difficulty.

The consultants who supplied informacion that has been used verbatim, abstracted, or paraphrased are: R. T. Avery, A. A. Garren, J. T. Gunn, and K. Halbach (all o: LBL),

P. F. Meads, Jr. (Wm. Brobeck \& Associates), C. E. Neilsen (Ohio State Infv.), and D. Norgren and F. S. Reinath (LBL). V. K. Nell (LLL) has been extremely helpful.

Others who contributed helpful dtscussions are: P. 'N. Al11son (LASL), E. D. Courant (BNL), N. Dean (SLAC), H. G. Hereward and P. M. Lapostolle (CERN), M. J. Lee (SLAC), F. E. M111:3 (BNL), P. L. Morton (SLAC), D. Moh1 (CERN-LBL), D. E. Nagle (LASL), K. H. Reich, F. J. Sacherer, and W. Schind1 (CERN), A. M. Sessler (LBL), F. C. Shoemaker (Princeton Untv.), and B. Zotter (CERN). 
DESIGN STUDY FOR A MEDIUM-ENERGY, INTENSE, PROTON-STORAGE RING (WNR FING)

compiled by

Ralph R. Fullwood

ABSTRACT

A design concept for a hig!h-intensity, medium-energy proton storage ring to be used for weapons-related and basic physics reser.rch is presented. This racetrack-type, strong-focusing ring would accumulate $800-\mathrm{MeV}$ protons up to currents of $100 \mathrm{~A}$ in the charge-exihange injection, low-duty mode. After bunching, this current would be extracted as a single 100-nsec pulse. The high-ducy mode accepts 25 turns of injected protons by a combination of orbit and tune shifting to achieve $60 \%$ phase density. In one configuration, the beam woulu ve bunched into five 5-nsec packets, each of which would be extracted separately at a rats of $500 \mathrm{pulses} / \mathrm{sec}$. This design uses the sector magnets of thr Gal-Tech synchrotron modifled to be combinerfunction and st:ong-focusing. Each $180^{\circ}$ bend is separated by a 15.74-m, $\pi-2 \pi$ maiched insert provicing $7 \mathrm{~m}$ of clear drift. Extraction is by a $1^{\circ}$ verical kick of the beam into Iron extraction septa. The design requires the particle energy to be less than the transition energy to avoid the "negative-mass" effect. An analysis of the ion-1nduced Instability requires a vacuur of $10^{-9}$ Torr; aluminum vacuum chambers are sfecified to reduce the resistive-wall effects.

\section{SUMMARY AND BACKGROUND}

Future development of sophisticated nuclear weapons will require better knowledge of neutronics and hydrodynamics. In weapons effects, knowledge of the system's operation in radiation environments, as well as detailed understanding of the physics for the calculations will be required. These facts, coupled with possible constraints on nuclearexplosions testing, point to laboratory acceleratorbased investigations.

It has been shown that medium-energy protons incident on heavy metal targets have an efficiency for neutron production exceeded only by $(d, t)$ fusion. ${ }^{1}$ This $(\mathrm{p}, \mathrm{xn})$ reaction which leads to 20-10 neutrons per incident proton has a spectrum bracketIng that of nuciear weapons. The spectrum decreases at high energy as $E^{-1.9}$, compared with that from electron bombardment $(e, \gamma, x n)$, which decreases as $E^{-2,8}$ (where $E$ is the neutron energy). The target heating is $56 \mathrm{MeV} /$ neutron, compared with the 2000$\mathrm{MeV} /$ neutron electron heating. This reduced target heating results in a higher neutron. burst capability than ocher metnods of neutron production. The neutrons from the $(P, x n)$ reaction have reduced gamma content because of the mode of production and target self-shielding. (Gamma production, if desired, can be achitved by loading the target with materials having strong gamma-production properties.)

To effectively support weapons research, however, requires a much larger pulse of protons for a shorter duration than the Los Al.amos Meson Physics Facility (LAMPF) can provide. Therefore, the recent development of storage rings becomes important. In $1956^{2,3}$ it was pointed out that: for relativistic beams, the center-of-mass energy in reactions between identical particles does not increase linearly, but as the square root of the bombarding energy. This could be circumvented by having simllar accelerators firing at each other, but such a procedure would be very inefficlent because interactions would seldom occur and the beams would be wasted. Therefore the concept of storing beams of 
particles and recirculating them to increase the reaction probability originated.

The reaction probability is proportional to the product of the interacting currents. This has led to intensive studies of beam-stability phenomena to try to raise the maximum current capability. The success of these efforts (as well as other technological developments) has led to the rapid progress in storage rings depicted in Table I and Fig. 1.

Design of the weapons neutron research (WNR) ring has beeli controlled primarily by the need to obtain the largest possible pulse of protons at a very low duty rate. This has led to adoption of charge-exchange injection ${ }^{4,5}$ to avoid the 1imitations on the amount of beam storage imposed by Llouville's theorem.

We do not visualize thar this mode of operation will rake a ling time, parcly for experimental setup reasous. Having designed for these large currents, we can certalrily store less current. Therefore, a high-duty, low-stored-current mode of operation is also planned. This mode would use conventional multiturn injection of the proton beam into radial and vertical becatron space and would be limited ts 25 turns. Table II summarizes the design performance specifications for the WNR ring.

These specifi ttions do not reflect the versatility of the ring, but rather represent certaia extreme conditions. The design requtres that rf bunching be used to provide a beam-free region to allow tine for the extraction magnet to come on and scabilize (2.5 nsec). Within this constraint and the constraint that the bunching factor be no greate: than 10 , other pulse patterns are permitted up to $250 \mathrm{nsec}$, the period of the storage ring. We also intend to provide very long pulses, called a slow spill, by shifting the tune onto a resonance. There is a blank space in the performance between 250 nsec and the nearly dc operation of a slow spill which can be filled only by the direct LAMPF beam.

TABLE I

VARIOUS STORAGE RINGS THROUGHOUT THE WORLD

\begin{tabular}{|c|c|c|c|c|c|c|}
\hline & & Status & Particles & $\begin{array}{c}\begin{array}{l}\text { Energy } \\
(\mathrm{GeV})\end{array} \\
\end{array}$ & $\begin{array}{l}\text { Ring Current } \\
\text { (A) }\end{array}$ & S17.e (M) \\
\hline CANADÁ: & $\begin{array}{l}\text { SASKATOON } \\
\text { TORONTO }\end{array}$ & $\begin{array}{l}\text { STUDY } \\
\text { STUDY }\end{array}$ & $\begin{array}{l}e^{*} \\
e^{-}\end{array}$ & $\begin{array}{c}0.1-0.3 \\
0.5\end{array}$ & 0.5 & \\
\hline CERN : & $\begin{array}{l}\text { GENEVA, CESAR } \\
\text { GENEVA, ISR } \\
\text { GENEVA, MSR }\end{array}$ & $\begin{array}{l}\text { 1963, RETIRED } \\
\text { 1971, OPERAT IWG } \\
\text { 1965, OPERAT ING }\end{array}$ & $\begin{array}{r}e^{-} \\
p, p \\
\mu^{-}\end{array}$ & $\begin{array}{l}0.002 \\
28.0 \\
1.3 \mathrm{GeV} / \mathrm{c}\end{array}$ & $\begin{array}{l}20.0 \\
40 \mu^{-/ P u l s e}\end{array}$ & $\begin{array}{r}7.6 \\
300.0 \\
5.0\end{array}$ \\
\hline FRANCE: & $\begin{array}{l}\text { GRSAY, ACO } \\
\text { SACLAY }\end{array}$ & $\begin{array}{l}\text { 1966, OPERATING } \\
\text { STUDY }\end{array}$ & $\begin{array}{c}e^{-}, e^{+} \\
e^{-}\end{array}$ & $\begin{array}{l}0.5 \\
0.045\end{array}$ & 0.5 & $\begin{array}{r}100.0 \\
7.0\end{array}$ \\
\hline GERMANY : & HAMBURC, DORIS & 1973, CONSTRUCTION & $e^{-}, e^{+}$ & 3.5 & 6.0 & $55 \times 110$ \\
\hline ITALY: & $\begin{array}{ll}\text { FRASCATI, ADA } \\
\text { FRASCATI, ADONE }\end{array}$ & $\begin{array}{l}1951, \text { RETIRED } \\
1967, \text { OPERATING }\end{array}$ & $\begin{array}{l}e^{-}, e^{+} \\
e^{-}, e^{+}\end{array}$ & $\begin{array}{l}0.25 \\
1.5\end{array}$ & $\begin{array}{l}0.001 \\
0.04\end{array}$ & $\begin{array}{r}3.0 \\
33.5\end{array}$ \\
\hline USSR: & $\begin{array}{l}\text { KHARKOV } \\
\text { NOVOSIBIRSK, VEP-1 } \\
\text { NOVOSIBIRSK } \\
\text { NOVOSIEIRSK, VEPP-2 } \\
\text { NOVOSIBLRSK, VEPP-3 } \\
\text { NOVOSIBIRSK, VAPP }\end{array}$ & $\begin{array}{l}\text { 1963, RETIRED } \\
\text { 1963, OPERATING } \\
\text { 1964, EXPERIMENT } \\
\text { 1966, OPERATING } \\
\text { 1970, OPERAT ING } \\
\text { CONSTRUCTION }\end{array}$ & $\begin{array}{c}e^{-}, e^{-} \\
e^{-}, e^{-} \\
H^{-}+p \\
e^{-}, e^{-} \\
e^{-}, e^{+} \\
p, \bar{p} ; e^{-}, e^{+}\end{array}$ & $\begin{array}{l}0.1 \\
0.13 \\
0.001 \\
0.7 \\
3.5 \\
23.6\end{array}$ & $\begin{array}{l}0.04 \\
1.0 \\
2, \quad 0.02 \\
0.5 \\
10,0.01\end{array}$ & $\begin{array}{l}2.0 \\
1.0 \\
0.42 \\
3.5 \\
28 \times 16 \\
90 \times 125\end{array}$ \\
\hline USA: & $\begin{array}{l}\text { CAMBRIDGE, BYPASS } \\
\text { LOS ALAMOS, WNR RING } \\
\text { LIVERMORE } \\
\text { WESTON, NAL } \\
\text { MADISON, MURA } \\
\text { PRINCETON/STANFORD } \\
\text { STANFORD, SLAC-SPEAR }\end{array}$ & $\begin{array}{l}\text { 1970, OPERATING } \\
\text { STUDY } \\
\text { 1971, CONSTRUCTION } \\
\text { STUDY } \\
\text { 1967, OPERATING } \\
\text { 1961, RETIRED } \\
\text { 1972, CONSTRUCIION }\end{array}$ & $\begin{array}{c}e^{-}, e^{+} \\
p, H^{-} \rightarrow p \\
e^{-} \\
p, p ; p, \bar{p} \\
e^{-}, e^{+} \\
e^{-}, e^{-} \\
e^{-}, e^{+}\end{array}$ & $\begin{array}{c}3.5 \\
0.8 \\
0.004 \\
100.0 \\
0.2 \\
0.5 \\
0.3\end{array}$ & $\begin{array}{c}0.03 \\
100,0.6 \\
200.0 \\
1450.0 \\
0.1 \\
0.1 \\
0.5\end{array}$ & $\begin{array}{c}72.0 \\
8.0 \\
8.0 \\
100.0 \\
3.0 \\
4.0 \\
60 \times 70\end{array}$ \\
\hline
\end{tabular}




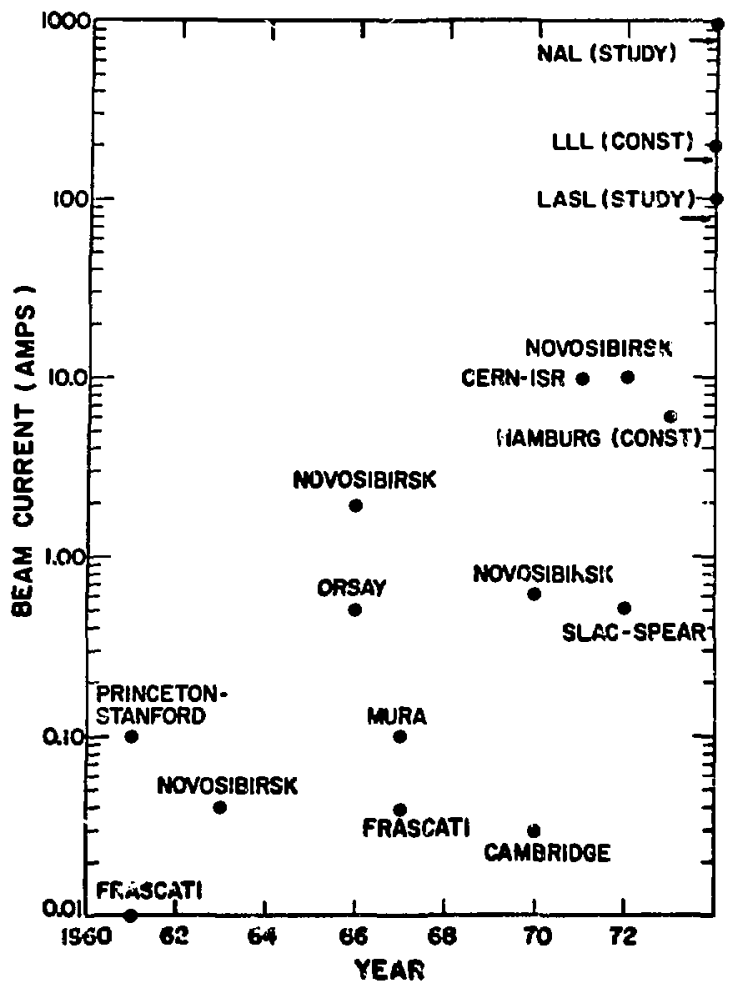

F1g, 1. Intensity evolution of various storage rings.

In studying the problems assoclated with achieving these specifications, we studied many different lattice configurations and performed perhaps a thousand parametric studies on them. This proposal would use the Califortia Institute of Technology electron synchrotron ${ }^{6}$ modified to become an alternatIng-gradient machine in the form of a racetrack and using "invisible inserts" 7 in the straight sections.

\section{STORAGE-RING DESIGN}

\section{A. Lattice Design}

The configuration of bending and focusing elements required to hold a circulating beam in a torus is central to the other problems of injection, extraction, and beam stability. The principal design characteristics for this ring are as follows.

1. Capabflity for sturing $800-\mathrm{MeV}$ protons having a $\gamma$ of 1.86 (specialfzed terms are defined fn the Glossary) and a magnetic rigidity, $B \rho$ of $4.88 \mathrm{Tm}$. Storage of lower energy particles to be possible, but perhaps at reduced intensity.

2. A 250-nsec period of revolution to be compressed by rf bunching into $100 \mathrm{nsec}$ to allow turnon tfme for the beam excraction. A second moda of operation to be five 5-nsec bunches with individual pulse extraction.
TABLE II

DESIGN-PERFORMANCE SPECIFICATIONS FOR WNR RING

\begin{tabular}{|c|c|c|}
\hline & $\begin{array}{l}\text { Low-Duty } \\
\text { Mode }\end{array}$ & $\begin{array}{l}\text { High-Duty } \\
\text { Bode }\end{array}$ \\
\hline Peak Extracted Beam Current (A) & 100 & 4 \\
\hline Pulse Duration for Above (nsec) & 100 & 5 \\
\hline Maximum Number of Protons Stored & $6 \times 10^{13}$ & $6 \times 10^{?} \cdot 1$ \\
\hline Maximum Repetition Rate & $1 / 10$ win & $600 / \mathrm{sec}$ \\
\hline Injected Yarticle Type & $\mathrm{H}^{-}$IOns & Protons \\
\hline Infection Carrent (mA) & $1 . j$ & 17 \\
\hline Infection Tile & $0.1 \mathrm{sec}$ & 6.5 Hsec \\
\hline Number of Turn's Infected & $2 \times 10^{4}$ & 25 \\
\hline Maximum Bunching Factor & 10 & 10 \\
\hline Harmonic Bunching Number & 1,5 & 1,5 \\
\hline $\begin{array}{l}\text { Neutron Production } \\
\text { (neutron/Incident proton) }\end{array}$ & 400 & 30 \\
\hline $\begin{array}{l}\text { Instantaneous Neutron } \\
\text { Production Rate }(\mathrm{n} / \mathrm{sec})\end{array}$ & $2 \times 10^{23}$ & $7 \times 10^{20}$ \\
\hline Neutrons/Pulse & $2 \times 10^{16}$ & $1 \times 10^{12}$ \\
\hline Target Average Power $(\mathrm{kW})$ & 2 & 19 \\
\hline Beam Po:er (kW) & 0.013 & 10 \\
\hline
\end{tabular}

3. Injection in two modes: charge-exchange injection of $2 \times 10^{4}$ turns ( $100 \mathrm{~A}$ for $1.7-\mathrm{mA} \mathrm{H} \mathrm{H}^{-}$beam). Injection into radial and vertfcal betatron phase space of 2.5 turns of $17-\mathrm{mA}$ proton beam.

4. Injected beam characte:-istics assumed to be $\pi / 3$ $\mathrm{cm}$ mrad in both planes with a $\Delta \mathrm{p} / \mathrm{p}$ of $\pm 0.2 \%$.

5. From the bunching action, $\mathrm{r}$ ing $\Delta \mathrm{p} / \mathrm{p}$ to be $\pm 2 \%$.

6. Beam containment time to be $0.1 \mathrm{sec}$.

7. Design to employ high-conducting, low-impedance wall naterials and inserts.

8. Aperture to be of the order of $10 \times 20 \mathrm{~cm}$ or greater.

9. Tuning variability to be \pm 0.25 .

Given these condtions, we conducted a survey of stitable existing designs. It soon became apparent that there was none that could be directly copied. There is only one operating proton storage ring, the CERN-ISR, ${ }^{8}$ whose design was governed by long storage time and the intersection of beam IInes -- neither of which is involved sh this disign. At $28 \mathrm{GeV}$, the ISR particle gamia is well above its ring gamma, so it should have different instability problems. The ISR uses synchrotron 
space injection; this was examined for the WNR ring and rejected in favor of charge-exchange injection for the high-current mode. For the low-current mode, it was rejected because of complexity and slowness compared with betatron-space injection.

Electron-storage ring designs were also studied, but the LAMPF proton gamma of 1.86 is very much lower than that of any electron ring. In fact, electrons of this gamma have only $440-\mathrm{keV}$ energy, and it would be highly impractical to build an electron ring whose particle gamma is below the ring gamia.

The advantage (which may also be a disadvantage) of electron rings is that the particles radiate synchrotron light, causing damping of the betatron oscillations. For $800 \mathrm{MeV}$ protons, the absence of dissipative forces leads to large aperture requirements. Electron cooling of the proton beam is being considered, but there are no plans for its use at an early pirase.

From this review it was apparent that the general principles of previous designs were about all that could be directly employed, and we began a survey for a suitable lattice* for the WNR ring.

The programs used in the lattice search are all well tested and have been used for design of accelerators and beam-transport lines throughout the world. The three principal programs are as follows.

SYNCH - a computer system ${ }^{9}$ for synchrotron design and orbit analysis. Mich of the notation and technique is from Courant and Snyder which adds usefulness to the code and probably accounts for its wide acceptance. It computes the elements of the Twiss matrix, of which the most important is the beta function that relates the beam size in the synchrotron to the emittance of the injected beam. This permits parametric study of lattices without reference to the injected beam. It also calculates the quantity $x_{e q}$, which relates the equilibrium orbit shift to the momentum dependence. It treats drift spaces, bending magnets of unliorm gradient, quadrupole magnets, misalignments, arbitrary elements specified by user-supplied matrices, and transformations not expressible in matrix form. It also provides matrix manipulation procedures and ray tracing.

$4 \mathrm{P}$-- a program ${ }^{10,11}$ like sYNCH, except that it does not work in the Courant and Snyder formalism. It can treat accelerators having 90 or fewer elements like those treated by SYNCH. Further, it can calculate the system tu third-order aberrations. The principai reason for its use in this study is its comprehensive method of parametric adjustment

*Others principally Involved in the lattice selection were Philip F. Meads, Jr., of Wn. M. Brobeck \& Associates, and Alper A. Garren of LBL. using a linear programming algorithm to satisfy up to 12 linear beam constraints and to minimize aberrations. Another reason for its use is its cathoderay tube generated output plots.

TRANSPORT -- a program 12 that differs from the preceding two in that it uses seven-element rather than three-element matrix manipulation. It was not designed for synchrotron analysis, and is not basically in the Courant and Snyder formalism. Its seven-element matrix form makes it useful in study of second-order and sextupole effects, the use to which it was applied.

The first calculated lattice was a fourfold separated-function design (Fig. 2). Separated function is considered because it provides greater freedom and independence of adjustment than does combined function. [The National Accelerator Laboratrry (NAI) accelerator, for example, is a separatedfunction machine.] The disadvantages of this lattice are high-field magnets and zero gamma transition. The latter fact means that che ring would exhibit the conventional negative-mass instability and no low-beam gamna advantage would be realized. Another design used eightfold synmetry (FIg. 3). It also used very high field bends (although not so high as NAL), but suffered from short $(2.75-\mathrm{m})$, free-drift lengths.

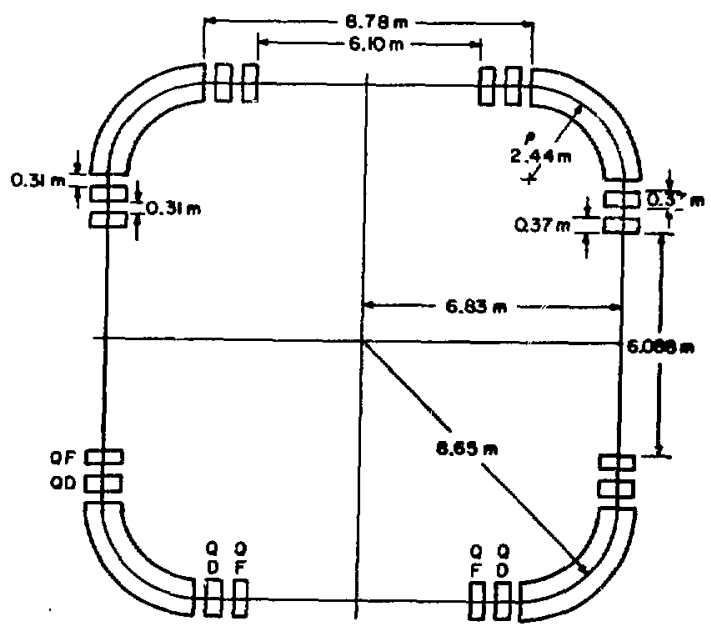

Fig. 2. A separated-function lattice study. Design parameters are: $B=20 \mathrm{kG}$; quadrupole length $=0.369 \mathrm{~m} ; \quad Q F-B^{\prime}=1.325 \mathrm{kG} / \mathrm{cm}$; $Q D-B^{\prime}=-1.515 \mathrm{kG} / \mathrm{cm}$. Maximum b etatron functions: $\hat{\beta}_{\mathrm{x}_{\mathrm{B}}}=2.954 \mathrm{~m}, \hat{\beta}_{\mathrm{y}}=13.803 \mathrm{~m}$ (bends): and $\hat{\beta}_{x}=7.471 \mathrm{~m}, \hat{\beta}_{y}=1.833 \mathrm{~m}$ (quadrupoles); $x_{\text {eq }}=-0.685$ (bends), $1.833 \mathrm{~m}$ (quadrupoles); $Y_{t r}=0$. Tunes: $v_{x}=2.751, v_{y}=2.750$. 


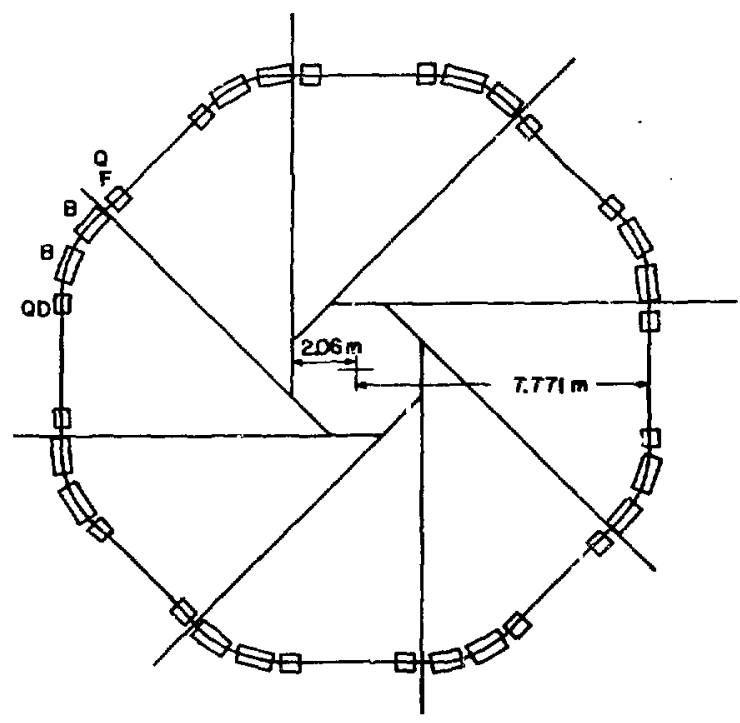

Fig. 3. A low-gradient separated-function lattice study. Design parameters are: $B=20 \mathrm{kG}$; quadrupole length $=0.4 \mathrm{~m} ; \quad \mathrm{QF}^{-} \mathrm{B}^{\prime}=0.6$ $\mathrm{kG} / \mathrm{cm} ; \mathrm{QD}-\mathrm{B}^{\prime}=-0.2 \mathrm{kG} / \mathrm{cm}$. Maximum betatron functions: $\hat{\beta}_{x}=6.646 \mathrm{~m}, \hat{\beta}_{y}=7.603$ $\mathrm{m}$ (bends); $\hat{\beta}_{\mathrm{x}}=8.043 \mathrm{~m}, \hat{\beta}_{\mathrm{y}}=9.517 \mathrm{~m}$ (quajrupoles); $x_{e q}=1.738 \mathrm{~m}$ (bends). $2.023 \mathrm{~m}$ (quadrupoles); $\gamma_{t r}=2.474$. Tunes: $v_{x}=2.446, v_{y}=1.366$.

Early in the study, two problems became apparent. First, the ring period, which had been specified as $200 \mathrm{nsec}$, required compact, high-field bending and focusing magnets to provide space for injection, extraction, and rf bunching. Second, to achieve fairly long field-free regions for these operations requires a systematic, special design of these sections. The phase advance should be some multiple of $\pi$ in these inserts so that the bending and focusing can be treated separately from the design of the drift sections.

The matching inserts known at this time were the Collins, ${ }^{13}$ which does not advance the phase by a multiple of $\pi$, and Garren's uncompensated $\pi-\pi .14$ Neither matches the closed orbit for off-energy particles. Other inserts are Garren's $\pi-\pi$ matched ${ }^{15,16}$ and Nakash's $2 \pi-2 \pi .^{17}$ Both satisfy this closed-orbit criterion, but the former must be designed to a specific lattice and the latter divides the drift region more or less uniformly thus not allowing large, empty regions.

As part of the study for the WNR ring, Meads discuvered the new $\pi-2 \pi$ insert. 7 (The $2 \pi$ phase advance 15 in the radial plane.) This insert satis-

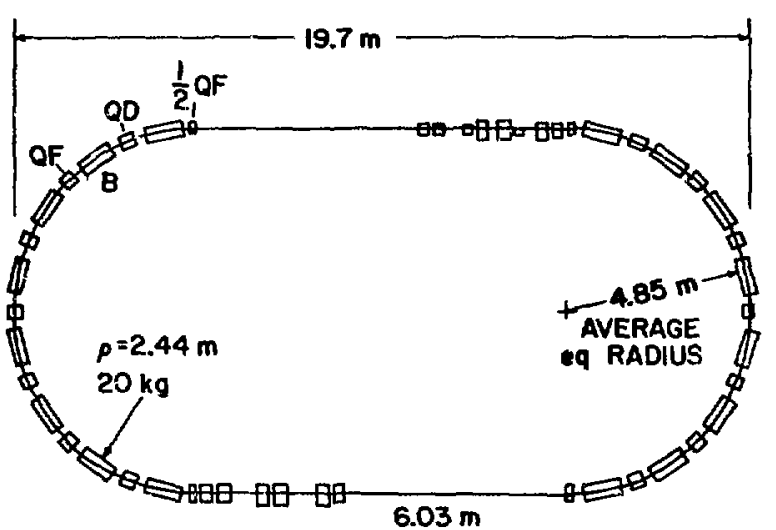

F1g. 4. A separated-function $\pi-2 \pi$ lattice study. Design parameters are: $B=20 \mathrm{kG}$ (edge focusing); quadrupole length $=0.4 \mathrm{~m}$; $Q F-B^{\prime}=1.00 \mathrm{kG} / \mathrm{m} ; \quad Q D-B^{\prime}=0.4 \mathrm{kG} / \mathrm{m}$. Maximum betatron functions: $\hat{\beta}_{x}=4.769 \mathrm{~m}$, $\hat{\beta}_{y}=9.849 \mathrm{~m}$ (normai cel1); $\hat{\beta}_{\mathbf{x}}=12.398 \mathrm{~m}$, $\hat{\beta}_{y}=33.107 m$ (long straight section); maximum $x_{\mathrm{eq}}=1.291 \mathrm{~m}$. Tunes: $\nu_{\mathrm{x}}=$ $4.375,{ }^{\prime} y=1.772$.

fles the requirement for invistibility in both planes and matching of the closed orbit for off-energy particles. The use of different phase advance in the two planes provides the freedom needed to group the magnetic lenses at each end of the drift reglon and thereby allow a large, empty space in the middle. Figure 4 shows an early study of a 16-cell separated-function racetrack with the $\pi-2 \pi$ insert employed asymmetrically.

During the study, we learned that the Cal-Tech synchrotron, which started as a quarter-scale model of the Bevatron, was being decommissioned and was available. Because the rigidity of the electrons it had been accelerating ( $B O=5.8 \mathrm{Tm}$ ) was about that of the protons from LAMPF ( $4.88 \mathrm{Tm}$ ), we recognized that these magnets were readily adaptable to the WNR ring. The most expeditious use of the CalTech synchrotron would be to use the existing magnets and copper coils. This constrains the possible designs to those having twofold or fourfold symetry.

Figure 5 shows a racetrack design using the modified Cal-Tech synchrotron for bending and focusing. The plan is to convert the weak-focusing synchrotron to a strong-focusing, combined-function ring by replacing the pole tips. (The vacuum chamber and rf systems; would also be discarded.) The problem in this design is that the coils extend some distance beyond the steel, and it is deemed that the 


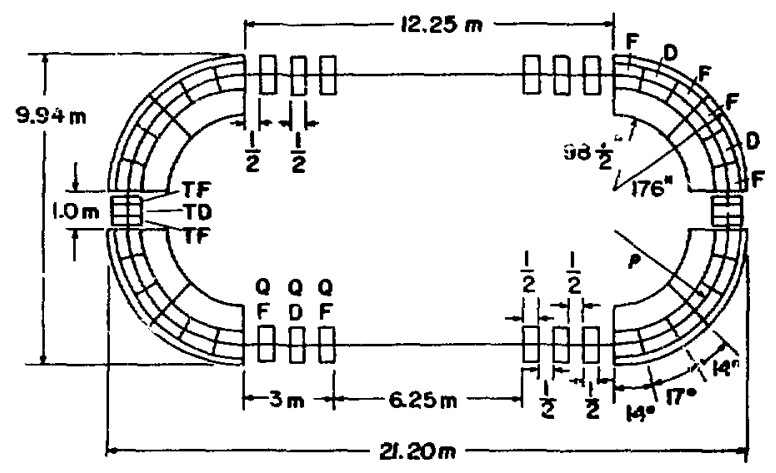

Fig. 5. A combined-function $\pi-2 \pi$ lattice study. Design parameters are: $B=12.795 \mathrm{kG}$; quadrupole length $=0.5 \mathrm{~m}$. Maximum betatron functions: $\hat{\beta}_{\mathrm{x}}=3.54 \mathrm{~m}, \hat{\beta}_{\mathrm{y}}=5.71 \mathrm{~m}$ (bends); $\gamma_{t r}=1.95$. Tunes: $\nu_{x}=4.069$, $v_{y}=2.258$.

$90^{\circ}$ sectors can be placed no closer than about $1 \mathrm{~m}$. This creates a very crowded situation for the triplet lens shown at the ends of the racetrack. There was also evidence that the triplets were not functioning well, and the beta functions were larger with than without the 1-m gap.

The next step was to expand the design to fourfold symmetry so that there would be adequate space for matching between the $90^{\circ}$ sections. This design, shown in Fig. 6, indeed, was considered suftable for detailed cost estimation. The initial estimate was slightly more than $\$ 2$ million. The major cost reduction was realized by a change of power-supply design, but, on reexanination, the racetrack was reconsidered.

Garren suggested that instead of trying to minimize the gap where the $90^{\circ}$ sectors meet, we introduce the needed gap, but include another, half as wide, at the other end of the sector as part of the cell (Fig. 7). Because the $\pi-2 \pi$ ilsert has unitmaynitude transfer matrices, the ring has fourfold symnetry. Only the off-energy, off-axis partfcle knows that it has twofold symmetry. Because of the invis:ible character of the insert, the sector lattice calculations proceeded in the usual fashion without the inserts, and the calculations for the inserts were studied and parametrized to discover the most economical design.

We observed that there is a trade-off between the betatron oscillation amplitude and the momentum compaction of the ring. If $\Delta p / p$ is 0.02 after bunching and we assume an emittance of $13.89 \times 10^{-5}$

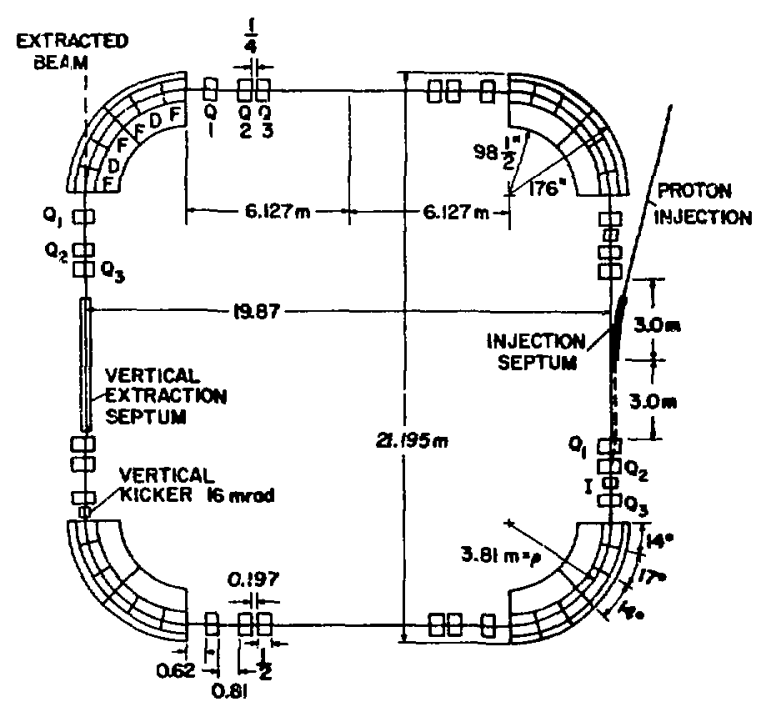

Fig. 6. Foursquare combined-function $\pi-2 \pi$ lattice study, Design parameters are: $B=12.81$ kG; profile parameters: $k_{F}=3.5 / \mathrm{m}, k_{D}=$ $-4.5 / \mathrm{m}$; quadrupole length $=0.5 \mathrm{~m}$; maximum betatron functions: $\hat{\beta}_{x}=3.697 \mathrm{~m}, \hat{\beta}_{y}=$ $1.574 \mathrm{~m}$ ( $F-F$ point in bends); $B_{x}=20.54$ $\mathrm{m}, \hat{\beta}_{\mathrm{y}}=21.44 \mathrm{~m}$ (long straight section); $x_{\mathrm{eq}}=1.0003$ (bends), $-2.333 \mathrm{~m}$ (1ong straight section). Tunes: $\nu_{\mathrm{x}}=6.389, \nu_{\mathrm{y}}$ $=3.408$.

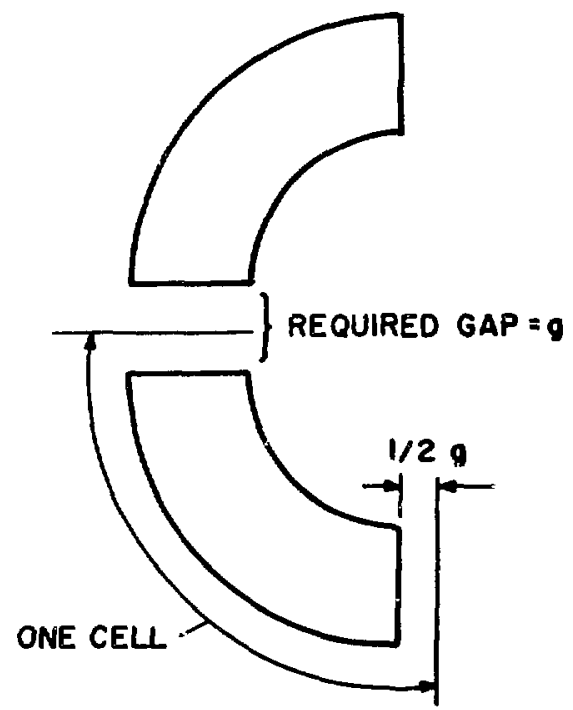

Ffg. 7. Cell symmetrization by introducing a gap into the long drift length. 
$\pi \mathrm{mrad}$ (25 turns of a $\pi / 3 \mathrm{~cm}$ mrad enittance and $60 \%$ packing efficiency in phase space), then the radial beam size is

$$
\Delta x(\mathrm{~cm})=2 \hat{\mathrm{x}}_{\mathrm{eq}}+1.179 \sqrt{\hat{\beta}},
$$

where $\hat{x}_{e q}$ and $\hat{\beta}$ are in meters. For good lattices, $\hat{\beta} \approx 7 \mathrm{~m}$, so, by expansion in a Taylor's series, we find the convenient form

$$
\Delta x(c m) \approx 1.56+0.22\left(\hat{\beta}+9 x_{e q}\right) .
$$

Thus, lattice considerations must weight increases in $x_{e q}$ nine times greater than increases in $\hat{\beta}$.

We also tried to determine the relationships among central drift length, quadrupole gradients, quadrupole spacing, and minimum $\hat{B}_{x}$. Meads investisated this problem and determined that there are only two free parameters that can be taken to be the radial magnification, $m$, and the central drift length, 2L. Because of reflection symmetry about the midpoint, the minimum apertures require that the endpoints be waist locations in both planes; also, the nidpoint must he a double-waist location. Meads shows by general arguments that the minimum $\hat{\mathrm{B}}_{\mathbf{x}}$ is $2 \mathrm{~L}$.

In the vertical plane, numerical work has shown that the optimum $\hat{\beta}_{y}$ is nearly independent of the magnification and decreases slightly with increasing central drift length. Fortunately, the conditions that yield the maximum central drift length and minimum radial aperture also yleld a minimum vertical aperture.

Further, attempts to increase the central drift length or reduce the magnification reduce the spacing between the second and third quadrupoles. This fact $i$ is the limiting phystcal parameter in the design. This spacing is therefore set to a minimum, and the insertion effects are studled by varying either the central drift length or the radial magnification. Furthermore, we decided to use identical quadrupoles in the design (for economy) and a magnification, $m$, of $-1 / \sqrt{2}$. This causes $\sim 50 \%$ of the drift to be in the central drift length. The final design constraint requires that the pole-tip field be less than $10 \mathrm{kG}$ to avold saturation. 18

The storage ring shown in Fig. 8 is the result of these considerations and is the one we propose. Table III summarizes the designs discussed above and several others leading to this design.

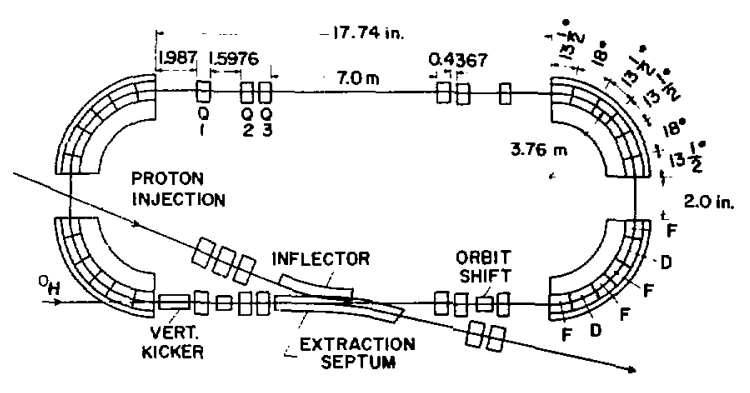

F1g. 8. Proposed 4-MHz, combined-function, racetrack WNR ring. Design parameters are: $B=$ $12.98 \mathrm{kG}$; quadrupole leng:h $=0.3 \mathrm{~m}$. MaxImum betatron functions: $\hat{\beta}_{x}=5.59 \mathrm{~m}, \hat{\beta}_{y}=$ $9.93 \mathrm{~m}$ (bends); $\hat{\beta}_{x}=7.67 \mathrm{~m}, \hat{\beta}_{y}=22.6 \mathrm{~m}$ (long straight section). Tunes: $v_{x}=4.39$, $v_{\mathrm{y}}=2.23 ; \gamma$-transition: 3.40 .

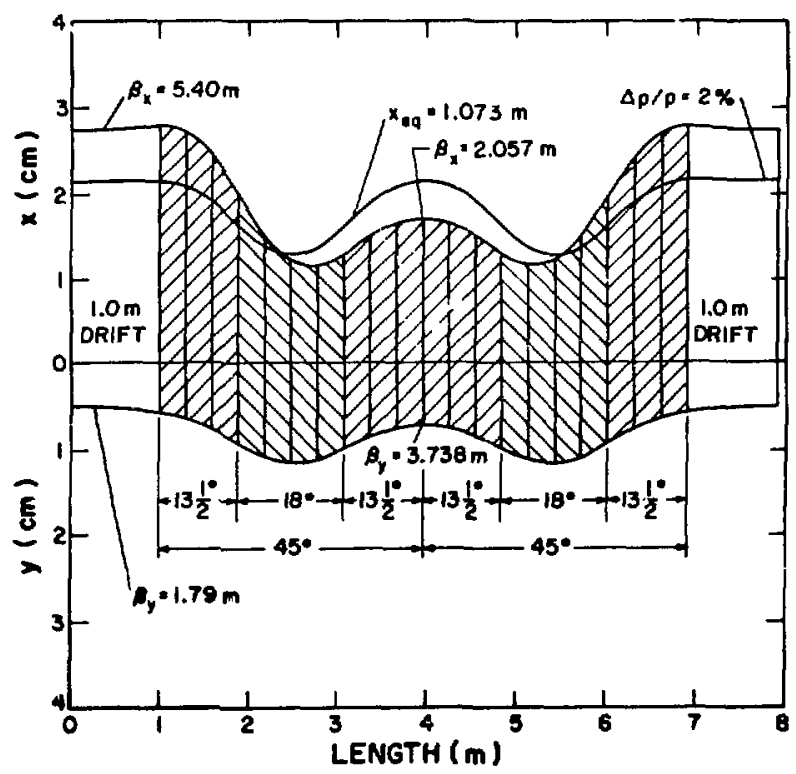

Fig. 9. Radial (upper) and vertical (lower) bezioscillation amplitudes in a $90^{\circ}$-sector marnet. Assumed emittance is $13.89 \pi \mathrm{cm}$ mrad radially and $1.347 \pi \mathrm{cm}$ mrad vertically.

Figure 9 shows th? beam envelope through one superperiod of the ring shown in Fig. 8. Figure 10 shows. the beam envelope through a $90^{\circ}$ bend. The $\Delta \mathrm{p} / \mathrm{p}=2 \%$ of $\mathrm{f}$-momentum orbit is also shown.

Table IV sunmarizes vartous propertles of the proposed WNR ring. 


\begin{tabular}{|c|c|c|c|c|c|c|c|c|c|c|c|c|c|c|c|}
\hline \multirow[b]{2}{*}{ Description } & \multirow{2}{*}{$\begin{array}{l}\text { Ref } \\
\text { Date } \\
(1971) \\
\end{array}$} & \multirow[b]{2}{*}{ Structure } & \multirow{2}{*}{$\mathrm{K}_{\mathrm{f}}$ or $\mathrm{B}_{\mathrm{f}}$} & \multirow[b]{2}{*}{$\mathrm{k}_{\mathrm{d}}$ or } & \multirow[b]{2}{*}{$\frac{\text { Longe }}{\text { No. }}$} & \multirow[b]{2}{*}{$\frac{\text { est Drifts }}{\text { Length(x) }}$} & \multirow[b]{2}{*}{$v_{x}$} & \multirow[b]{2}{*}{$v_{z}$} & \multicolumn{3}{|c|}{ Max values in Bends } & \multicolumn{3}{|c|}{ Max In Lattice } & \multirow[b]{2}{*}{$\gamma_{\text {tr }}$} \\
\hline & & & & & & & & & $\underline{B_{x}(m)}$ & $B_{y}(n)$ & $\begin{array}{c}\left|x_{e q}\right| \\
(\mathrm{m})\end{array}$ & $\underline{\beta_{x}(m)}$ & $B_{y}(m)$ & $\begin{array}{c}\left|x_{\text {eq }}\right| \\
(\mathrm{m}) \\
\end{array}$ & \\
\hline $\begin{array}{l}\text { 4-cel1, sep-func, } 90^{\circ} \text {, } \\
20-k G \text { bends and doub- } \\
\text { lets (F1g. 2) }\end{array}$ & $4 / 12$ & $08 \square 80$ & $1.325 \mathrm{kG} / \mathrm{cm}$ & $-1.515 \mathrm{~kg} / \mathrm{cm}$ & 4 & 6.09 & 2.75 & 2.75 & 2.954 & 13.803 & 0.685 & 7.471 & 18.449 & 1.833 & 0 \\
\hline $\begin{array}{l}\text { 16-ce11 Fordood, } \\
\text { 12-kG magnets }\end{array}$ & $4 / 12$ & FOFDOOD & $8.823 / \mathrm{m}$ & $-9.242 / m$ & 16 & 1.06 & 3.25 & 3.25 & 4.348 & 3.564 & 1.063 & & & & \\
\hline $\begin{array}{l}\text { 4-cel1, sep-fure, } \\
20-k G \text { and triplets }\end{array}$ & $4 / 12$ & $080 \square 080$ & $1.229 \mathrm{~kg} / \mathrm{cm}$ & $-2.241 \mathrm{kG} / \mathrm{cm}$ & 4 & 4.0 & 2.75 & 6.25 & 3.242 & 3.863 & 0.85 & 25.25 & 7.478 & 3.095 & \\
\hline $\begin{array}{l}\text { FOEDOD Racetrack } \\
\text { and } \pi-2 \pi\end{array}$ & $4 / 24$ & FOFDOD O 18 & & & 2 & 5.0 & 3.75 & 2.75 & 4.963 & 5.119 & 2.164 & 10.059 & 49.862 & 2.164 & \\
\hline $\begin{array}{l}\text { FOFDOD Racetrack } \\
\text { and } \pi-2 \pi\end{array}$ & $4 / 24$ & FOFDOD 080 & & & 2 & 5.0 & 3.25 & 2.25 & 5.369 & 5.515 & 3.692 & 10.079 & 33.937 & 3.692 & \\
\hline $\begin{array}{l}\text { 12-cell FOOFDOD, } \\
\text { 12-kG magnets }\end{array}$ & $4 / 24$ & FOOFDOD & $8.345 / \mathrm{m}$ & $-7.9 / \mathrm{m}$ & 12 & 1.58 & 4.25 & 4.25 & 4.154 & 8.534 & 0.637 & & & & \\
\hline PDFD Racetrack, $\pi-2 \pi$ & $4 / 30$ & FDFD 080 & & & 2 & 5.0 & 4.25 & 2.25 & 4.253 & 7.051 & 1.346 & 10.199 & 37.2 & 1.346 & \\
\hline $\begin{array}{l}\text { 4-ce11, sep-func, } 90^{\circ}, \\
10-k 6 \text { bends and } \\
\text { doublets }\end{array}$ & $4 / 2 i$ & $08 \square 80$ & $1.25 \mathrm{kG} / \mathrm{cm}$ & $-1.5 \mathrm{kG} / \mathrm{cm}$ & 2 & 6.09 & 2.52 & 2.89 & 3.722 & 13.01 & 0.413 & 6.801 & 17.378 & 2.042 & \\
\hline $\begin{array}{l}\text { 8-cel1, low-gradient, } \\
\text { eeparated-function }\end{array}$ & $5 / 4$ & $0 \square \square 0$ & $0.2 \mathrm{~kg} / \mathrm{cm}$ & & 8 & 2.72 & 1.86 & 0.60 & 4.398 & 16.931 & 2.263 & 4.628 & 16.931 & 2.454 & \\
\hline $\begin{array}{l}\text { 8-cell, loin-gradient, } \\
\text { aep-fune (F1g. 3) }\end{array}$ & $5 / 4$ & $0 \square \square$ & $0.6 \mathrm{~kg} / \mathrm{co}$ & $-0.2 \mathrm{kG} / \mathrm{cm}$ & 8 & 2.72 & 2.47 & 1.37 & 6.646 & 7.603 & 1.738 & 8.043 & 9.517 & 2.023 & 2.47 \\
\hline Ca1-Tech 8-cell A.G. & $5 / 10$ & FBDBF & $7 / m$ & $-12 / \mathrm{m}$ & & & $\begin{array}{l}2.20+ \\
\text { NLSS }\end{array}$ & $\begin{array}{l}0.868+ \\
\mathrm{N}_{L S S}\end{array}$ & 2.278 & 5.528 & 0.911 & & & & \\
\hline Cal-Tech 8-cell A.G. & $5 / 10$ & BPBDB & 9/m & $-8 / \mathrm{m}$ & & & $\frac{1.708+}{25 S}$ & $\begin{array}{l}0.592+ \\
\text { NLS }\end{array}$ & 2.648 & 7.570 & 1.423 & & & & \\
\hline Cal-Tech 8-cell A.G. & $5 / 10$ & BFBDB & $13 / \mathbf{m}$ & $-13 / \mathrm{a}$ & & & $\frac{1.93+}{\mathrm{N}_{\text {LSS }}}$ & $\underset{\mathrm{N}}{1.64+}$ & 2.589 & 3.034 & 1.178 & & & & \\
\hline $\begin{array}{l}\text { Sep-func racetrack with } \\
\text { LSS (F1g. 4) 20-kG } \\
\text { berda }\end{array}$ & $5 / 12$ & 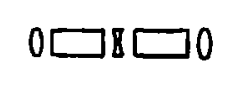 & $\begin{array}{l}1 \text { and } \\
2.93 \mathrm{kG} / \mathrm{cm}\end{array}$ & $\begin{array}{l}0.4 \mathrm{and} \\
-3.48 \mathrm{kG} / \mathrm{cm}\end{array}$ & 2 & 6.03 & 4.375 & 1.772 & 4.769 & 9.849 & 1.291 & 6.636 & 17.163 & 1.291 & 2.95 \\
\hline $\begin{array}{l}\text { Cal-Tech A.G. race- } \\
\text { track with LSS (F18. 5) }\end{array}$ & $5 / 27$ & FDF 080 & $3 / \mathbf{x}$ & $-4 / m$ & 2 & 6.254 & 4.069 & 2.258 & 3.54 & 5.71 & 1.23 & & & & 1.95 \\
\hline $\begin{array}{l}\text { Cel-Tech A.G. four- } \\
\text { equare with LSS (F18. 6) }\end{array}$ & $6 / 30$ & FDE 080 & $\begin{array}{l}3.5 / \mathrm{m} \\
1.42 \mathrm{kG} / \mathrm{cm}\end{array}$ & $\begin{array}{l}-4.5 / \mathrm{m} \\
-1.38 \mathrm{kG} / \mathrm{cm}\end{array}$ & 4 & 6 & 5.39 & 3.41 & 3.697 & 1.57 & 1.00029 & 20.12 & 2.924 & 2.33 & \\
\hline $\begin{array}{l}\text { Cal-Tech A.G. racetrack } \\
\text { 4-Bgle (Pig, } 7)\end{array}$ & $12 / 2$ & FDP 010 & $3.2 / 1$ & $-4 / m$ & 2 & 7 & 4.39 & 2.23 & 5.59 & 9.93 & 1.072 & 7.67 & 22.6 & 1.07 & 3.40 \\
\hline
\end{tabular}




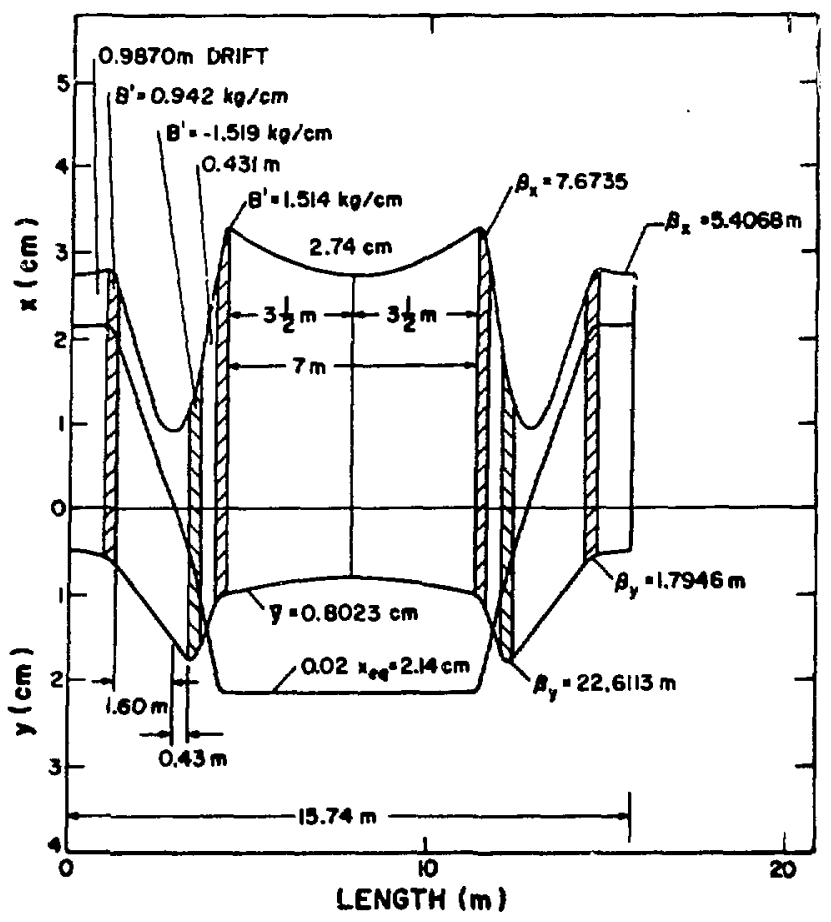

F1g. 10. Radial (upper) and vertical (lower) beamoscillation amplitudes in the long straight section. Same emittance as Fig. 9.

\section{B. Injection}

1. General Discussion. Liouville's theorem ${ }^{17}$ states that in a conservative system, phase density is also conserved. Table IV shows an $a_{x}-200 \mathrm{~cm}$ mrad; $a_{y}=67.8 \mathrm{~cm}$ mrad phase space available in the drift region. The injected beam is expected to have emittances of $\varepsilon_{x}=\varepsilon_{y}=\pi / 3 \mathrm{~cm}$ mrad. Hence, within the bounds of Liouville's theorem, 192 turns could be injected into the radial betatron phase space and 65 turns into vertical betatron phase space, or 12,480 turns Into the combined spaces. For a peak injected current of $17 \mathrm{~mA}$, only 5900 turns (assuming $100 \%$ efficiency) need be injected to provide the 100 $A$ of circulating beam. Previous accelerator experience, however, indicates that only a few turns can be injected in this manner. For the Omnitron study, an Injection scheme was devised for stacking 30 turns in betatron space.

The CERN-ISR is loaded by infecting 800 turns into synchrotron space, $1 . e .$, injection by varying the energy between the incoming particles and the
TABLE IV

SUMMARY OF PROPERTIES OF PROPOSED WNR RING

Overal1 Properties

Max Dimensions: $21.2 \times 10.94 \mathrm{~m}(69.6 \times 35.9 \mathrm{ft})$

Period: 250 nsec

Circumference: $63.01 \mathrm{~m}(206.7 \mathrm{ft})$

Equivalent Radius: $10.03 \mathrm{~m}(32.91 \mathrm{ft})$

Design Particle Kinetic Energy: $800 \mathrm{MeV}$

Deslgn Particle $\gamma: 1.8526$

Design Particle $\beta$ : 0.84181

Design Particle Magnetic Rigidity (BP): $4.881 \mathrm{Tm}$

Design Particle Momentum (pc): $1.4633 \mathrm{GeV}$

Design Particle 1/velocity: $3.9625 \mathrm{nsec} / \mathrm{m}$

Ring Tune: $v_{x}=4.39, v_{z}=2.23$

Ring $\gamma$ Transition: 3.4023; $\eta=1 / \gamma^{2}-1 / \gamma_{t r}^{2}=0.2050$

Maximum Ring Momentum Spread: $\Delta p / p= \pm 2 \%$

Infection Emittance: $\varepsilon_{x}=\varepsilon_{y}=\pi / 3 \mathrm{~cm} \mathrm{mrad}$

Injection-Momentum Spread: $\Delta p / p= \pm 0.2 \%$

Form Factor: $F_{x}=3.36, F_{y}=5.02,\langle F\rangle=4.19$

\section{$90^{\circ}$ Sector}

Radius of Equilibrium Orbit: $3.7592 \mathrm{~m}$

Equilibrium-Orbit Guide Field: $12.9839 \mathrm{kG}$

Gradient-Profile Parameters: $k_{f}=3.2 / m ; K_{d}=-4 / m$ Magnetic Gradient: $\mathrm{n}_{\mathrm{f}}=-12.03 ; \mathrm{n}_{\mathrm{d}}=15.04$

Maximum $B: \quad \hat{B}_{x}=5.59 / \mathrm{m} ; \hat{\beta}_{y}=9.93 / \mathrm{m}$

Maximum $x_{e q}: 1.072 \mathrm{~m}$

Aperture: $10 \times 20 \mathrm{~cm}(3.94 \times 7.87 \mathrm{1n}$., approximately elliptical)

Magnet Power: $1 \mathrm{MW}$

Magnet Weight: 155 tons of iron; 18 tons of copper Magnet Cooling: $92.1 \mathrm{gpm}$ for $\Delta \mathrm{T}-40^{\circ} \mathrm{C}$

Pressure Differential: 175 psi

Insert Length: $17.74 \frac{\pi-2 \pi}{(58.2 \mathrm{ft})}$

Center Drift Length: $7 \mathrm{~m}(23.0 \mathrm{ft})$

Quadrupole Gradients: $0.4419 \mathrm{kG} / \mathrm{cm} ;-1.5192 \mathrm{kG} / \mathrm{cm}$; $1.51424 \mathrm{kG} / \mathrm{cm}$

Quadrupole Magnetic Length: $10 \mathrm{~cm}(4 \mathrm{1n}.) ; 35.6 \mathrm{~cm}$ (14 1n.); $35.6 \mathrm{~cm}$ (14 in.)

Quadrupole Aperture: 15.24 (6 in.)

Minimum Aperture: $13.97 \mathrm{~cm}(5.5 \mathrm{ln}$.

Quadrupole Power:" $30.8 \mathrm{~kW}$ each

Quadrupole Cooling: $2.9 \mathrm{gal} / \mathrm{min}$

Admittance: $a_{x}: 200 \mathrm{~cm}$ mrad; $a_{y}=67.8 \mathrm{~cm} \mathrm{mr} a d$ 
stored beam. This can be done because the stored beam is out of synchronism with the $r f$ voltages used to modify the energy of the particles being. raised to a parking orbit. This infection scheme, which requires about $1 \mathrm{~h}$ to fill the storage ring, has an eificiency of $50 \%$. This was the first injection scheme studied for the WNR ring, but it was rejectIf because of the $50 \%$ loss which would have created undesirable radloactivity in the ring, because of problems imposed in shifting the synchrotron frequency at the 120-pps rate of LAMPF, and because of expected poorer LAMPF beam quality compared with the CERN-PS which is the injector for the CERN-ISR.

Professor F. C. Shoemaker, of Princeton, after examining the various parameters and design goals, suggested two rings. The first would receive protons by storing in betatron space up to the limit of this technique. This would be done with a large enough rf voltage to contain the momentum spread. Then the rf voltage would be adlabatically decreased to homogenize the beam. A final momentum spread of $\Delta \mathrm{F} / \mathrm{P} \approx 0.01 \%$ was expected (see Sec. IV.A). Th1s very high-quality beam would then be stored by injection into synchrotron space of a second ring in the manner of the CERN-ISR. As beautiful as this scheme is, it was rejected because of complexity in favor of the charge-exchange injection technique advocated by Nagle. However, a variation is discussed in Sec. II.s.2.

2. Charge-Exchange Injection. In the same paper ${ }^{4}$ that established the principle of the tandem Van de Graaff, Alvarez also stated the principle of chargeexchange injection into a circular accelerator. The first known test of the scheme was the work of Budker and Dimov at Novosibirsk. ${ }^{5}$ A $1-\mathrm{MeV}$ beam of $\mathrm{H}^{-}$ions charge-exchanged into $a$ ring of 100-nsec period for about 1000 turns resulted in 1-A circulating current. This circulating current is about $1 / 2$ that allowed by incoherent space-charge effects. The stripping was accomplished by a pulsed nitrogen jet.

Argonne National Laboratories is working on charge-exchange injection into the Cornell synchrotron which is being remodeled into a storage ring. 19 The beam from this ring would be used to inject into the Zero Gradient Synchrotron (ZGS) at a higher energy than the original design. Meanwhile, experi- ments on charge-exckange injection directly into the ZGS are under way.

The Tri-Universities TR IUMPF sector-focused cyclotron, which should have nearly a tenth the intenstty of LAMPF, will use $\mathrm{H}^{-}$stripping to extract a proton beam with $100 \%$ efficiency. ${ }^{20}$ The inefficiency of extraction from circular accelerators has been a primary reason for the linear accelerator design of LAMPF.

A stripper employing photons and electric or magnetic fields would be ideal. It could be pulsed, beam heating would not be a problem, and beam scattering would be minimized. However, direct electric stripping, even to $\mathrm{H}^{\circ}$, is not practical. Magnetic stripping to $\mathrm{H}^{\circ}$ is very easy; a 5-kG field, equivalent to an electric field of $2.3 \mathrm{MV} / \mathrm{cm}$, will strip $\mathrm{H}^{-}$ions to $\mathrm{H}^{\circ}$ ions in $2.2 \mu \mathrm{sec}$. Because the binding energy of this electron is only $0.755 \mathrm{eV}$, 1mpactically high magnetic flelds would be required to strip $\mathrm{H}^{\circ}$ Ions to protons for which the binding energy is $13.5 \mathrm{ej}$.

A proposed initial experiment on LAMPF $^{21}$ employs a 45-MW laser injecting into a mirror cavity to produce electric flelds strong enough to strip $\mathrm{H}^{-}$ to $\mathrm{H}^{\circ}$. The laser pulse will be only of such duration that one micropulse will be affected. This neutralized bunch will be separated from the rest of the beam by magnetic selection, and the $\mathrm{H}^{\circ}$ pulse will be stripped to protons in a foil.

Having found that a material stripper is necessary to extract the last electron, we must decide where this will be done in the ring and just what form this stripper must take. A further condition is that the stripping must occur in the circulating beam region because stripping before the beam has reached this region is tantamount to proton injection.

In the injection shown in Fig. 11, advantage is taken of two facts: $\mathrm{H}^{-}$ions follow the mirrorimage trajectory of protons in the same magnetic field, and the $2 \pi$ radial phase advance in the straight section allows the type of injection shown. The equilibrium-orbit deflectors are shown causing the phase to advance by $\pi$, and the $\mathrm{H}^{-}$heam is injected on a mirror-image trajectory. This requires a very shallow angle of injection. An alternative would be to cause the first equilibrium-orbit deflector to over-deflect so that the beam would be 


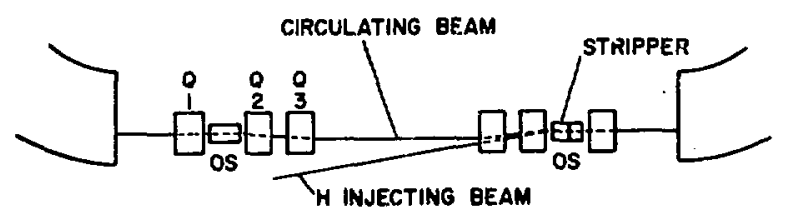

Fig. 11. $\mathrm{H}^{-}$injection using a mirror-image path and the orbit-shift magnets. Q1, 2, 3 are half the quadrupoles for a $\pi-2 \pi$ insert. OS is the orbit-shift magnet.

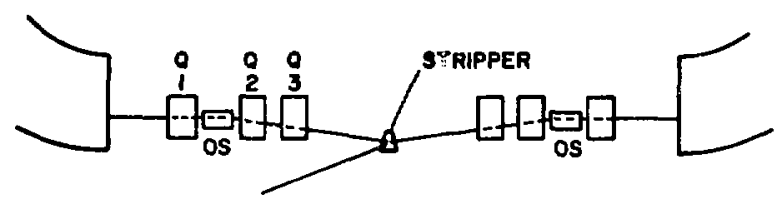

Fig. 12. $\mathrm{H}^{-}$injection using a mirror-image path, excesslve orbit shifting, and a wedge magnet.

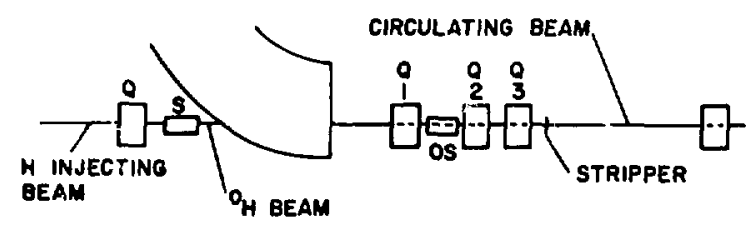

Fig. 13. $\mathrm{H}^{-}$injection using magnetic stripping to $\mathrm{H}^{\circ}$. $\mathrm{S}$ is the stripping magnet.

bending slightly outward (Fig. 12). A mixer magnet would cause an equal inward trajectory for the protons. The $\mathrm{H}^{-}$ions following the mirror image of the protons would merge with them on leaving the mixer magnet.

The techniques shown in Figs. 11 and 12 have the following problems: (1) The $\mathrm{H}^{-}$beam must be small and must enter very near the center of $Q_{4}$ to avoid being magnetically stripped, (2) both techniques complicate the injection-extraction region which is already fairly crowded, and (3) both reduce the latitude on stripper types. The method shown 1n F1g. 12 may fntroduce a superpertod of one into the ring. In spite of these objections, either scheme could be added lacer without a major redesign.

Figure 13 shows the $\mathrm{H}^{-}$beam being focused and magnetically stripped, and entering the ring on the equilibrium orbit in the straight section. Magnetic stripping is used because Allison and Emigh's data ${ }^{22}$ show that, at the optimum thickness for material stripping, the ratios for $H^{-}: H^{\circ}: p$ are $20: 60: 20 \%$. This $40 \%$ beam Iuss would be ineffictent and would produce radioactive bufldup.
To use magnetic stripping, it must be shown that nelther the statistical nature of the stripping nor the effects of the stripping magnet's fringing field will cause an undesirable increase in beam emittance.

We begin by assuming that the decay from $\mathrm{H}^{-}$to $\mathrm{H}^{\mathrm{O}}$ in a magnetic field $\mathrm{d}^{23}$ is represented by

$$
f^{-}=e^{-t / \tau},
$$

where $\mathrm{f}^{-}$is the fraction of the original $\mathrm{H}^{-}$beam after time $(t)$;

$$
\tau(\sec )=\frac{7.96 \times 10^{-14}}{E} \mathrm{e}^{42.56 / \varepsilon},
$$

and

$$
\varepsilon=0.3 \mathrm{BYB} \text {, }
$$

where $\varepsilon$ is the electric field gradient in inegavolts per centimeter, $\beta$ and $Y$ have the usual meanings, and $B$ is the magnetic $F$ ield in kllogauss.

The rate of formation of $\mathrm{H}^{\circ}$ lons is obtalned by differentiating Eq. (1).

$$
\frac{d f^{o}}{d t}=\frac{1}{\tau} e^{-t / \tau}
$$

Time is not of direct interest, but the spatial distribution of $\mathrm{H}^{\circ}$ formation, obtained from $x=$ Bct where $x$ is the depth of penetration of the fringing field, is. With this change of variables,

$$
\frac{d f^{0}}{d x}=\frac{1}{t \bar{B}_{c}} e^{-B c x / t} .
$$

We will now assume that the fringing field is zero one gap distance away and increases linearly in the direction of the magnet; $i . e ., B=B_{0} x / g$ (note that time is also taken to be zero at $x=0$ ). Using these assumptions; Eqs. (2), (3), and (5); and reasonable values for $B_{0}=20 \mathrm{kG}$ and $g=6 \mathrm{~cm}$, we show the distribution function $\mathrm{df}^{\circ} / \mathrm{dx}$ in Fig. 14.

The differential angular deflection of the $\mathrm{H}^{-}$ ion in the fringing fleld is

$$
d \theta=\frac{B_{o} x d x}{(B \rho) g},
$$

where the same linear assumption on the fringing field has been used. The angular deflection of the $\mathrm{H}^{-}$ion in this field before it strips is

$$
\theta=\int_{0}^{x} \frac{B_{o} x d x}{(B \rho) g}=\frac{B_{o} x^{2}}{2(B \rho) g} ;
$$




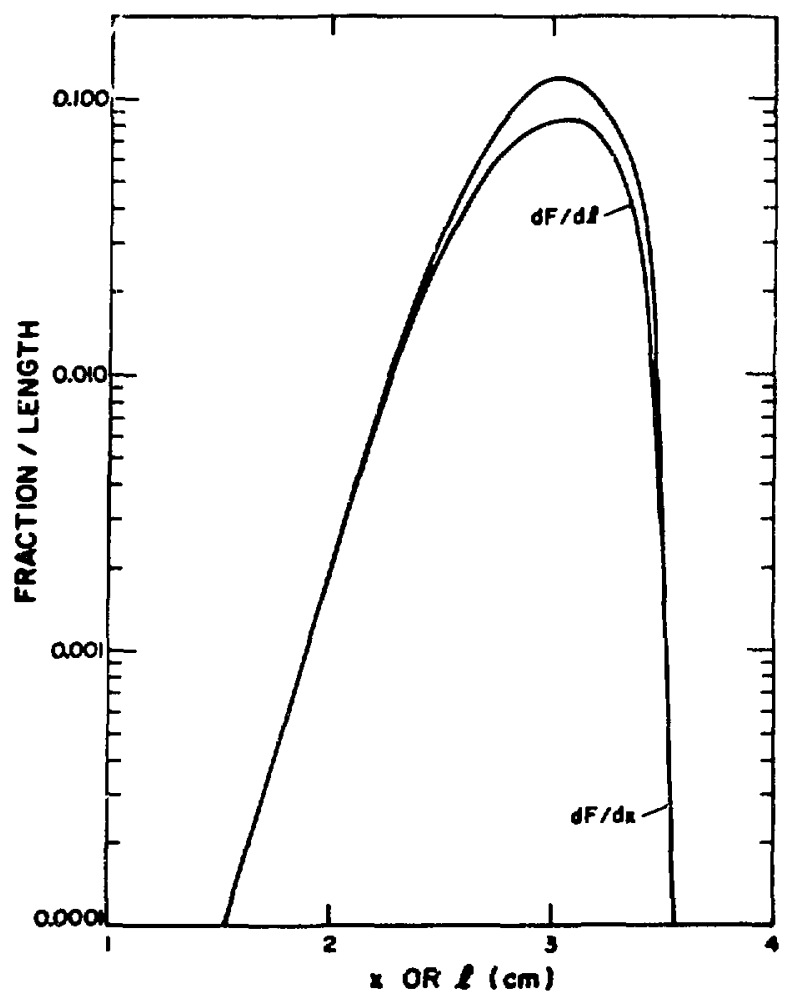

Fig. 14. Fraction of $\mathrm{H}^{-}$ions stripped to neutrals as a function of depth $(d f / d x)$ in the magnetic-stripping field and of deflection from the beam axis (df/dl).

however, we need not the angle, iut the deflection (l) of the $H^{2}$ beam on the stripper located at distance $L$ inside the lattice.

$$
\ell=\mathrm{L} \theta
$$

so

$$
\ell=\frac{L B_{o} x^{2}}{2(B p) g}
$$

Equation (9) can be used to change the variables of Eq. (5) to $\ell$ and $d f^{\circ} / d \ell$, using $L=7 \mathrm{~m}$. Figure 14 which also shows this functional dependence, indicates that the beam would be broadened by about $1 \mathrm{~cm}$ if magnetic stripping were used as out]ined. [Logarithmic differentiation of Eq. (9) shows that the magnetic dispersion due to the beam-momentum spread is an insignificant effect compared with the stripping dispersion. 1 Hence, the 1-cm angular deflection at $7 \mathrm{~m}$ is slight $1 \mathrm{y}$ less than a milliradian, so

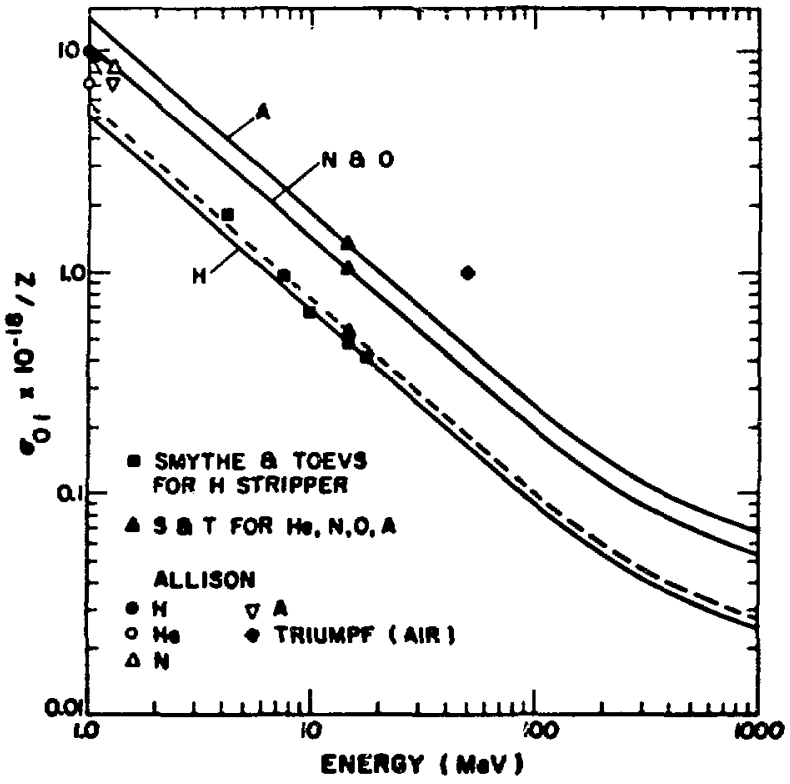

Fig. 15. Stripping cross section for various materials as a function of energy.

one can safely assume that the beam emittance in the radial plane will be increased $1 \mathrm{~cm}$ mrad by magnet ic stripping.

Having injected an $\mathrm{H}^{\circ}$ beam into the ring with little emittance degradation, we must now Indicate a method for conversion to protons. The first problem is to determine the quantity of material required to perform the conversion with $1 \%$ or less $\mathrm{H}^{\circ}$ contamination. Cross sections, $\sigma_{01}$, for stripping $H^{0}$ ions to protons are avallable mostly at energies below $1 \mathrm{MeV}$ and are sumbarized in S. K. Allison's review papers. ${ }^{24}$ Above $1 \mathrm{MeV}$ and below $18 \mathrm{MeV}$, there are sose data by Smythe and Toevs; ${ }^{26}$ at $50 \mathrm{MeV}$ there is an unpublished datum from TRIUMPF. 27 Consfdering the paucity of approprlace data, extrapolation schemes had to be developed. These were reviewed by Thiessen ${ }^{28}$ who proposes using Bethe"s primary speciffe lonization $\mathrm{j}_{\mathrm{p}} 29$ as the scaling factor. This is the same as $P$. W. Allison's last suggestion of energy scaling by $\mathrm{dE} / \mathrm{dx}$. Figure 15 shows this energy scalling (solid line) normalfzed to the data of Smythe and Toevs. The ordinate is plotted as $a_{01} / z$ where $z$ is the atomic number of the target atom, becaus? this seems to remove much of the atomic dependence, as demonstrated by S. K. Allison's data at 1 MeV. The Smythe and Toevs hydrogen data do not scale as $1 / E$ 
as they should for low energy according to Wright's theor $y^{30}$ and from the $\mathrm{dE} / \mathrm{dx}$ postulated energy dependence. Note that the Smythe and Toevs point for arjon does not extrapolate back to $S$. K. Allison's data at $1 \mathrm{MeV}$. Despite tinese apparent inconsistencles, we use a single curve,

$$
\frac{\sigma_{01}(E)}{2}=\frac{1.41 \times 10^{-18}(\mathrm{dE} / \mathrm{dx})_{E}}{(\mathrm{dE} / \mathrm{dx})_{10 \mathrm{MeV}}},
$$

for all elements. Tt is is the curve for nitrogen and oxygen in Fig. 15. This choice extrapolates well to S. K. Allison's nitrogen, argon, and hydrogen data at $1 \mathrm{MeV}$.

The fraction of protons after the beam has penetrated a stripper $\delta$ atoms $/ \mathrm{cm}^{2}$ thick ${ }^{24}$ is

$$
F_{p}=\left(1-e^{-\delta \sigma_{01}}\right) \text {. }
$$

where the cross section, ${ }^{\circ} 10$, is assumed to be zero. For $F_{p}=0.99, \delta \sigma_{01}=4.6$. Fron F1g. $15, \sigma_{01} / 2=$ $5.83 \times 10^{-20} \mathrm{~cm}^{2}$; hence, for $1 \% 1^{\circ}$ contamination the stripper must have a chickness of $\delta=7.89 x$ $10^{19} / 2$ atoms $/ \mathrm{cm}^{2}$.

Table $V$ presents thicknesses and other parameters for various solid strippers. Important criteria are high melting points, low energy loss, and low multiple scattering. Boron, although attractive, is not readily fabricated, whereas carbon is fabricated in $5-\mu \mathrm{g} / \mathrm{cm}^{2}$ thicknesses, $1-\mathrm{cm}$ square. ${ }^{31}$

Nickel is readily fabricated in thin sheets. There may be considerable latitude in the choice of a solid stripper, but for our immedtate purposes, we will use carbon as an example.

The best location for the stripper is the offmomentum zrossover (Fig. 10) with $\beta_{x}=5.79 \mathrm{~m}$ and $B_{y}=14 \mathrm{~m}$, which will be considered later for a vapor stripper. However, to reduce stripper heating, the equilibrium orbit-shift magnets will be used to shift the beam away from the foll. Thus a location immediately after $Q_{3}$ is selected for the carbon stripper; here $\beta_{x}=7.67 \mathrm{~m}$ and $\beta_{y}=5.79 \mathrm{~m}$. We will assume that the injected $H^{\circ}$ beam has an emittance of $E_{x}=2 \pi / 3 \times 10^{-5}$ mrad, or is doubled by the magnetic stripping. The least beam enlargement results from matching the infected beam $\hat{\beta}$ to the ring $B$ at this location. 17 With this assumption, the beam size should be 1.54 and $1.16 \mathrm{~cm}$ in the $x$ and $z$ planes, respectively

TABLE V

PROPERTIES OF VARIOUS SOLID ELEMENTS FOR 99\% STRIPPING

\begin{tabular}{|c|c|c|c|c|c|c|}
\hline Element & $\begin{array}{l}\text { Nelting } \\
\text { Poinc }\left({ }^{\circ} \mathrm{C}\right)^{a}\end{array}$ & $\mathrm{t}\left(\mu \mathrm{g} / \mathrm{cm}^{2}\right)$ & $t(\mu n)$ & $\left.\Delta \mathrm{E}^{\mathrm{keV}}\right)^{\mathrm{b}}$ & $\sqrt{\theta^{2}}(\mu \mathrm{rad})^{c}$ & $\begin{array}{c}\text { Work } \\
\text { Function }(\mathrm{eV})^{a} \\
\end{array}$ \\
\hline $\mathbf{A l}$ & 660.2 & 272 & 101 & 508 & 17.5 & 4.08 \\
\hline B & 2300 & 283 & 121 & 563 & 10.1 & 4.5 \\
\hline c & 2355 . & 262 & 131 & 563 & 10.8 & 4.6 \\
\hline $\mathrm{Cr}$ & 1083. & 287 & 32 & 472 & 27.6 & --- \\
\hline Ni & 1453. & 275 & 31 & 473 & 27.1 & 5.03 \\
\hline$n_{s}$ & 3000. & 328 & 14.5 & 420 & 48.8 & 4.55 \\
\hline$P_{t}$ & 1769. & 328 & 15.3 & 420 & 49.8 & 5.36 \\
\hline Ag & 960.8 & 301 & 28.7 & 443 & 36.7 & 4.56 \\
\hline Ta & 2996. & 325 & 19.7 & 420 & 46.2 & 4.19 \\
\hline II & $\begin{array}{l}1675 \\
\text { (3260 b.p.) }\end{array}$ & 285 & 62.8 & 476 & 23.4 & 3.95 \\
\hline$w$ & 3460. & 326 & 16.9 & 420 & 47.5 & 4.52 \\
\hline$z \mathbf{r}$ & 1452. & 299 & 45.8 & 465 & 33.2 & 4.21 \\
\hline
\end{tabular}
OF $\|^{\circ}$ IONS BY ONE STRIPPER TRAVERSAL

3 Ref. 32 .

Ref. 33.

cRef. 34 . 
The required low-ducy beam requires 10 macropulses of the LAMPr $\mathrm{H}^{-}$beam, or $2 \times 10^{4}$ turns. The bear's angular divergence will increase as $\sqrt{\mathrm{N}}$ where $\mathrm{N}$ is the number of foil traversals. Using the carbon data from Table $V$, we find the angular spread from $2 \times 10^{4}$ tiaversals to be $1.4 \mathrm{mrad}$. Toward the end of the injection, the circulating current is $34 \mathrm{~A}$, which if it all intercepted the stripper would be $1.91 \times 10^{4} \mathrm{~W}$. The problem is to reduce this power dissipation so that it will not destroy the stripper.

The mechanisms of stripper cooling are conduction, radiation, and thermfonic emission (a type of evaporation). Conduction is easily shown to be insignificant. Northcliffe $e^{35}$ and Mackenzie ${ }^{36}$ have analyzed radiation cooling of strippers. The Stefan-Boltzmann equation is

$$
W_{T}=\varepsilon \sigma\left(T^{4}-T_{0}^{4}\right),
$$

where $T_{0}$ is the ambient temperature, $E=0.81$ for carbon (Table V), and $\sigma=5.67 \times 10^{-12} \mathrm{w} / \mathrm{cm}^{2}-{ }^{0} \mathrm{~K}^{4}$ (Ref. 32). The radiative power density for carbon is presented graphically in Fig. 16.

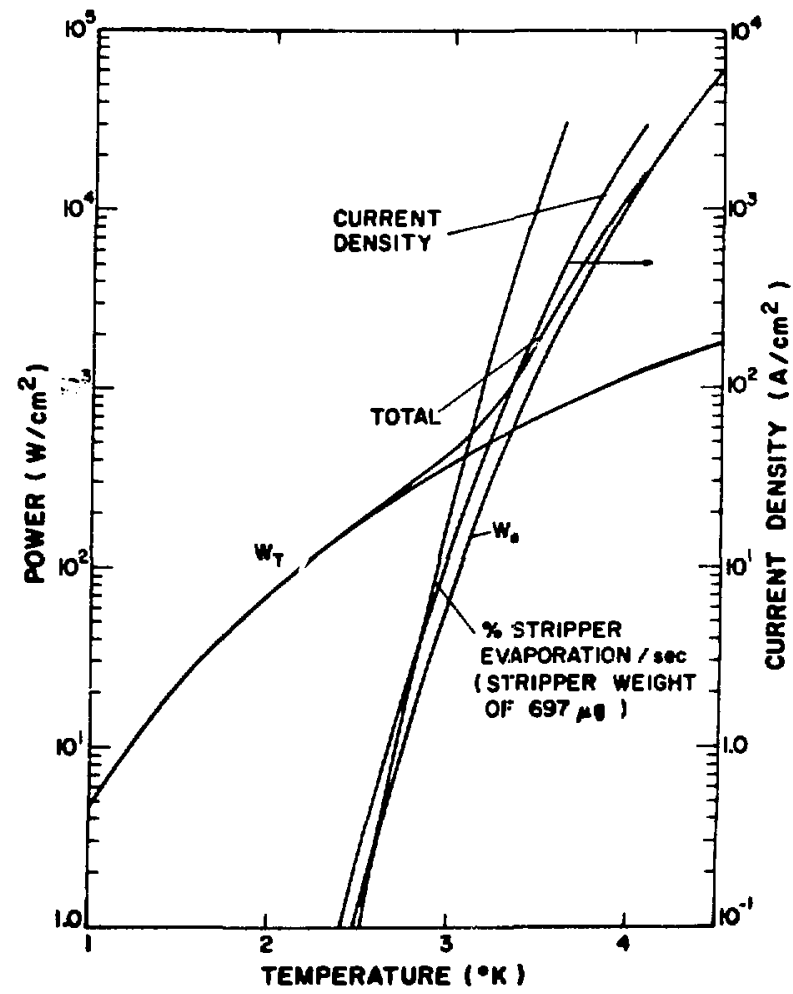

F1g. 16. Power dissipation and thermionic current density from a carbon stripper as a function of temperature.
Vacuum-tube emitters are of ten cooled when heavy currents are drawn; a related phenomenon is ionic cooling of electronic components. ${ }^{37}$ In the development of direct-power converters using thermionic emission, the power removed by this cooling must be replaced by the heat source. ${ }^{38}$

Each electron emitted carries an energy of $\Phi_{E}+$ $2 \mathrm{kT}$, where $\phi_{E}$ is the work function of the emitter (stripper, in this case) and $2 \mathrm{kT}$ is the average kinetic energy of the evaporated electrons. The current density is obtained from a modified form of the Richardson's Equation to give a rate of

$$
W_{e}=1.2 \times 10^{2}\left(\Phi_{E}+8.62 \times 10^{-5} \mathrm{~T}\right) \mathrm{T}^{2} \mathrm{e}^{-1.16 \times 10^{4} \Phi_{E} / \mathrm{T}},
$$

where $\phi_{E}$ for carbon (Table V) is $4.7 \mathrm{eV}$ and $T$ is the emitter temperature in ${ }^{\circ} \mathrm{K}$. This also is plotted in Fig. 16 as well as the sum $w_{e}+w_{T}$.

Stripper heating can be reduced by use of the beam's betatron oscillations. Figure 17 shows the beam being injected $0.96 \mathrm{~cm}$ below the equilibrium orbit and $2.49 \mathrm{~cm}$ to the right of center. If the equilibrium orbit were held fixed in the center of the vacuum pipe as shown, the bearn would fill the aperture as shown, but the current density would not be uniform. We will therefore have to inject in conjunction with equilibrtum shifting to obtain a

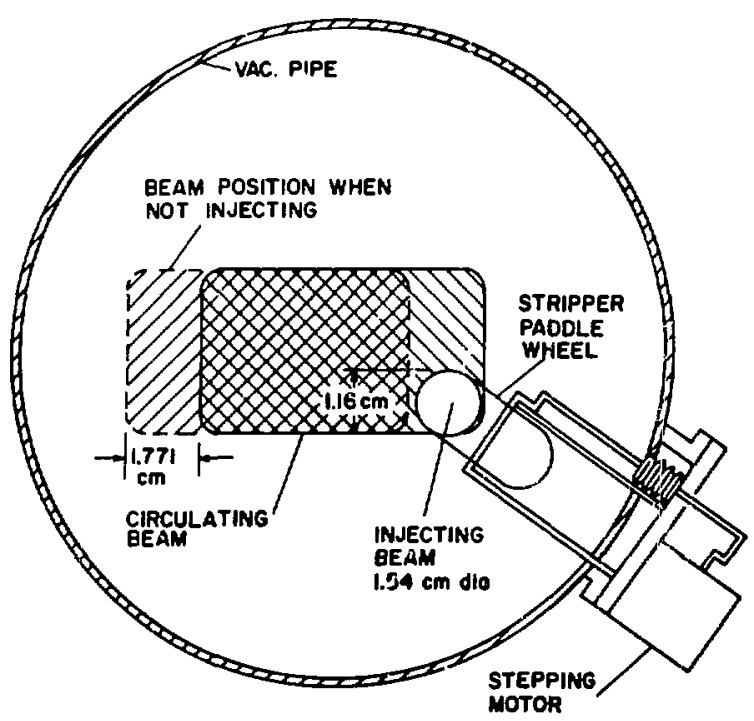

Fig. 17. Beam dispersion by betatron osctilations and stripper changer. 
uniform curcent distribution. If this is done, the ratio of current intercepting the stripper to that of the whole beam is 1:12.93; cherefore, the peak heat dissipation in the stripper is $1.9 \times 10^{4} / 12.73$ $=1.477 \mathrm{~kW}$. The stripper area is $2.66 \mathrm{~cm}^{2}$ (the stripper has two sides) resulting in a power density of $555 \mathrm{~W} / \mathrm{cm}^{2}$. Figure 16 shows the temperature at this power density to be $3100^{\circ} \mathrm{K}$. Table VI gives the final temperature as a function of macropulse number.

TABLE VI

CARBON STRIPPER TEMPERATURE AS A FUNCTION OF INJECTION-CYCLE NUMBER

\begin{tabular}{ccc}
$\begin{array}{c}\text { Injection-Cycle } \\
\text { Number }\end{array}$ & $\begin{array}{c}\text { Max Power } \\
\text { Density } \\
\left(W / \mathrm{cm}^{2}\right)\end{array}$ & $\begin{array}{c}\text { Max } \\
\text { Temperature } \\
\left({ }^{\circ} \mathrm{K}\right)\end{array}$ \\
\cline { 3 - 4 } 1 & 55.5 & 1750 \\
2 & 111 & 2200 \\
3 & 166.5 & 2400 \\
4 & 222 & 2600 \\
5 & 277.5 & 2750 \\
6 & 333 & 2850 \\
7 & 388.5 & 2900 \\
8 & 444 & 3000 \\
9 & 499.4 & 3050 \\
10 & 555 & 3100
\end{tabular}

Note that if electron-emission cooling were not used the peak temperature would be $3350^{\circ} \mathrm{K}$. By the same token, use of a stripper with a smaller work function would considerably reduce the temperature. Thoriated tungsten might, therefore, be a useful stripper material if it can be fabricated thin enough. Table $\mathrm{V}$ indicates a very high rms scatterIng for tungsten; however, when the dilution factor from off-axis infection is used, the total rms scattering is only $1.86^{\circ} \mathrm{mrad}$.

These high temperatures require investigation of the stripper evaporation rate. Figure 18 shows data from the Smithsonian Physical Tables ${ }^{39}$ adjusted to express the percent of evaporation per second. At the final temperature $\left(3100^{\circ} \mathrm{K}\right)$ of Table VI, the target is evaporating at $60 \% / \mathrm{sec}$; however, because the whole injection cycle requires only $0.1 \mathrm{sec}$ (the beam is on for only $5 \mathrm{msec}$ ), less than $6 \%$ of the target evaporates during one injection. Note that there has been no allowance for stripper coolIng due to the heat of vaporization removed by evaporation, because of the absence of data.

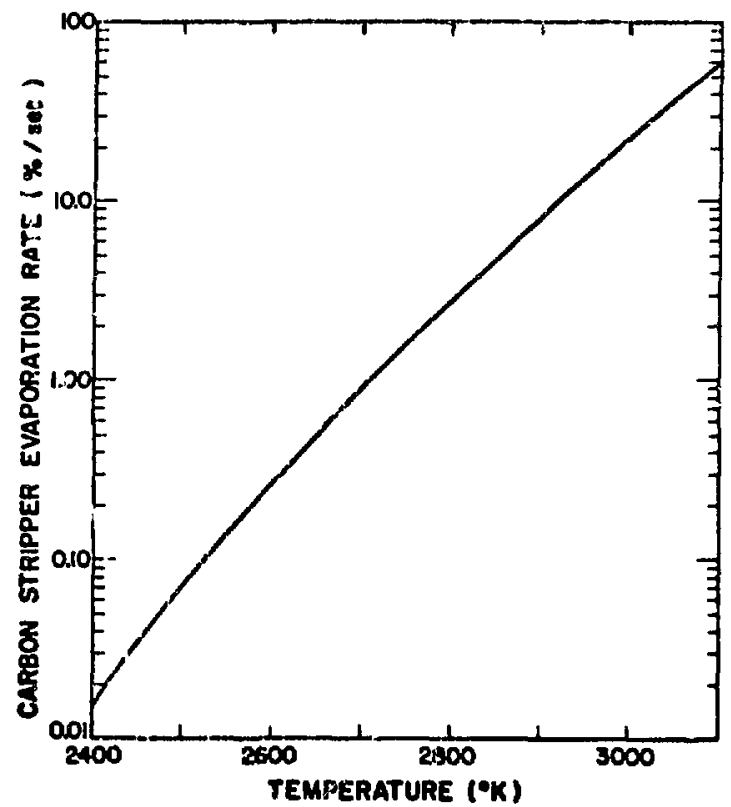

Fig. 18. Catbon target evaporation as a function of temperature.

From the forexoing arguments, carbon is a possible stripping material but it seems to hive a short lifetime. There may be better materials, especlally those with a lower work function so that thermionic cooking can become effective at a lower temperature.

Before leaving the discussion of . Jlid strippers, we note that there is a useful procedure whereby a carbon stripper can be held at $1750^{\circ} \mathrm{K}$. This method is very similax to Shoemaker's suggestion: a macropulse of $\mathrm{H}^{-}$is Injected using a carbon foll to strip. A 201-in\}z cavity operating in phase-1ock with LAMFF would be operated at such voltage that the micropulses could be accepted. During the LAMPF off cycle, the rf voltage would be adlabatically decreased, hotiogenizing the energy. This method produces the necessary packing density for synchrotron space. Next, or concurrently, the beam energy would be sinifted so that on the next injection cycle the previrusily stored beams would not intercept the stripper. To estimate the energy gain or loss needed per $t w n, x_{e q}$ is $1.072 \mathrm{~m}$; to shift the beam by $1.34 \mathrm{~cm}$ (the width of the stripper) requires a momentum shift of $1.44 \%$ and an energy shift of $2.21 \%$. Th1s is $.7 .71 \mathrm{MeV}$ occurring in $7730 \mu \mathrm{sec}$, or 30,920 revolutions of the beam in the ring; hence, the 
energy change per turn is $572.9 \mathrm{eV}$. This is easily done, and we give further analysis in Sec. IV.

Vapor stripping is an attractive alternative to solid stripping because of the possibility of rapid insertion and removal of the stripper and because the heating problem is ameliorated. A gas-jet stripper was used in the charge-exchange-injection Novosibirsk storage ring; ${ }^{5}$ a sodium-vapor beam is used for beam-profile scanning in the ISR storage ring; ${ }^{40}$ and a supersonic lithium jet is used for stripping cross-section measurements. ${ }^{41}$

The vapor stripper required for the wNR ring differs from those just cited in that a much larger amount of material is required in the beam. Smith ${ }^{42}$ describes a titanium getter pump using electron-beam evaporation of $500 \mathrm{~g} / \mathrm{h}$ of titanim. The mean velocity of these atoms is

$$
\bar{v}=0.22 \sqrt{\frac{\mathrm{T}\left(\overrightarrow{\left.{ }^{\circ} \mathrm{K}\right)}\right.}{\mathrm{A} 300}} \mathrm{~cm} / \mathrm{usec},
$$

where $A$ is the atomic number of titanium, and $i$ is the vapor temperatur: which, because the atoms lose $7.02 \mathrm{eV}$ in evaporacing, is not the same as the temperature of the sputtering surface. As a working number, assume that $\mathrm{T}$ is $900^{\circ} \mathrm{K}$; then $\overline{\mathrm{v}}$ is $55 \mathrm{~cm} / \mathrm{msec}$. The number density of titanium atoms is

$$
N\left(\text { atoms } / \mathrm{cm}^{3}\right)=j\left(\text { atoms } / \mathrm{cm}^{2}-\mathrm{sec}\right) / \bar{v}(\mathrm{~cm} / \mathrm{sec}),
$$

where $j$ is the current density of the stripper beam.

A reasonable location for this stripper is at the off-momentum crossover following $Q_{1}$. Here the $B$ :unctions are $B_{x}=0.579 \mathrm{~m}$ and $B_{z}=1.40 \mathrm{~m}$. Again, if the injected beam of $\varepsilon=2 \pi / 3 \times 1.0^{-5} \mathrm{mrad}$ is matched to the lattice, the beam will be 3.92 min wide and $h 11$ high. Assuming that a suitable ventura can be designed so that the vapor is this wide, then for the $500-\mathrm{g} / \mathrm{h}$ pump and a $10-\mathrm{cm}-10 \mathrm{ng}$ vapor, the current, $j$, is $4.46 \times 10^{20} \mathrm{atom} / \mathrm{cm}^{2}-\mathrm{sec}$. Thus, the thickness Is $8.1 \times 10^{16}$ atoms $/ \mathrm{cm}^{2}$, but the required thickness for $99 \%$ stripping is $3.58 \times 10^{18}$ atoms $/ \mathrm{cm}^{2}$. This factor of 44 density increase can possib1y be achieved by a 1-kG 1cagitudinal magnetic field that would cause $0.345-\mathrm{cm}$ spirals (assuming that the ions are singly charged and much smaller if multiply charged). Unfortunately, the electron beam must he about $100 \mathrm{keV}$ to penetrate this mag- nelic field. 'To avold this problem, we could use laser heating of the titanium.

P. W. Allison has suggested the hydrocarbon tran-Decalin $\left(\mathrm{C}_{10} \mathrm{H}_{18}\right)$. It vaporizes at room temperature, so it would not require a boiler; also, tt freezes out easily to a low vapor pressure. Its large molecule results in low velocity at room temperature such as is needed to increase the density. Unfortunately, there are no valves fast enough to admit the vapor with a short rise time compared with $500 \mu \mathrm{sec}$. Another problem is the probable radiation damage to the molecules.

Therefore, presently, radiation- and thermioniccooled strippers with $r f$ beam-orbit shifting seem the most satisfactory approach to this method of injection. Besides maintaining a satisfactory stripper temperature, this approach permits current storage that is not limited by the stripper.

Before discussing proton injertion, we must examine the question of particle loss in the targets due to nuclear Inisractions. The cross section is about $50 \mathrm{mbar} /$ nucleon, and the stripper attenuation is $7.88 \times 10^{-6}$ after 20,000 traversals. Using the dilution factor of 0.077 due to injection as shown in FIg. 17, we $f$ ind that the loss is $1.2 \%$ whtch is comparable to the $1 \%$ loss from not stripping all of the $\mathrm{H}^{\circ}$ ions. Again, $\mathrm{rf}$ orbit shifting will reduce this loss to $0.12 \%$.

3. Proton Injection. The problem of injecting particles into a closed ring designed to contain them seems Insurmountable because, if time reversal is invuked, there is no particular reason why the particles would come out of the ring and go back up the injection channel.

Fortunately the problem is not this simple. It is possible to inject off the equilibrlum orbit, and the normal betatror osclilations then cause the injected beam to miss the inflector for several turns (depending upon the tune). Most proton-injection methods have used this betatron injection for only a few turns, during which time the magnetic field or particle energy was changing; hence, further turns would miss the inflector. References to past work are contained in Kolomensky and Lebedev, ${ }^{43}$ Livingood, 44 and the Green and Courant "Handbuch" article, 45 but perhaps the most advanced concepts are in the Omitron study ${ }^{46}$ and the AGS Improvement Study. ${ }^{47}$ The 
scherne proposed here is an extension of this previous work.*

A plot of $\sqrt{\beta} x^{\prime}$ or $x / \sqrt{\beta}$ transforms the elliptical acceptance volume of the ring into a circle with oscillations describad as polar rotations. The problem is to pack the injected phase volumes (ellipses) into this circle most efficiently. It can be shown that if $\theta \beta=$ Modulo $\left(2 \pi \nu_{x}\right)$ and $\rho$ is the equilibrium-orbit deflection in units of $\mathrm{x} / \sqrt{\beta}$, then $\rho \theta \beta$ is constant and we find a hyperbolic relationship.

A physical realization of this type of injection is shown in Fig. 19. Note that the 27 th turn would hit the inflecting septum. However, the injection shown is into radial betatron space, whereas vertical off-equilibrium-axis injection will produce oscillations that will cause the inflector to be missed. Indee., a plot like Fig. 19 could also be devised for vertical space injection, but we have no plans for programmed infection into this space. Figure 19 also points up another problem of multiturn injection; the filling efficiency is greatest at midcycle. Initially the inefficiency arises from packing ellipses using small off-axis injection; toward the end of the cycle, the inefficiency arises because the large radius of curvature does not allow the preceding turn to miss the inflector.

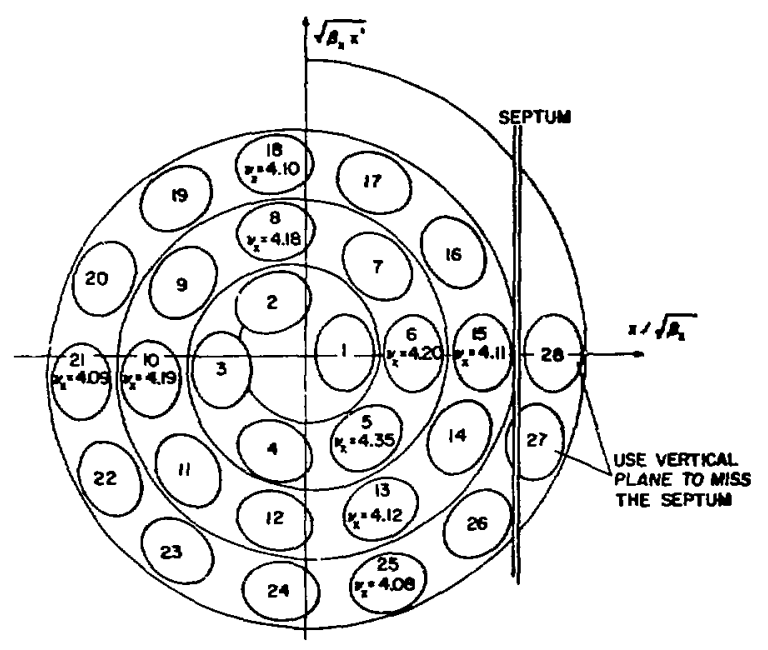

Fig. 19. Normalized betatron phase-space injection for 28 turns.

*The proton-injection method proposed here is by P. F. Meads of William Brobeck and Associates.

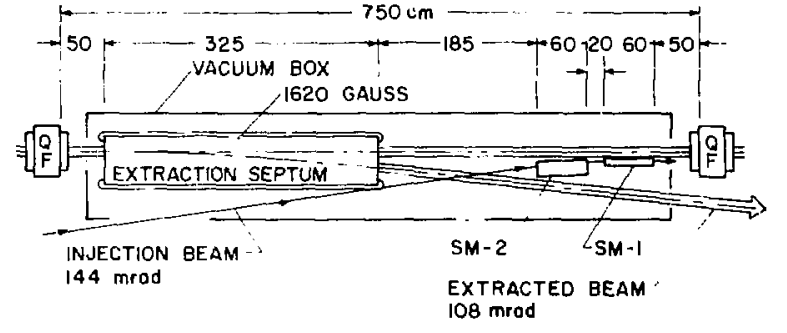

Fig. 20. Proton injection Erom outside the ring (Scheme A).

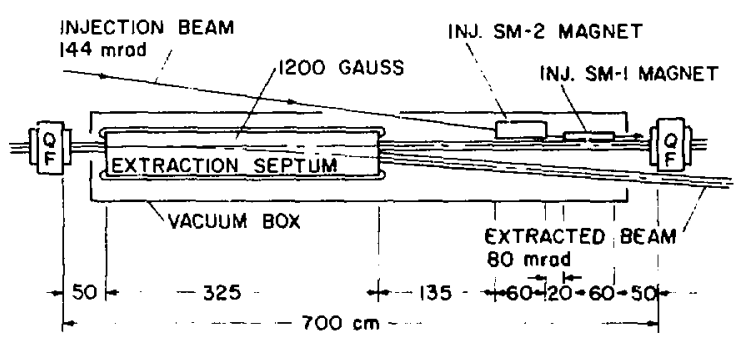

Fig. 21. Proton injection from instde the ring (Scheme B).

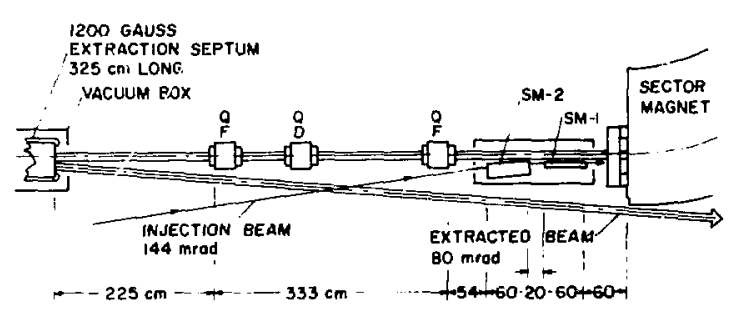

Fig. 22. Proton injection from outside the ring (Schere C).

The hardware details of the preceding design,* except for the tune-shifting ferrite quadrupoles, have been investigated. Such devices have been used at CEA for Landau damping by tune shifts during the passage of the burch.

Figures 20 through 22 show possible injection methods. The first two require that the injection and extraction septa be close together and enclosed in one vacuum box. Figure 22 places the injector just before the sector magnet and requires special quadrupole-magnet designs for compactness. The method shown in Fig. 21 is the most conservative but requires a beam-handling system for proton injection

*This study is by Robert T. Avery, LLL. 
qui.te separate and distinct from t'at for $\mathrm{H}^{-}$injection. However, unless indicated otherwise, it is the method being discussed. Central to all. these techniques are the injection septa, SM-1 and SM-2. Septum magnets ${ }^{48,49}$ are usually dc magnets of special shapes for production of ideally discontinuous magnetic field conditions. The dividing wall referred to in the name is typically millimeters thick and may be either current-carrying or rerromagnetic.

Figure 23 shows the design of SM-1 and its relation to the beam in the lattice. It is a one-turn magnet, with the square water-cooled copper bar being one of the conductors and the 3-ma watercooled copper strip being the other conductor and the septum. The pertinent design parameters are abstracted in Table VII. This picture of a septum assumes that the field vanishes at the outer boundaries of the conductors and that there are no fringIng flelds at the grp ends. Both of these assumptions are untrue, so compensation by correcting windings is neceisary. To a first order, both effects can be compensated for by a "back-leg" winding that shunts 1 to $3 \%$ of the current from either the septum or return conductor to produce $\oint \mathrm{B} \cdot \mathrm{d} l=0$

along all trajectories. It may not be possible to make this integral vanish everywhere, and some trim windings along the iron core may be necessary.

Figure 24 shows the conceptual design of SM-2. Here greater distance from the cirnulating beam permits three turns of copper, but the gap is larger (0.560) than in SM-1 because of the assumption that the beam is brought to a small-diameter focus

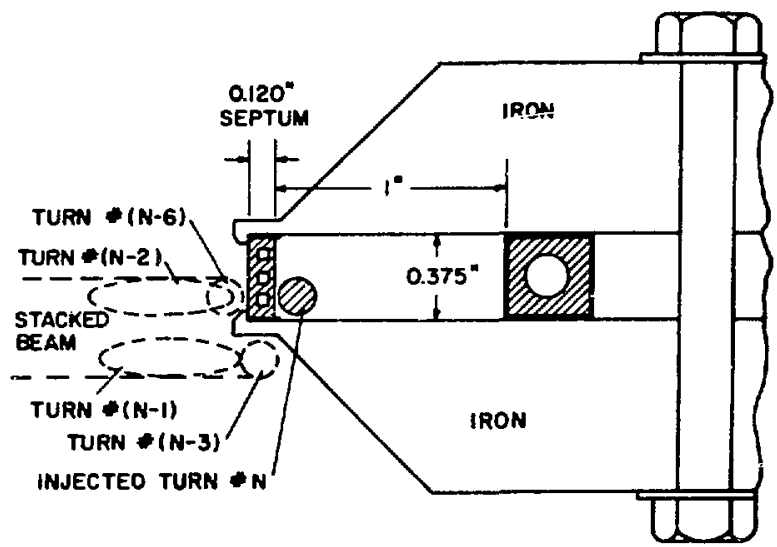

Fig. 23. Current septum magnet SM-1 conceptual design.
TABLE VII

\section{SEPTA DESIGN PARAMETERS}

\begin{tabular}{llll} 
& \multicolumn{1}{c}{$S M-1$} & & $S M-2$ \\
\cline { 2 - 2 } $\begin{array}{l}\text { Field } \\
\text { Length }\end{array}$ & $3.9 \mathrm{kG}$ & & $7.8 \mathrm{kG}$ \\
$\begin{array}{l}\text { Deflection Angle } \\
\text { (800-MeV orntuns) }\end{array}$ & $48 \mathrm{~cm}$ & & $60 \mathrm{~cm}$ \\
Gap & $0.375 \mathrm{in}$. & $0.56 \mathrm{in}$. \\
Magnetic Efficiency & $99.4 \%$ & $96 \mathrm{mrad}$ \\
& & $99.3 \%$
\end{tabular}

Septum Values

Turns

Current Density

Resistance

$14 \mathrm{kA} / \mathrm{cm}^{2}$

3

Voltage

$0.67 \mathrm{~m} \Omega$

$5.25 \mathrm{kA} / \mathrm{cm}^{2}$

Voltage

$2.0 \mathrm{~V}$

$0.25 \mathrm{~m} \Omega /$ turn

Current

$3.0 \mathrm{kA}$

$0.75 \mathrm{v} /$ turn

Power

$6.0 \mathrm{~kW}$

$2.95 \mathrm{kA}$

Cooling

Pressure Drop

$0.7 \mathrm{gpm}$

$2.2 \mathrm{~kW}$

68 psi

$0.7 \mathrm{gpm}$

Septum and Return

$\begin{array}{lll}\text { Resistance } & 1.5 \mathrm{~m} \Omega & 1.5 \mathrm{~m} \Omega \\ \text { Voltage } & 4.5 \mathrm{~V} & 4.5 \mathrm{~V} \\ \text { Current } & 3 \mathrm{kA} & 3 \mathrm{kA} \\ \text { Power } & 13.5 \mathrm{~kW} & 13.5 \mathrm{~kW} \\ \text { Temperature Rise } & 30^{\circ} \mathrm{C} & --- \\ \text { Cooling } & 1.9 \mathrm{gpm} & 2.1 \mathrm{gpm} \\ \text { D.essure Drop } & 91 \mathrm{psi} & 69 \mathrm{psi}\end{array}$

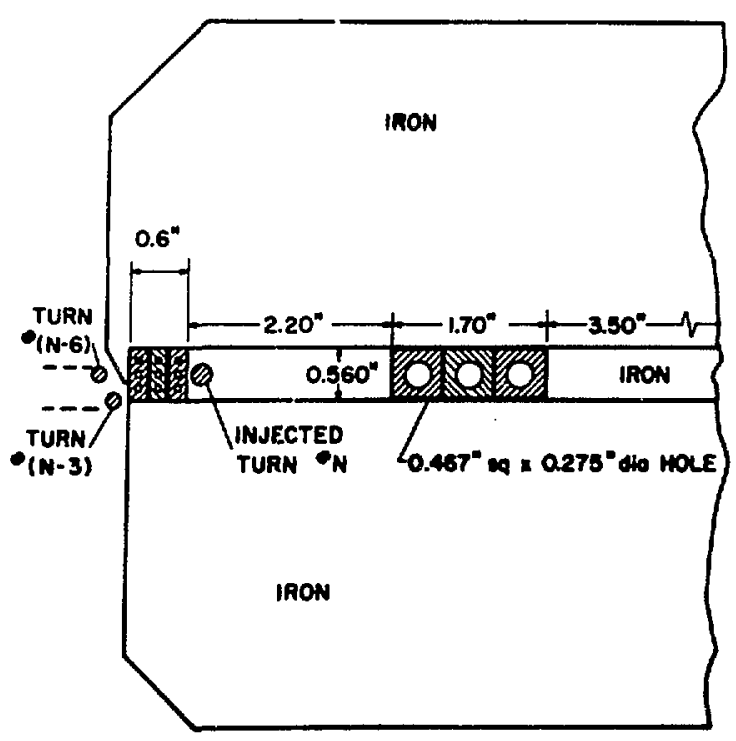

Fig. 24. Current septum magnet SH-2 conceptual resign. 


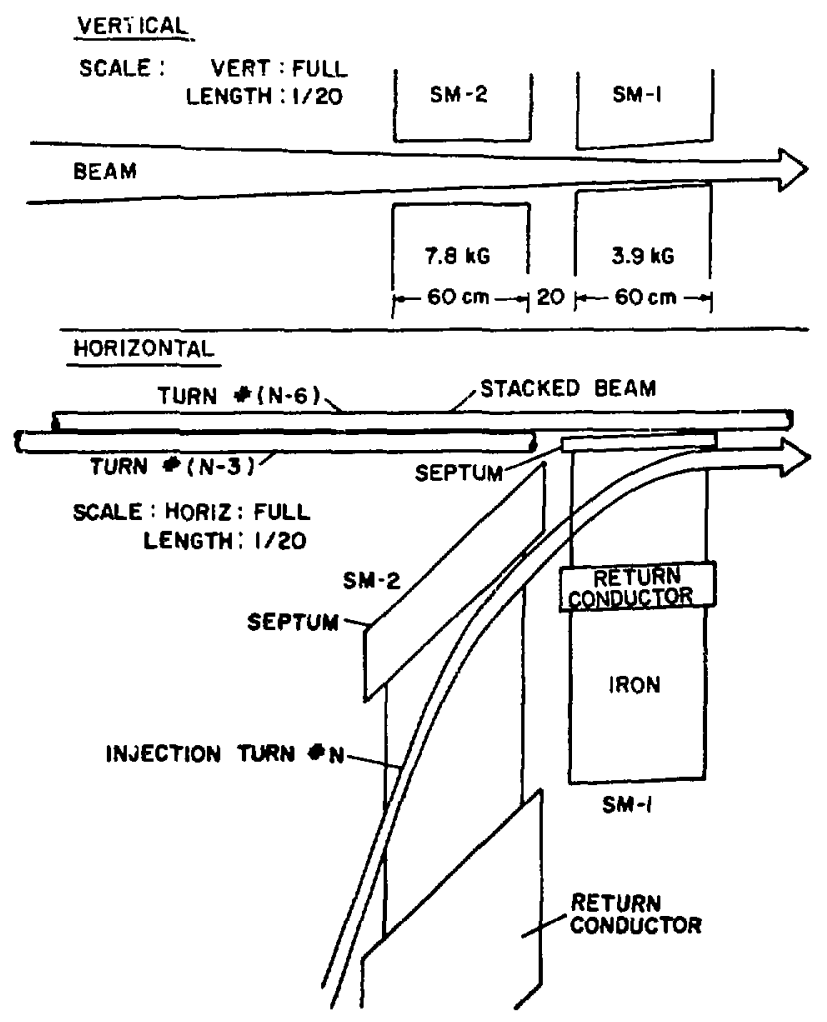

Fig. 25. Relationship of the sepia to the injected and stored beams (not to scale).

immediately after SM-1. The design parameters of SM-2 are also summarized in Table VII. The relationship between the septa and the injected and circulating beams is shown in Fig. 25 .

\section{Extraction*}

1. Fast Extraction. Hav _.4g filled the ring with protons by charge exchange or direct proton injection into betatron space, we must now extract the beam in a fraction of the rotational period.

As guides to extractor design there are roviews by Reich ${ }^{50}$ and Forsyth and Fruitman, 51 as well as many unpublished ducuments. Exeraction from the WRR ring poses an unusual high-duty problem by requiring that the "kicker" (fast-deflection mognet) have not otily a fast rise time but also a fast fall time with essentially full recovery after the pulse. These conditions are posed by the desire iv remove a single bunch, leaving the other four bunches und is-

The designs discussed in this section are primarlly those of Avery and Faltens, L.BL.

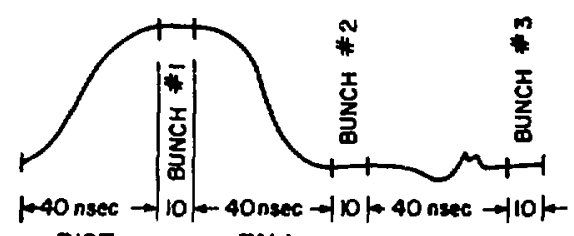

RISE

FALL

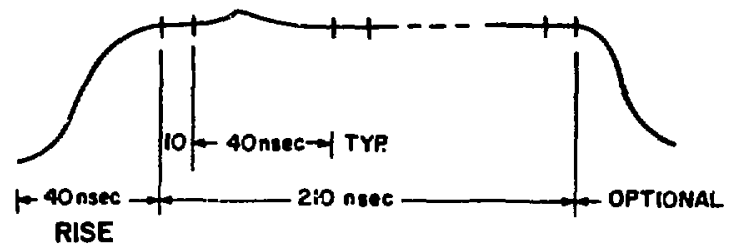

Fig. 26. Kicker pulses. High-duty mode (top), lowduty mode (bottom).

turbed and circulating in the ring. These two mode requirements are shiown in $\mathrm{Fig}, 26$.

To minimize costs and satisfy the stringent requirements for high-duty operation, the flatness of the beam (Fig. 27) suggests a vertical kick. This requires less deflection angle, hence less kicker fleld, than any other scheme studied.

Because of WNR architecture and the shielding thickness above the ring, an 1ron septum in the long straight section is used to intercept the beam and deflect it horizontally (F1g. 28). The kick in the vertical plane is shown in Fig. 29.

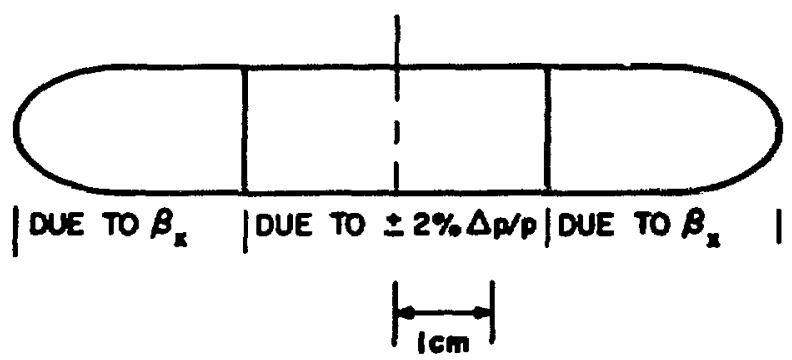

FULL SCALE

Fig. 27. Benm shape at the extraction septum.

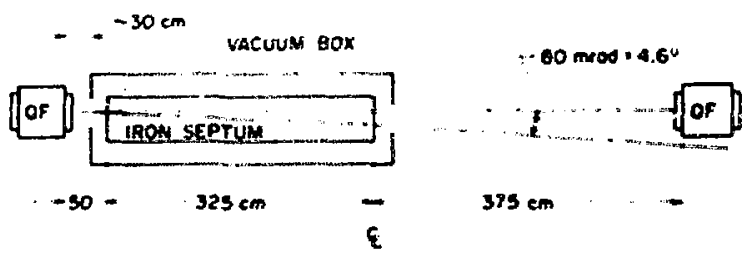

Fig. 28. Horizontal-beam extraction with an iron septus. 


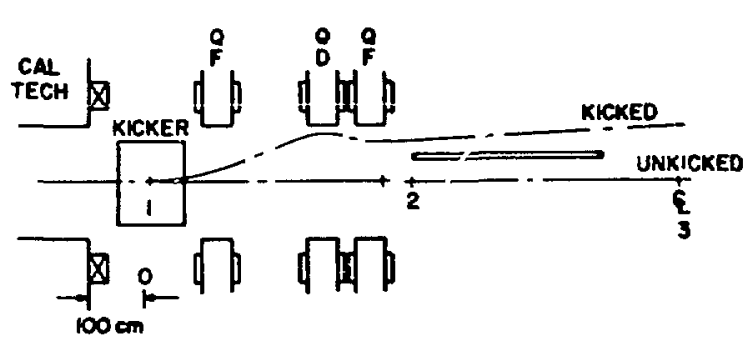

Fig. 29. Vertical kick into the iron septum. 0 : $1 \mathrm{~m}$ from sector magnet exit; 1: kicker midlength at $s=6 \mathrm{~cm}$; 2: start of septum at $s=4.87 \mathrm{a} ; 3$ : center of insert at $s=$ $7.87 \mathrm{~m}$.

Using this conceptual design, the first step will be to determine the deflection sensitivity when deflecting through the quadrupole lenses. Next, the seption design must be established, and, finally, we return to the design of the kicker and its pulsing circultry.

We assume that the kicker is a short distance (location 1 in Fig. 29) downstream from the entrance (location 0 ) of the $7-2 \pi$ insert. The transfer element from location 0 to the midpoint of the long drift (location 3) is especially simple:

$$
\left(\begin{array}{l}
y \\
y^{\prime}
\end{array}\right)_{3}=\left(\begin{array}{ll}
0 & f \\
-1 / f & 0
\end{array}\right) \quad\left(\begin{array}{l}
y \\
y^{\prime}
\end{array}\right)_{0}
$$

where $f$, the focal length, is $2.928 \mathrm{~m}$.

The ancrices for the drift spaces (c) to (1) and (2) to (3) are:

$$
\left(\begin{array}{ll}
1 & \hat{i} \\
0 & 1
\end{array}\right)_{01}:\left(\begin{array}{ll}
1 & 6 \\
0 & 1
\end{array}\right)_{23}
$$

Hence, the cransfor patrix is

$\left(\begin{array}{l}y \\ y^{\prime}\end{array}\right)=\left(\begin{array}{ll}1 & 1 \\ 0 & 1\end{array}\right)\left(\begin{array}{ll}0 & 1 \\ -1 / 5 & 0\end{array}\right)\left(\begin{array}{ll}1 & 1 \\ 0 & 1\end{array}\right)\left(\begin{array}{l}y \\ y^{\prime}\end{array}\right)$

Thls is evaluated numerically to give

$$
\left(\begin{array}{l}
y \\
y^{\prime}
\end{array}\right)_{2}=\left(\begin{array}{cc}
1.0246 & 2.866 \\
-0.3415 & 0.02049
\end{array}\right)\left(\begin{array}{l}
y \\
y^{\prime}
\end{array}\right),
$$

for $\ell=6 \mathrm{~cm}$ and $L=3 \mathrm{~m}$. Hence, $y_{2}=2.866 \mathrm{y}_{1}^{\prime}$, and to get a $3-\mathrm{cm}$ displacement of the beam at the septum entrance requires $10.5 \mathrm{mrad}$ of kick. The beam angle in the septum will be 0.225 mrad. If the septum is $3.25 \mathrm{~m}$ long, the height gain therein will be $0.7 \mathrm{~mm}$. Referring to F1g. 10, note that the vertical envelope decreases from $0.93 \mathrm{~cm}$ at the entrance to $0.80 \mathrm{~cm}$ at the exit. These effects provide an additlonal 2-mm clearance at the exit.

Figure 30 shows the iron extraction septum and how the kicked and unkicked bean would fit. This 3.0-ca deflection is $220 \%$ more than the minimum needed for extraction. Figure 31 shows the appearance of the fuld septum in 1/4 scale. The parameters are listed in rable VIII.

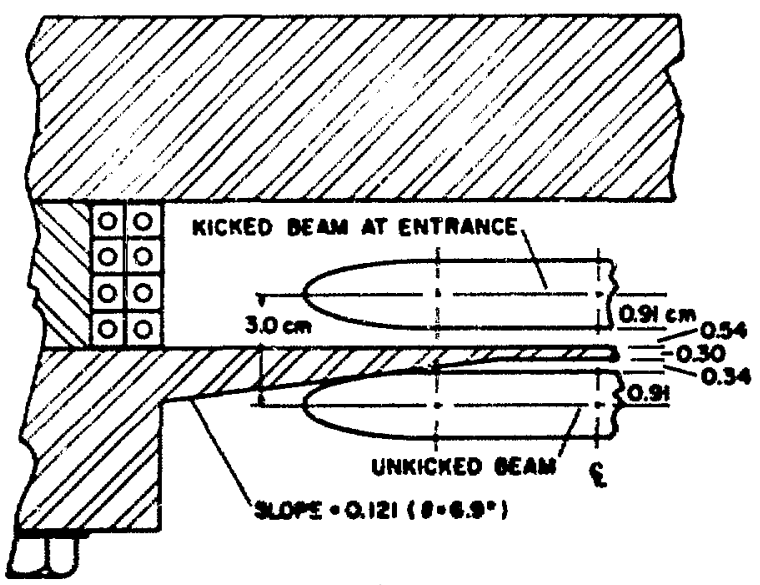

Fig. 30. Iron horigontinl-extraction septum.

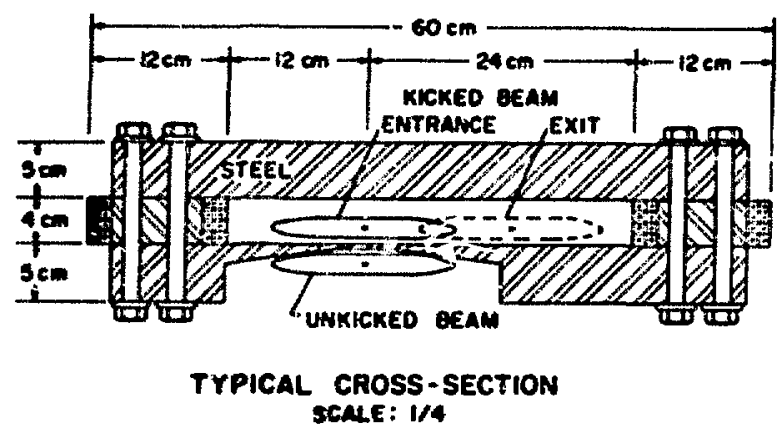

Fig. 31. Full drawing of the fron horizontalextrastion septuas. 


\section{TABLE VIII}

WH-RIHG ERTTACTIOH-SEPTUM PARAMETERS

Magnetic Field: $1200 \mathrm{G}$

Deflection Angle: $80 \mathrm{mrad}\left(4.6^{\circ}\right)$

Septum at Thinnest: 0.3 mos

Leakage Field: $\sim 3 \mathrm{G}$

Steel: 1010 Annealed at $1500^{\circ} \mathrm{F}$

Length: $3.25 \mathrm{~m}$

Turns: 8

Current: 550 A

Conductor: Copper, 0.340-1n. ${ }^{2}, 0.1835-1 n .-d i a m$ cooling hole

Resistance: $18.4 \mathrm{~m} \Omega$ for each of the two coils

Total Voltage: $22 \mathrm{~V}$

Total Power: $12.1 \mathrm{~kW}$

Water Flow: $2.48 \mathrm{pm}$

Pressure Drop: 80 psi (no manifold allowance)

Weight: 130 1b copper; 2950 lb steel

Special Requirements: Because the coil is in vacuum and the desired vacuum is $<10^{-8}$ Torr, inorganic insulation will be required. Because of the low cofl voltage, glow discharge should not be a prob1em.

This design uses back-leg colls in preference to saddle coils which might adversely affect the beam owing to stray fields.

We now consider the kicker used to deflect the bear into this extractor. The high frequencies involved rule out the use of steel to shape the field. Figure 32 shows a conceptual design formed of two conductors. Heavy currents flow in opposite directions, so the $B$ fleld is horfzontal and the kfck is verticsl.

To acinleve the necessary 10.5 mrad of kick, 512 $G$ are needed for $1 \mathrm{~m}$ (at $800-\mathrm{MeV}$ proton energy). 8000 A will create a $570-G$ field to give a safety factor of $11 \%$. The characteristic impedance of these plates in the geometry shown is $21.4 \Omega$, and the voltage needed is $10^{5} \mathrm{~V}$.

Conceptually the driving pulses for such a kicker could use lumped constants; but, considering the pulse flatness, the rise time and fall time, and the

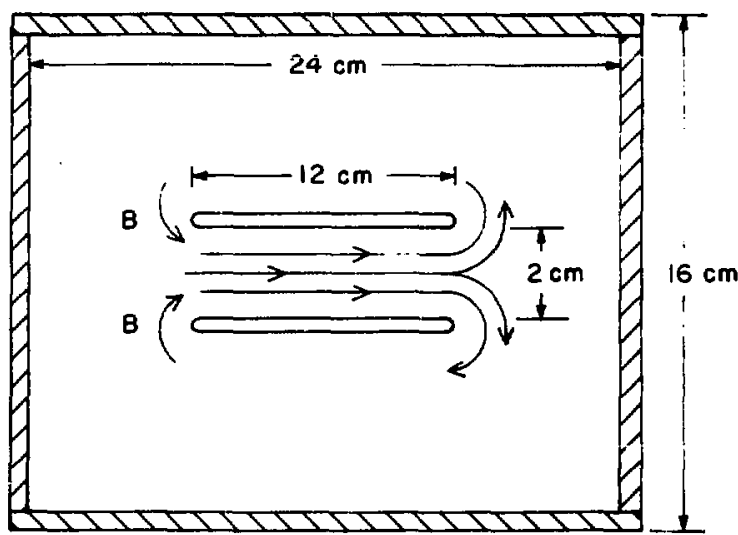

Fig. 32. Vertical kicker using flat conductors.

\section{TOP CONDUCTOR} REMOVEO

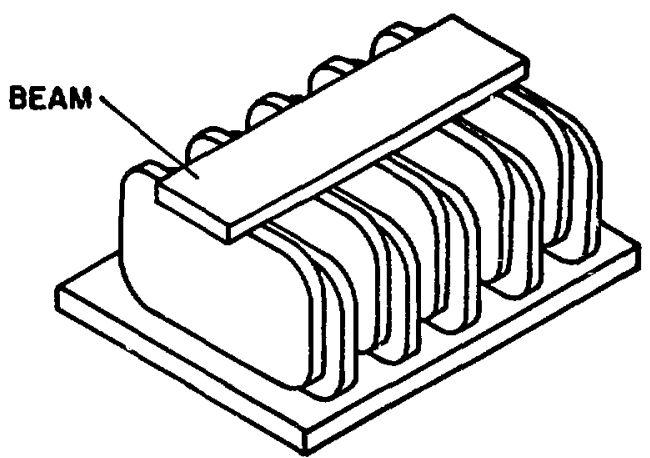

Fig. 33. Vertical kicker using capacity loading.

short pulse requirements, a distributed-constant pulse-forming network would probably be the mnst reasonable approach. However, $10^{5} \mathrm{~V}$ on the conductor means, for a simple circuit, $2 \times 10^{5} \mathrm{~V}$ on the pulse-forming network before discharge. Usual highvoltage cables such as RG 19 or RG 222 are charged to only about $25 \mathrm{kV}$, so clearly something must be done.

At this point the design closely follows that of Brückner 52,53 for the CERN-PI extractor; parallelplate. capacitive loading is used to redure the transmission line impedance to $1.56 \Omega$. This is the impedance of 32 RG 19 coaxial cables in parallel, and the $6000 \mathrm{~A}$ will be attained with $12,480 \mathrm{~V}$ or, using simple techniques, $24,960 \mathrm{~V}$ for charging the lines.

The most important design parameters are presented in Table IX, and the kicker is shown concepcually in Fig. 33. 
TABLE IX

PARAMETERS FOR THE CAPACITY-LOADED VERTICAL KICKER

Deflection Angle: $10.5 \mathrm{mrad}\left(0.6^{\circ}\right)$

Magnetic Field: $570 \mathrm{G}$

Effective Kicker Length: $1 \mathrm{~m}$

Conductor Width: $12 \mathrm{~cm}$

Required Current: $8000 \mathrm{~A}$

Required Voltage: $12,480 \mathrm{~V}$

Impedance: $1.56 \Omega$

Gap Width: $4 \mathrm{~mm}$

Capacitor Plate: $55 \times 24 \mathrm{~cm}^{2}, 0.6 \mathrm{~cm}$ thick

Number of Plates: 400 (both conductors and ground)

Propagation Velocity: $2.19 \mathrm{~cm} / \mathrm{nsec}(\beta=0.073)$

Rise and Fall Times: $\leq 30 \mathrm{nsec}$

This $\beta$ value would result in a kicker-filling time of $46 \mathrm{nsec}$. To handle the high-duty rzquirements, this must be shortened. Dividing th」kicker in half and driving the halves separately shortens this time to 23 nsec.

There may be some question as to whether $4 \mathrm{~mm}$ of vacuum will hold off $25 \mathrm{kV}$. (If the kicker is not part of the pulse-forming network, this number is reduced to $12.5 \mathrm{kV}$.) LBL design data give the following dc breakdown voltages in vacuum (for a 4-num gap).

\begin{tabular}{lc}
\multicolumn{1}{c}{ Material } & Voltage $(\mathrm{kV})$ \\
\hline 316 Stainless Steel & 360 \\
Inconel & 260 \\
Copper & 148 \\
Aluminum & 114
\end{tabular}

The paper by Bolin et al. ${ }^{54}$ lists materials of increasing desirability as: carbon, beryllium, lead, aluminum, copper, nickel, iron, stainless steel, titanium, tantalum, molybdenum, and tungsten. They indicate that this gradient is satisfactory but close to marginal. They also present data indicating very substantial improvements $(2 x)$ from anodizing of the aluminum electrodes. They include data for metal oxides, fluorides, organic films, and epoxies. A dielectric coating on the cathode acts to inhibit field emission; a coating on the anode is usually detrimental. Hold-off voltage is improved by conditioning the electrodes in vacuum under voltage. This application, however, is for short pulses, and the data on time-dependent effects are not conclusive; hence, dc values are assumed to apply.

The WNR extraction kicker is compared to others in Table $X$ (other entries are from Ref. 51). This table shows that the problems are comparable to those of some very large accelerators. Note that both the present AGS kicker and the present CERN-PS kickers are capable of multishot operation like that required for the WNR ring, except that they have less stringent rise-time requirements and their recovery time is $150-200 \mathrm{msec}$, compared with the WNR-ring kicker-recovery time of 1.67 msec (or 25 nsec for the magnet).

Thus we come to the difficulties suggested above. The problem is that the best-known thyratrons (CX 1174 ) are rated for only $10,000 \mathrm{~A} / \mathrm{usec}$; the present kicker design requires $100,000 \mathrm{~A} / \mu \mathrm{sec}$. We present various solutions, none of which can be guaranteed to be a solution, let alone the optional solution.

\section{(1) Pushed Thyratrons}

Apparently the anode rise-time current ratings are very conservative. Fudin ${ }^{55}$ states that 20-nsec rise times to full current can be achieved. He cites data from CERN for a CX 1157 which indicate that the time to full current as a function of reservoir heater currents is $50 \mathrm{nsec}$ at $5.8 \mathrm{~V}, 25 \mathrm{nsec}$ at $6.2 \mathrm{~V}, 14 \mathrm{nsec}$ at $6.6 \mathrm{~V}$, and $12 \mathrm{nsec}$ at $6.8 \mathrm{~V}$. This application was for a spark-chamber pulser, and repetition rate information is unavallable. Fudin also refers to $0^{\prime H a n l o n}$ and Zadasco's work (CERN) ${ }^{56}$ using the $\mathrm{CX} 1168$ at $5 \mathrm{j} \mathrm{kV}$ and $1800 \mathrm{~A}$. They find for the rise time as a function of reservoir voltage: $120 \mathrm{nsec}$ at $5.0 \mathrm{~V}, 60 \mathrm{nsec}$ at $5.5 \mathrm{~V}$, and $40 \mathrm{nsec}$ at $6.0 \mathrm{~V}$. It is significant that the increase in reservolr pressure did not cause breakdown at $50 \mathrm{kV}$, which is the general effect of increasing the reservolr temperature. Time jitter cited in both of these reports is under 2 nsec. The data presented in Table XI compare various potential thyratrons for this application. 
TABLE $X$

WNR-RING KICKER COMPARED WITH KICKERS OF REF. 51

\begin{tabular}{|c|c|c|c|c|c|c|c|c|c|c|c|}
\hline Installation & $\begin{array}{l}\text { Max } \\
\text { Proton } \\
\text { Energy } \\
(\mathrm{GeV}) \\
\end{array}$ & $\begin{array}{c}\text { Magnet } \\
\text { Type }\end{array}$ & $\begin{array}{c}\text { Individual } \\
\text { Magnet } \\
\text { Aperture } \\
\text { w } \mathrm{h} \mathrm{x} \\
\left(\mathrm{cm}^{3}\right) \\
\end{array}$ & $\begin{array}{l}\text { No. of } \\
\text { Magnet } \\
\text { Sections } \\
\end{array}$ & $\begin{array}{l}\text { Total } \\
\text { Def lect- } \\
\text { Ing Force } \\
(\mathrm{T}-\mathrm{m}) \\
\end{array}$ & $\begin{array}{l}\text { E Max } \\
\text { Charge } \\
\text { (kV) } \\
\end{array}$ & $\begin{array}{l}Z_{0} \text { per } \\
\text { Magnet } \\
(12)\end{array}$ & $\begin{array}{l}\text { Bunch } \\
\text { Separation } \\
\text { (1rsec) } \\
\end{array}$ & $\begin{array}{l}W_{s} \\
(\mu w) \\
\end{array}$ & Switches & Comments \\
\hline LASL WNR Ring & 0.8 & $\begin{array}{l}\text { Trans- } \\
\text { mission } \\
\text { Line, } \\
\text { Fu11 } \\
\text { Aperture }\end{array}$ & 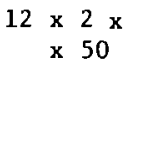 & 2 & 0.058 & 25 & 1.56 & 50 & 128 & $\begin{array}{l}\text { Deuterium } \\
\text { Thyratron? }\end{array}$ & $\begin{array}{l}\text { Requires clean recovery } \\
\text { for multiple pulse } \\
\text { extraction. }\end{array}$ \\
\hline $\begin{array}{l}\text { CERN Booster } \\
\text { Extraction Kicker }\end{array}$ & 0.8 & $\begin{array}{l}\text { Trans- } \\
\text { mission } \\
\text { Line, } \\
\text { Full } \\
\text { Aperture }\end{array}$ & $\begin{array}{r}11.5 \times 7 \\
\times 48\end{array}$ & 4 & 0.04 & 33 & $\begin{array}{l}25 \\
\text { (produces } \\
\text { F. on ter- } \\
\text { mlnat Ion) }\end{array}$ & 50 & 106 & $\begin{array}{l}\text { Deuterium } \\
\text { Thyratron } \\
\text { plus spark } \\
\text { gap }\end{array}$ & $\begin{array}{l}\text { Part of complex four- } \\
\text { ring injection system. }\end{array}$ \\
\hline $\begin{array}{l}\text { Postconversion } \\
\text { AGS Kicker }\end{array}$ & 30 & $\begin{array}{l}\text { Lumped } \\
\text { Magnet, } \\
\text { Full } \\
\text { Aperture }\end{array}$ & $\begin{array}{r}15.3 \times 7 \\
\times 38\end{array}$ & 4 & 0.2 & 100 & 14 & 200 & 1240 & $\begin{array}{l}\text { 4-Deuterium } \\
\text { Thyratrons }\end{array}$ & $\begin{array}{l}\text { Under development -- } \\
\text { Blumlein circuit used. }\end{array}$ \\
\hline $\begin{array}{l}\text { Present AGS } \\
\text { Kicker }\end{array}$ & 30 & $\begin{array}{l}\text { Lumped } \\
\text { Magnet, } \\
\text { Fu11 } \\
\text { Aperture }\end{array}$ & $\begin{aligned} 15 & \times 6.7 \\
& \times 38\end{aligned}$ & 4 & 0.08 & 40 & 7 & 200 & 170 & $\begin{array}{l}\text { 2-Deuter fum } \\
\text { Thyratrons }\end{array}$ & $\begin{array}{l}\text { Gapable of full beam ex- } \\
\text { traction or mu1tiple } \\
\text { sirgle-bunch extractions } \\
100 \text { msec apart. }\end{array}$ \\
\hline $\begin{array}{l}\text { NAt Booster } \\
\text { Extractor }\end{array}$ & 8 & $\begin{array}{l}\text { Unloaded } \\
\text { Trans. } \\
\text { Line }\end{array}$ & $\begin{array}{r}6.9 \times 6.9 \\
\times 100\end{array}$ & 4 & 0.03 & 70 & 50 & 45 & 19 & $\begin{array}{l}\text { 4-Deuterium } \\
\text { Thyratrons }\end{array}$ & $\begin{array}{l}\text { No extra capacity needed } \\
\text { to operate at this } \\
\text { impedance. }\end{array}$ \\
\hline $\begin{array}{l}\text { CERN-PS } \\
\text { Extraction }\end{array}$ & 25 & $\begin{array}{l}\text { Trans. } \\
\text { Line }\end{array}$ & $\begin{aligned} 15 & \times 5.5 \\
\times & 23\end{aligned}$ & 12 & 0.17 & 80 & 15 & 100 & 750 & $\begin{array}{l}\text { 36-Deuterfum } \\
\text { Thyratrons }\end{array}$ & Under development. \\
\hline $\begin{array}{l}\text { Present CERN-PS } \\
\text { Kicker }\end{array}$ & 25 & $\begin{array}{l}\text { Trans. } \\
\text { Line } \\
\text { Mobile }\end{array}$ & $\begin{aligned} 2.2 & \times 2 \\
& \times 28\end{aligned}$ & 2 & 0.14 & 70 & 10 & 100 & 110 & 6-Spark Gaps & $\begin{array}{l}\text { Capable of multislot } \\
\text { operation after } 150-\text { to } \\
200-\text { msec recharge. }\end{array}$ \\
\hline
\end{tabular}


TABLE XI

POSSIBLE KICKER TBYRATRONS

Tube Peak Forward Peak Anod

Type Volrage ( $\mathrm{kV}$ ) Current (kt) Cost

\begin{tabular}{|c|c|c|c|c|}
\hline 1174 & 40 & 6.0 & $\$ 2500$ & Ceramic deute. an \\
\hline CX 1154 & 40 & 2.5 & 1590 & Ceranic deutertum ce \\
\hline $\begin{array}{r}1159 \\
7384\end{array}$ & $\begin{array}{l}33 \\
25\end{array}$ & $\begin{array}{l}1.0 \\
1.0\end{array}$ & $\begin{array}{l}590 \\
425\end{array}$ & $\begin{array}{l}\text { Glass deuteriw tetrod } \\
\text { Glass hydrogen cetrode }\end{array}$ \\
\hline 1180 & 25 & 1.0 & 985 & Ceramtc hy \\
\hline
\end{tabular}

\section{(2) Corrective Networks}

A kicker is ideally a magnetic switch, and conditions intermediate to OFF or ON are not of interest except for the problems they present. Therefore, the use of capacitors, Inductors, and stub lines at various places in the circuit to correct the performance is quite approprlate. Such trimming, although guided by theory, cannot be assured of success beforehand and is more suitable for model adjustment.

\section{(3) Elux Concentration}

The kicker shown in Figs. 32 and 33 uses no ferromagnetic materials. Ferrites have the necessary high-frequency properties and permeabilities of $\sim 100$, and can, literally, be fabricated in any shape. It may be possible to design a ferriteloaded kicker, conceptually shown in Fig. 34.

This concept has not been developed; it might provide a factor of 1.5 flux concentration that, in conjunction with solutions (1) and (2), would probably meet the requirements. The closed box as shown is probably not suitable because of possible leakage currents in the ferrite caused by the high electric fields. However it should be possible to introduce gaps across which the fleld could be developed with only negligible reluctance increase.

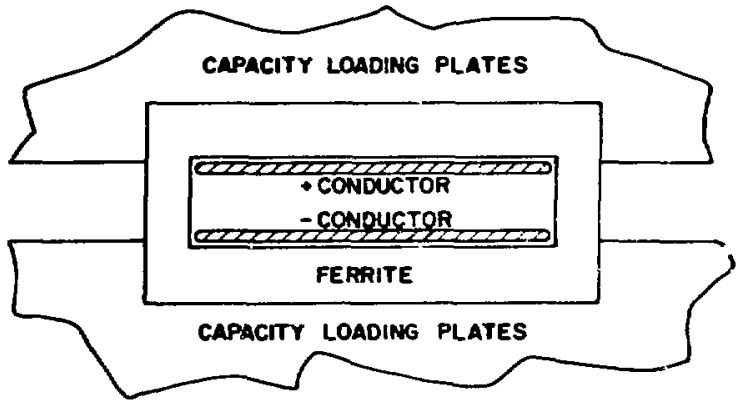

Fig. 34. Ferrite box loading of the kicker.

\section{(4) Shock Lines}

In the orlginal planning for the kicker, we thought that the use of shock lines 52,57 would keep the rate of current rise from posing a problem. Shock lines are transmission lines whose propagation velocity is a function of the voltage or current transmitted. Thus the "top" of the pulse goes faster than the "bottom," and a shock front with a rise tme of $\downarrow 1$ nsec develops. In this application, the problem arfses in trying to get fase curnoff at the trailing edge; the shock line reads to slow the fall times. Brückner 52 uses a "tail-biting" spark gap to achleve fast turnoff. Objections to spark gaps are given in the next section.

ot: solution is to use a shork line with a clipping stub so that the fast $r$ ise is reflected and used to turn of the kicker (Fig. 35). The undesfrable aspects come from the pulses that reflect from the end of the pulse-forming network (PFN) and travel back to the magnet. It may be possible to absorb these pulses in the charging network by switching in a load. Another problem is that the reverse wave brings the shock line out of saturation, causing impedance mismatch.

Katayev 57 shows an elegant solution using biased double shock lines (Fig. 36). The operacion is substantially as follows.

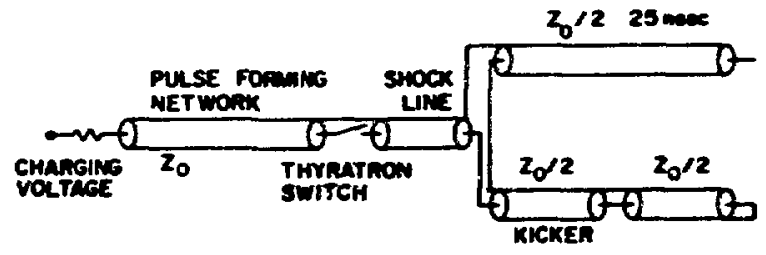

Fig. 35. A shock 1 fine and clipping stub.

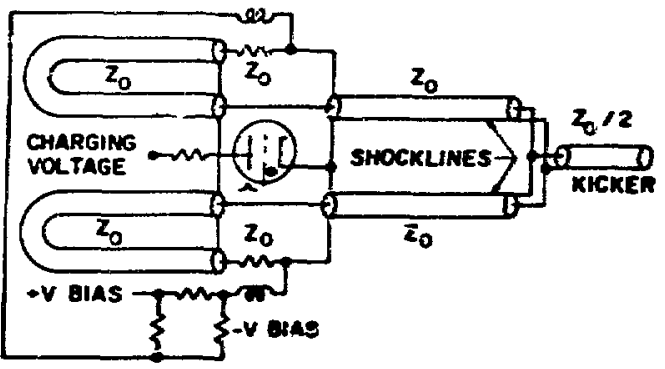

Fig. 36. Blased double shock line (Ref. 57). 
The two PFi generate identical pulses; the two shock lines are preblased with equal currents of opposite polarity but variable magnicude. If the preblas curtent is zezo, the output fulse is zero. How ever, preblasing oppositely causes more energy to be absorbed froe the leading edge of one pulse than from the other, so it arrives later. The kicker is pulset during the tine becween the artital of these two shock fronts. The llelay ingerval is controlled by the preblasing currents used.

In principle, there should be no secondery pulses, both shock lines should stay in saturation, and the load resistors $\left(2_{0}\right)$ should absorb the reverse vaves; however, such ideal operation would probably not be reallzed.

A decided disadvantage of this design is lts cosplexicy. Further, the thyracton has to carry four closes the current requited for the klcker. Because the teflectors are split to reduce the filling tiac, and because there are two conductors per deflector. 32 thyratrons each carrying a ka would be required. The operacion of chyratrons it parallel requires balancing networks that add to the complexity.

\section{(5) Spark Gaps}

Spark gaps can readily achleve the requited current rise times. They vere used in the stanford Mark III Linac and are used fo the LBL Electron Ring Accelerato: (ERA). The ERA expertence is that after $5 \times 10^{5}$ shots at $10 \mathrm{kA}$. the gaps require processing. ht the 600 pps of the high-duty mode. this is only 14 min of operation. To operace through 1 week $(100 \mathrm{~h})$ az high duzy requires a spark gap life of $2 \times 10^{8}$.

A possible approach suggeseed by Falcens ${ }^{58}$ is the use of aercury-wected iron-sponge spark gaps developed during World tar II. Glasoe and Lebacq 59 report operation of two such gaps in serles at 24.5 kT, $925 \mathrm{~A}, 2$ usec, and 240 pps with a litietlae in excess of $4 \times 10^{8}$.

Sparik gaps are comerelally available only for "crabar" applications, so lifet foes of $10^{6}$ are sak + factory. Any designs cabodykng spark gaps puld he a developent rask.

\section{(6) Eapty Bucket}

It is certainly possible to desise an rf systez or LAtPF inject Ion-blanking system that would leave one if bucket empty, thereby doubling the time allowed to operate the kicker. This is an option that can be used at any the and wich would reduce: the intensity by $20 \%$. It thereford seems unnecessary to use chis recourse unt 11 the other options are shown to be infeasible.

\section{(7) More Thyratrons}

Certainly chis approach is possible, but it is economically qucstionable and requires balancing nezworks.

\section{(B) Hard-Tube Pulser}

This approach is considered prohibitively expensive in view of the $100 \mathrm{w}$ co be switched, and

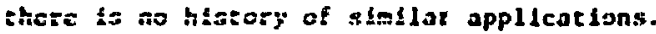

In concluston, combinations of solutions (1), (2), and (3), being the least expenstve, should be Invese lgated first.

\section{Slar-Spill Extracelon. A storage ring is} basically a duty-cycle manipulator; besides the rtquireacent for pulse coepression and, hence, rast extraction, there are applifeations for which slow extraction is desirable. One of the earllesit schemes, the energy-loss target aethod. 50 is not suttable for the present design becatite of the vertically located extraction siysizen.

A generally mote cifictent method that appears applicable to the whe $r i n g$ is resonance extraction. Resonance extraction secess to provide the advantages of efficient long-burst slection with practically no increase in circulating-beas caicrance. The basic idea is to shitt the zune onto a betatron resonance that will rause large enough beam osclilation to enter the extraction system.

In the theosy of resonance extraction, ${ }^{50}$ the harwontc equation describing the beas notion is dztuat by a torce represented by a harmontc expanslon. For slou extraction resonances, one should use the nonlinvar zesonances above the second erder because tiw betatron trequency is a function of asplitule which makes it possible to resonate the outer extrealcies of the bean winfle the rest is stable. Once the bean is asstable, the growth rate is faster than exponential. 


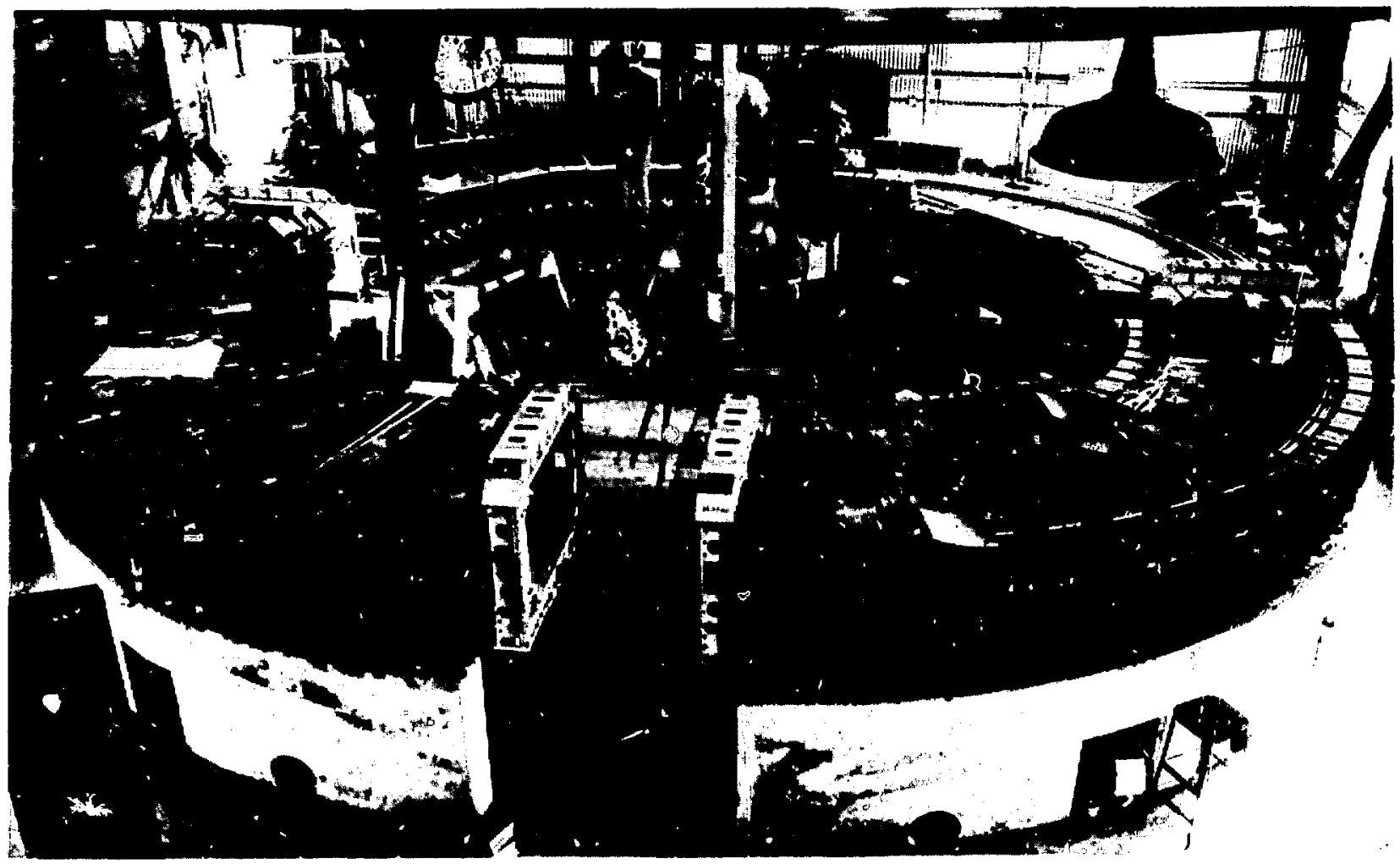

Fig. 37. Quarter-scale bevatron (Cal-Tech synchrotron) during assembly.

No design work has been done on chis cype of extraction for the WNR ring, but it seems that with the fast cune control needed for the betatron injection and with the various triming fields, this cype of extraction is possible. A racher distressing point is that only about $70 z$ ef flclency has been achieved. This may cause an intolerable radianctive buildup in the storage $\mathrm{I} i \mathrm{ng}$ and require podffication of past techniques.

\section{Sector Magnets}

A key cconony aspect of this proposal is the use of the quarter-scale bevatron/Cal-tech synchrotron for the bending magnets. Flgure 37 shows these 4-90 bending sectors during assembly at Berkeley. Figure 38 shows a secto- with the placement of the $F$ and $D$ pole tips providing the strong focusing, and Fig. 39 gives nore cietall of the iron as well as a possible concrete supporting structure. Figure 40 shows details of the extruded vacuum chamber located between
Fhese pole tips, and Fig. 41 shows the details of the pole tips.

The Cal-Tech synchrotron as fresenty avallable is a weak tocusing accelerator. Tt will be necissary to replace the present vauuum chamber ard fole tips to adapt te :or use as a strong-focusing, highintensity storage ring.

Given the values for the profile parazeters from Table IV, we must devise appropriately shaped pole tlps for the magects to realize these paramecers. The design in Fig. 41 is not final; it was calculated on the basis of real, nonlinear irun in the pole tips and infinitely pertaeable fron in the return legs. The forward problew was calculated for for the vector manetic potentfal uslag the progran POtssoN; the inverse or synthesis was caiculated using SAIRT. 60

The prograp PoISSON sriginated with the twodimensional weapons-diffusion code ty Uinslow (LLL).

The present pole-tip destgn is by K. Halbach (LBL) assisted by S. Magary (t,BI.). 


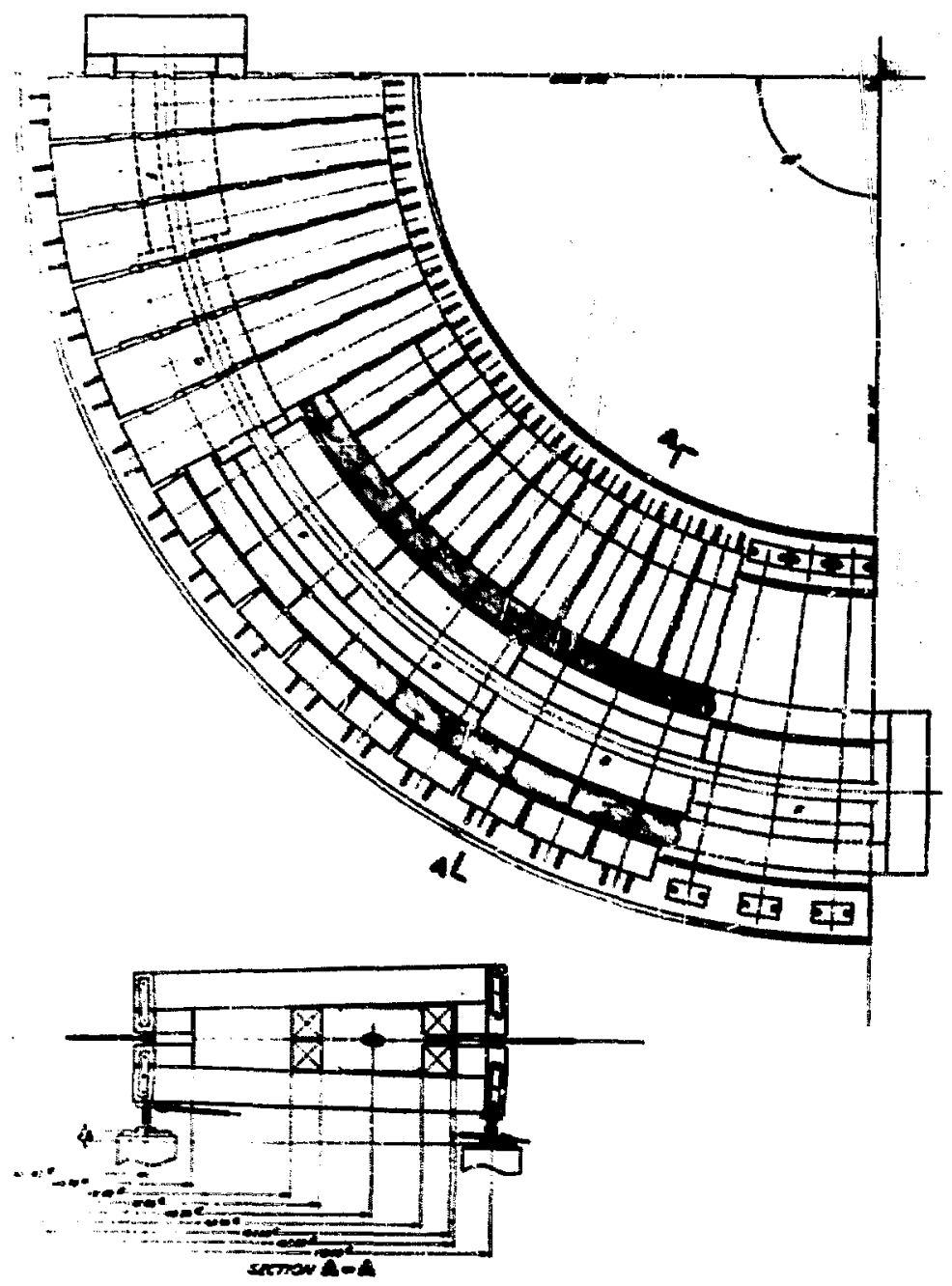

F18. 38. Ninety-degree-sector magnet showing piacenent of $F$ and $D$ pole tips. Cross-aection view of a sector.

Colonius (LDL) rewrote it into the program that solves Posisson's equation in vector-potential form using a triengular wesh along which the permeability Is assumed constant. A new vector potential is expressed as a sumation over old values plus an inhowogeneous current-source term and equals the old vector potential plus an over-relaxation tere. Aboue 200 iteractons are required for a problem in Infinitely perceable Iron.

The sypthests prozrans, SAIRT or PISh, 60 invert the forward prozras by finding the parameter set chat aininizes a veighted sun of the squares of the deviations between the destred and accoaplished perfornance of a systea. This is done subject to the restratuing conditions that require certain perfor- mance opecifications to be met: exactly. PISh is writcen in a general form for use on a variety of problems, but it is especially ouftable for mnenstostatics. The secondary variable (extenaive parawecer) is expressed as a welghted least-aquares sum in which the veighting can be used advantageously when certain secondary variables (the agnetic potential) wust be fitted wore accurately than at other lcca". tions. The least squares are minifized using Lagrange multipliers subject to the restraining conditions that aust te wet exactly. The nusertcal solution of the probles follows from a Taylar's sartes expansiton of the secondary paxameters. The syste paraneters suth as the perweabllity result fron a solution by standasd atrix aethods. 


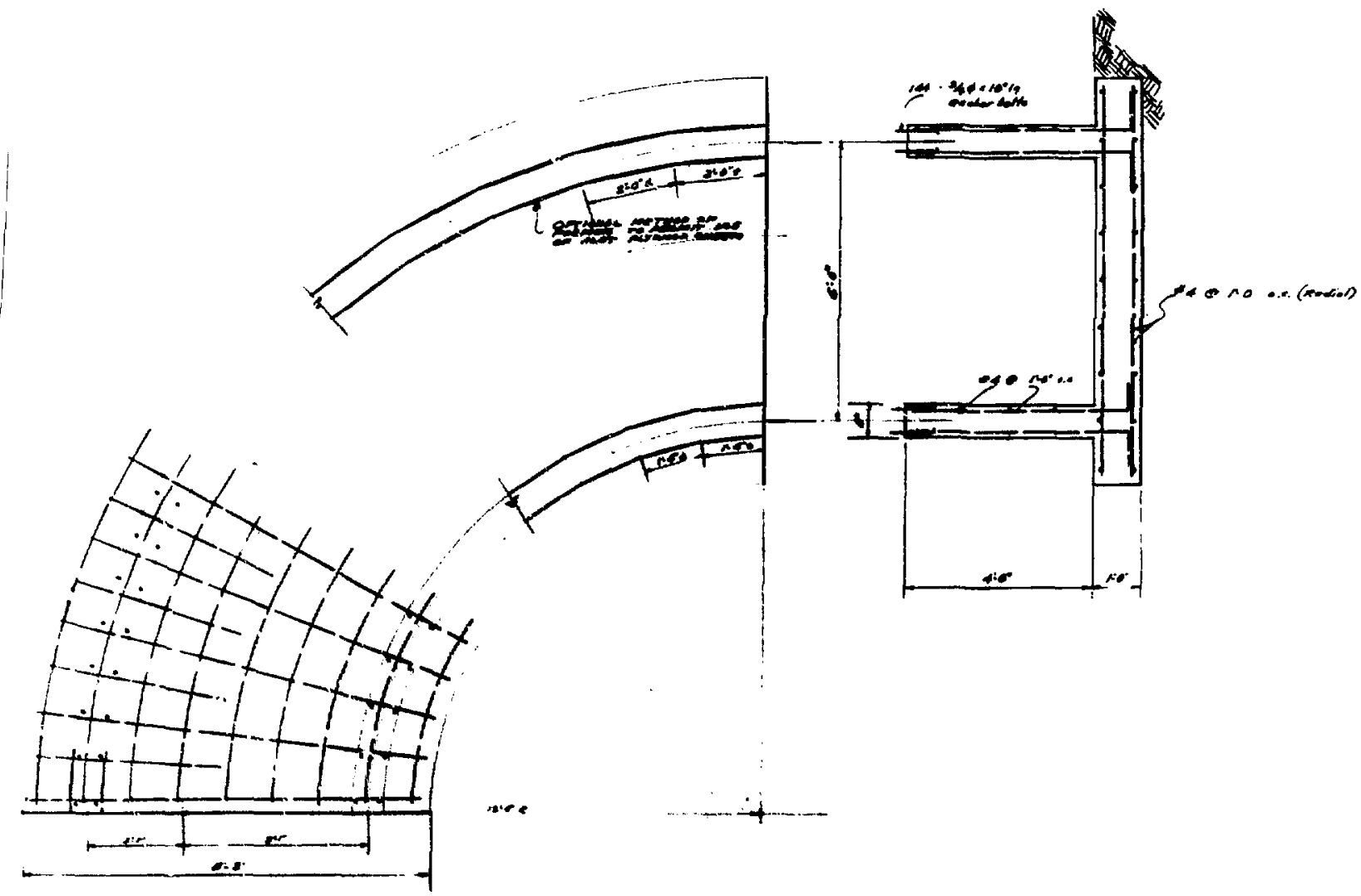

Fig. 39. Ninety-degree-sector magnet and support stand.

Voge! and Yound ${ }^{61}$ have compared POISSON using the previously described triangular mesh with the progran LINDA (by R. Christian, Purdue) which uses a quadrilateral mesh. If the boundartes are curved, the POISSON mesh triangles become severely distorted and accuracy is lost. If the magnet can be conformaily mapped into a dipole, the mesh is fairly symmetrical and good accuracy is achieved. This was the procedure followed by Vogel and Yound who found good agreement between the $t$ kn computational procedures. It seems fron the foregoing that the poletip design should be reralculated for real iron and that results calculated by POISSON should be checked using LINDA before actual machining begins.

\section{E. Vacuum System}

Storage rings operate at ? $10^{-9}$ Torr vacuum without beam, ${ }^{52}$ and in electron storage rings the vacuum may deteriorate to $\sim 10^{-8}$ Torr with beam owing to photo-gas desorption. In the CERN-ISR the vacuum is $10^{-9}$ Turr in the rings 8 and $10^{-11}$ Torr in the interaction region. In that ring, the vacuum criterion is set by the requirement that the beam coast for $>10 \mathrm{~h}$; in the Interaction region, the criterion is set by the ratio of events due to beambeam interaction and those due to beam background. In the specifications for the hNR ring, we assume that: a vacuum of $\sim 10^{-9}$ Torr is required on the basis of the other storage rings; it is, however, interesting to apply scme standard criteria to estimating the vacuum requirements.

Moliére has obtained a formula for atomic scattering using a Fermi-Thomas potential which Courant ${ }^{63}$ has appified to the problem of beam scattering. Using his formulae for $800-\mathrm{MeV}$ protons and nitrogen as the residurl gas, we find a cross section of

$$
\sigma=4.17 \times 10^{-33} \mathrm{~m}^{2},
$$




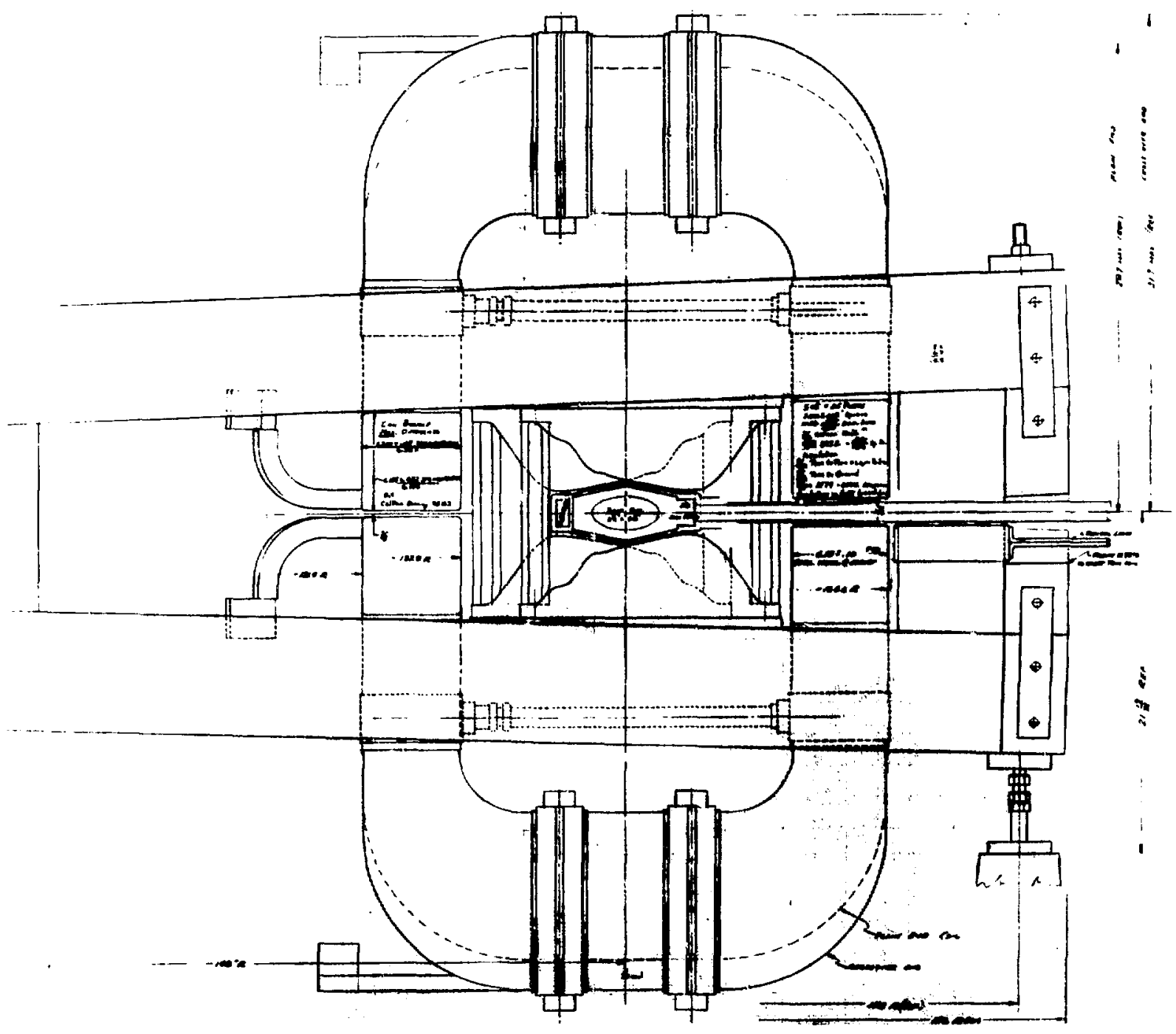

Fig. 40. End view of a sector magnet showing the relationship of pole tips, vacuum chamber, and coil returns.

where the maximum allowable angular change is $\delta \theta \mathrm{m}=$ $U Y / R=0.007 \mathrm{rad}, \nu$ is the vertical tune, $Y$ is the vertical aperture, and $k$ is the equivalent ring radius. Following Bruck, ${ }^{17}$ the growth amplitude is

$$
\overline{\hat{y}^{2}}=n \pi^{2} \sigma\left(s-s_{0}\right),
$$

where $t$ is the betatron wavelength divided by $2 \pi$ and $s-s_{0}$ is the distance traveled by the beam. The vertical aperture is set at $\sim 1 \mathrm{~cm}$ by the iron septum. Substituting this number and $\lambda=7.06 \mathrm{~m}$ in the above equation gives a product of $n\left(s-s_{0}\right)=4 x$ $10^{27} / \mathrm{m}^{2}$. Converting this to more practical units gives a pressure-time criterion of

$$
\mathrm{p} \text { (Torr) } \mathrm{t}(\mathrm{sec})<2.9 \times 10^{-4} \text {. }
$$

It is therefore apparent that the vacuum requirements for 1-sec beam containment set by multiple scattering are easily met.

Beam passage through a plasma environment can cause a tune shift onto an unstable resonance, much like the resistive wall effect (see Sec. III). Hereward, Morton and Schind ${ }^{64}$ have analyzed this problem. In the motion of a round beam in a round chamber, a change in radius of a uniform beam does not change the electric or magnetic field at the 


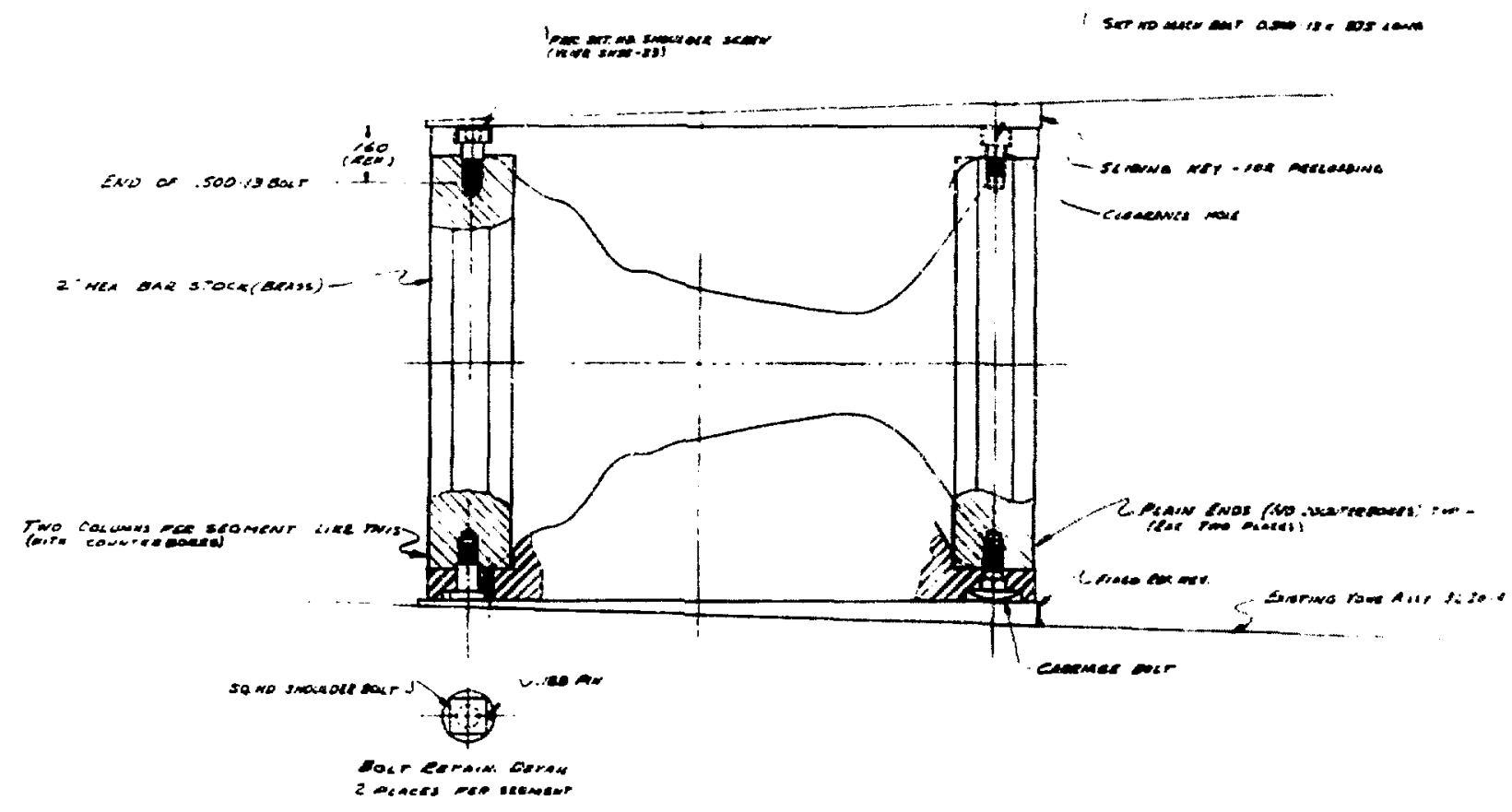

Fig. 41. Strong-focusing pole tips.

vacuum chamber wall and the only effect of the wall is caused by the variation of beam radius in azimuthal position around the ring. Hence, unstable monopole oscillations caused by the walls grow very slowly. In contrast, the motion of an fon inside the beam is affected by the beam radius and can produce unstable monopole oscillations because of the memory field left behind.

Following their analysis, we find an electron oscillation frequency of $0.909 \mathrm{rad} / \mathrm{nsec}$ and an ion e-folding rate of 0.887 usec. In the low-duty bunched mode before efection, the time between the head and tail is $150 \mathrm{nsec}$, so the electrons execute $136 \mathrm{ral}$ while the ion undergoes 0.85 of an e-folding. Thus the electrons are not captured by the beam as assumed in the derivation, and the ions undergo nearly an e-folding in contradiction to the assumption of the derivation.

Ignoring this problem and continuing with their theory, In Table XII we fiadicate the growth rates for the fastest modes, $\pi=7$ and 8 in the radial plane and $n=3$ and 4 in the vertical piane. This table ind icates tha: a vacuum of $10^{-8}$ Torr must be attained, but tilat $10^{-9}$ Torr should be sought because of the experience of others and some yuestions of the strict applicability of Hereward, Morton, and Schindl's theory to this problew.

TABLE XII

ION-PRODUCED THROBBLHG-BEAH GROWTH RATES (IN SECONDS) FOR THE FASTEST HODES

\begin{tabular}{|c|c|c|c|c|}
\hline \multirow{2}{*}{$\begin{array}{l}\text { Pressure } \\
\text { (Torr) }\end{array}$} & \multicolumn{2}{|c|}{ Tune: $v_{x}=4.39$} & \multicolumn{2}{|c|}{ Tune: $v_{y}=2.23$} \\
\hline & $n=7$ & $n=8$ & $n=3$ & $n=4$ \\
\hline $\begin{array}{l}10^{-7} \\
10^{-8} \\
10^{-9}\end{array}$ & $\begin{array}{l}0.142 \\
0.775 \\
7.75\end{array}$ & $\begin{array}{l}0.0775 \\
1.42 \\
14.2\end{array}$ & $\begin{array}{l}0.0775 \\
0.775 \\
7.75\end{array}$ & $\begin{array}{l}0.037 \\
0.37 \\
3.7\end{array}$ \\
\hline
\end{tabular}

For the WNR vacuum system, we selected aluminus as the vacuum-chamber waterial primarily for the efficacy of its high conductivity in suppressing the resistive wall instability (Bee Sec. III). Seconjary reasons are low cost and eace of fabrication. The SLAC-SPEAR uses aluminum primarily to achieve the heat conductivity necessary to carry off the $50 \mathrm{~kW}$ of power resulting from synchrotron 11ght.

The decision to use aluminum carries witi it certafn problems. It limits the bake-out temperature to about $200^{\circ} \mathrm{C}$, and all-metal demountable aluminum flanges create some problems. 

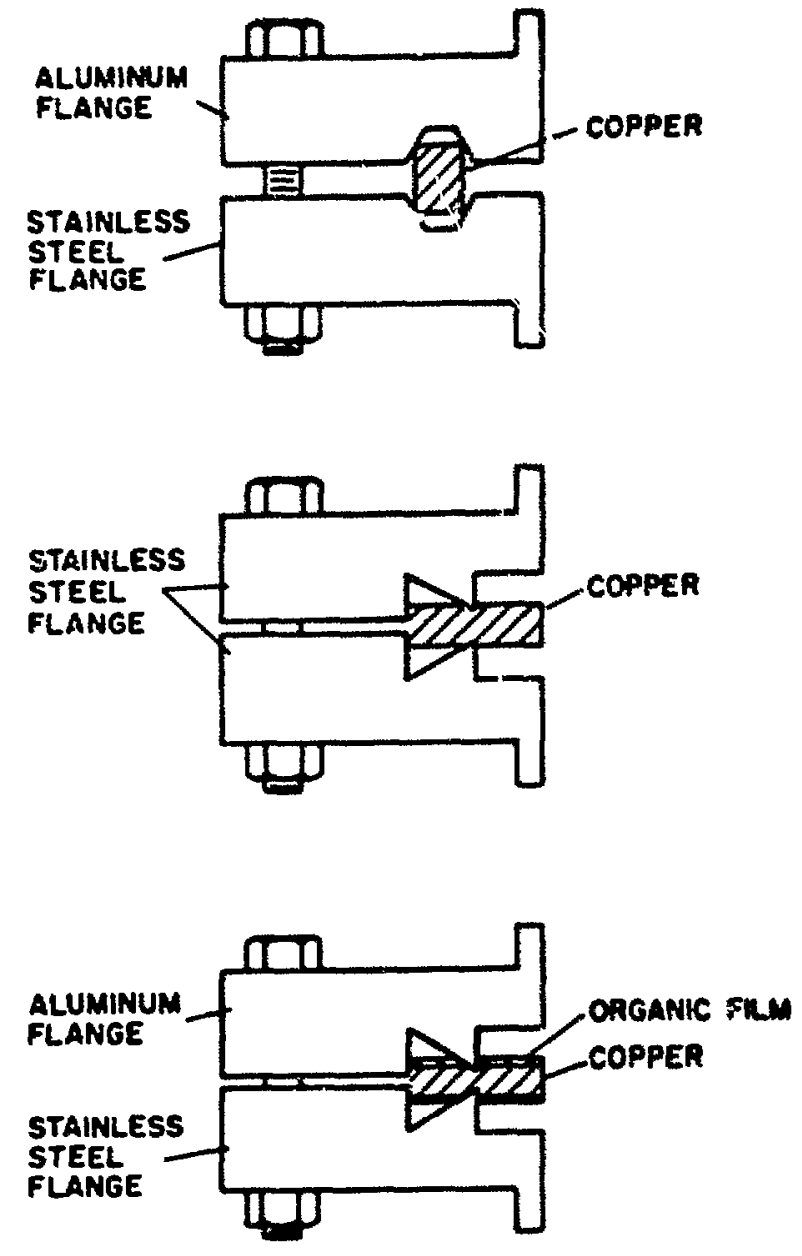

F1g. 42. Hall seal (upper), Vartan seal (centar), Panielson seal (botcon).

Roth $^{65}$ presents a review of metal-to-betal seals but none specifically for joining aluminum to aluminum. A metal-to-metal technique for joining stainless steel to aluoinus is the thall ${ }^{66}$ seal (Fig. 42. upper). SLAC repores ${ }^{67} 1254$ bake-out cycles (20$180^{\circ} \mathrm{C}$ ) on an $11-$ by $4-1$ in. seal using half-hard copper gaskets with 57 gasket changes. Presurably the same seal would be satisfactory for joining aluminum co aluminum.

Another approach is Danielson's, ${ }^{68}$ also for jolning aluminum to stainless steel. A Varian seal of the cype used for joining stainless dreel to stainless steel (FIg. 42, center) is modified by replacing the usual copper gasket with a copper gasket coated with an uncured silfcone called "Panshield" (bow Corning corp.). This merial 13 brushed on and cured at $250^{\circ} \mathrm{C}$ for $8 \mathrm{~h}$. After curing, the coatling is $\$ 0.00025 \mathrm{ln}$. thick (FIg. 42, bottom). With use. Che diufinu surface becones slightly flatcened, but les sealing ubility is not impalred. Such a seal between aluminup and stainless steel was baked overnight at $250^{\circ} \mathrm{C}$, with a vacuus of $2 \times 10^{21} \mathrm{Torr}$ boing achleved. The same seal was leak cesced at $250^{\circ} \mathrm{C}$ ond liquid nitroges cemperature with no leaks decected.

ocher techniques are explosive bonding of stainless sceel flanges to aluminum, 69 which is a form of pressure bofiding. Rotin ${ }^{65}$ does not give any velding cechniques for joinins scainless stecl co alusinua but does indicato chat aluminum can bo bonded to cancaduse, placinum, tron-nickel, and lron by resiscance welding. Rott, (Rot. 65, p. 265) dexctibes sote-soldaring of aluminum to stainless stect but calls for a tranation section of brass or copper. A final approach is tho use of vitzon "o" rings: we believe that thi nothod should be adopted only if mecal-to-cal seals are found unsatisfactory. The reasons are radiat ton damige and outgassing. [Appsrently, howwer, vitron can bo baked to about as high a temperature $\left(200^{\circ} \mathrm{C}\right)$ as altimintu.

The proposud vacuum chamber, shown in Fig. 43. is foned by velting together two extruded sections. Using eirror-inage excrustions involves only une die cost. The water passage show is usud to disstpate the $I^{2} R$ heating from the $t r$ to colls in the extruded finst. The uscer passage could be used as a steam passage for bake-out. The bakc-out can also be done by sloply renoving the water and using the crim colls as heating elements. The extrusion for the SLAC-SPEAR design does nut livolve welding, but uses blends for the die suppores. The integrity of the flows at the blends was cesced by driving wedges into the ends. They report that in most cases rupture occurred, not at the blends, but in other areas. It way be possible to use their cechniques to eliminate the welds alcogether.

Also shown in Fig. 43 is a chamber for dietributed spucter-ion pumps pioneered by SLAC-SPEAR. These pumps provide the advantages of operacing with the magnetic guide field and being located so close to the pumped volume that the coupling impedance is negligible. Any conventional pump would have to be located far enough away that the pump's magnetic 


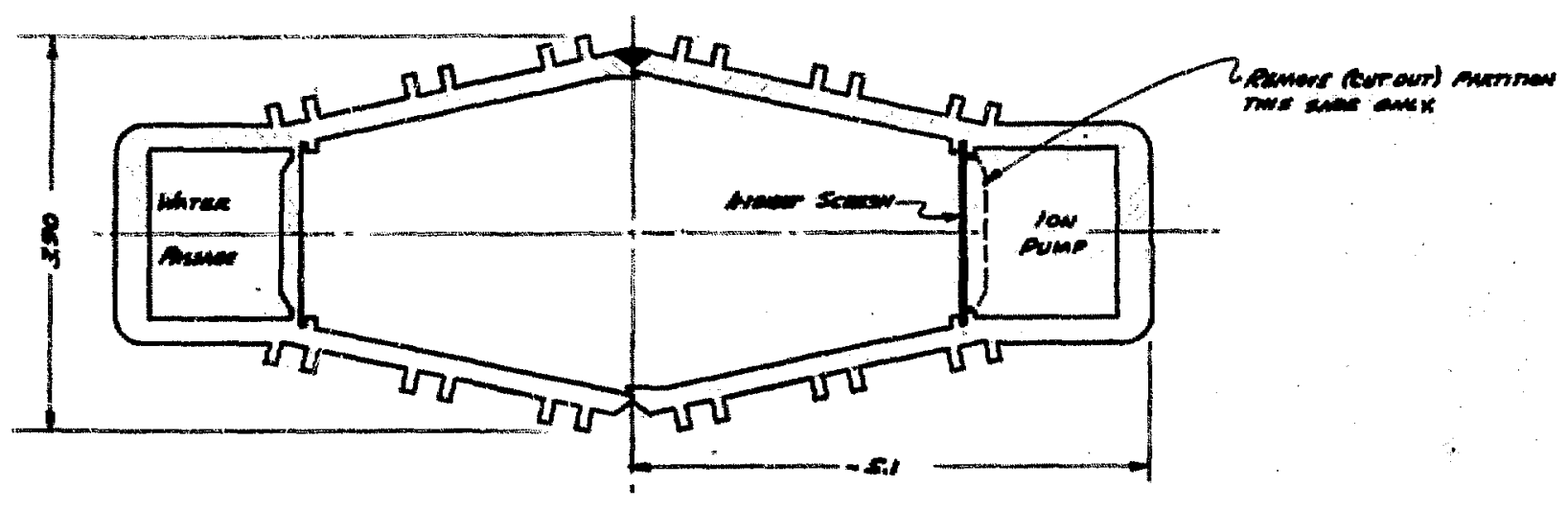

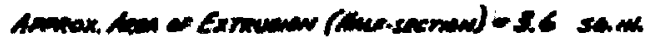

Fig. 43. Proposed vacuus-chaber cross section.

field did not percurb the orbit. The stuc-spesh design ${ }^{67}$ consests of a sathode of 185 tubular colls, d/2 in. In dias by $1.1 \mathrm{kn}$. high, formed of 16-nil cypo 304 stainloss-stecl cubing wolded to nakt a twe-cell-wide array. The cathodes are upper and loser citaniur plates, 90 ails chick oy $1.4 \mathrm{in}$. wide. A screen (Fig. 43) aust be used as a spucter shield to protect the vacuum chamber from citanium deposits, but perhaps more imporcant for a highIntenstey storage ring. it prevents beam-produced ciectronagnetic fields fron penetrating to the vacuum pump. The pumping speed is constant for flelds at above $3.5 \mathrm{kG}$, and the voltagn for constant pumpling speed is $7.3 \mathrm{kV}$.

Under these conditions, the nitrogen pumping speed is 600 liters/sec with a hydrogen speed of about 200 liters/sec. It has been stated that noble-gas pumping for sputcer-ion pumps can be 1mproved greatly by using some tantalum cathodes, 70 but this was not done in the Sl.AC-SPEAR design.

The long $\pi-2 \pi$ stralght sections of the WNR ring constitute " $1 / 2$ of the circumference. Figure 4 shows conceptual.ly how distributed sputter-ion pumps could be located in quadrupole magnets to provice low-impedance pumping in this region.

Another type of pump planned for the stratght sectlons is the SNECM curbomolecular pump. SNSCM, the largest French manufacturer of jet engines, is the developer of the vertical-axis, multistage turbomolecular pump. One of the SNECMN designs consists of an 11-in.-diam rotor spinning at 12,000 rpm

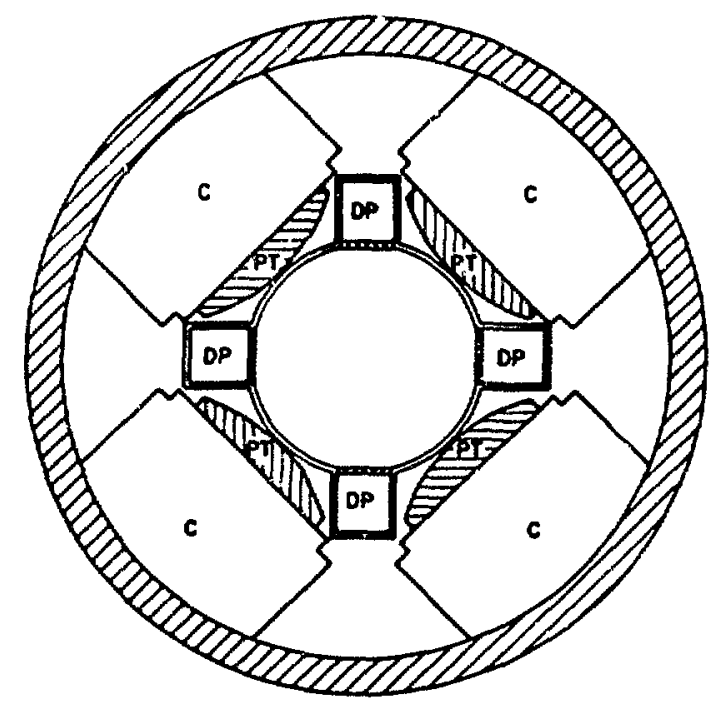

Fig. 44. Conceptual location of distributed sputterIon pumps in a quadrupole magnet. DP, distributed pump; C, exciting coils; PT, pole tips.

and having $a$ tip veloctcy of $580 \mathrm{ft} / \mathrm{sec}$. The pump consists of 4 low-pressure stages with a $4.4: 1$ compression ratio and 10 high-pressure stages with a 2.1:1 pressure ratlo for a cotal of 14 stages.

Timbomolecular pumps have the following advantages.

1. The vacuum is extremely clean $\left(10^{-11}\right.$ Torr ultimate vacuum). The rotating vanes provide a trap for back-sireaming fore-pump ofls. This serves to protect sputter-ion pumps which tend to be palsoned by pump oils.

2. There is no need for $\mathrm{LN}_{2}$ traps. 
3. They pump all gases.

4. Rough pumping can be through the turbomolecular pump.

5. The pumping speed is essentially constant for all gases over a pressure range of $10^{-1}$ to $5 \times 10^{-8}$ Torr.

6. The pump is not harmed by catastrophic venting to atmospheric pressure, nor by accidental. loss of the roughing pump.

7. There are no rotating seals between the atmosphere and yacuum, nor any belts or gears.

Table XIII presents the performance of several models of the cwemA pumps, which are sold in the U.S. by Airco-Temescal, Berkeley, CA.

\section{TABLE XIII}

PERFORHANCE OF VARIOUS MODELS OF SNECMA PUMPS

\begin{tabular}{lrrrr}
\multicolumn{1}{c}{ Model } & $\underline{9016}$ & $\underline{614}$ & $\underline{314}$ & $\underline{114}$ \\
$\begin{array}{l}\text { Pumping Speed } \\
\text { (11ters/sec) }\end{array}$ & 9000 & 650 & 400 & 100 \\
$\begin{array}{l}\text { Voltage (V) } \\
\begin{array}{l}\text { Starting Current } \\
\text { (A) }\end{array}\end{array}$ & 200 & 220 & 220 & 220 \\
$\begin{array}{l}\text { Running Current } \\
\begin{array}{l}\text { Approximate } \\
\text { Price }\end{array}\end{array}$ & 4 & 0.8 & 0.1 & 0.08 \\
\end{tabular}

Two vacuum systems* were designed for the WNR ring. System 1 was designed when the lattice had the superperiod of four $(F 1 g, 6)$. The present lattice has been changed somewhat, and, In fact, system 2 also does not calculate the present design. exactly. We wlll follow design 1 closely, but with corrections for numerical differences. Table XIV presents the distrib:ation of surface areas identified in Fig. 45 .

The rough pumping of this volume is by liquid nitrogen-cooled sorption pumps. This volume requires about $2001 \mathrm{lb}$ of molecular sieve; six commercial sorption pumps* are located in the two short section and at each end of the long straight sections. The pump-down time to reach $10^{-3}$ Torr would be $10-20$ mi،. Then two 100-1iter/sec sputter-ion pumps*t in the short straight section and three 400-11ter/sec turbomolecular puraps would be turned on. Two of these turbomolecular pumps would be in the extraction straigit section; the other wot ' be in the if straight section. The total pumping speed would then be 1400 liters/sec.

*System 1 was designed by Reinath and Gunn, and system 2 by Norgren and Gunn, all of LBL.

**Ion Equipment Corporation pumps, for example.

TABLE XIV

TOTAL VACUUM-SURFACE AREAS OF THE WNR RING

\begin{tabular}{|c|c|c|c|c|}
\hline Vacuum Chamber & $\begin{array}{l}\text { Cross-Section } \\
\text { Perimeter (m) }\end{array}$ & Length (m) & Area $\left(m^{2}\right)$ & $\begin{array}{l}\text { Volume } \\
\text { (11ters) }\end{array}$ \\
\hline A (elliptisal) & 0.414 & 23.62 & 9.78 & 121 \\
\hline B (round) & 0.478 & 4.0 & 1.91 & 73 \\
\hline$c$ (round) & 0.478 & 17.74 & 8.48 & 323 \\
\hline$R \vec{F}$ cavities (line $C)^{a}$ & 4.52 & 1 & 4.52 & 88 \\
\hline$D$ (round) & 0.478 & 13.74 & 6.57 & 251 \\
\hline Vertlcal Kicker & $\begin{array}{c}1.4 \\
\text { (box on } 1 y \text { ) }\end{array}$ & 1.91 & 15.47 & 500 \\
\hline Injection Septa & & 1.4 & 2.3 & 27.7 \\
\hline Extraction Septum ${ }^{a}$ & & 3.25 & 12.4 & 273 \\
\hline Total & & & 61.43 & 1657 \\
\hline
\end{tabular}

\footnotetext{
We assume that all these items will be in the vacuum systems (no ceramic sections).

bo subtraction for volume displacement by hardware.
} 


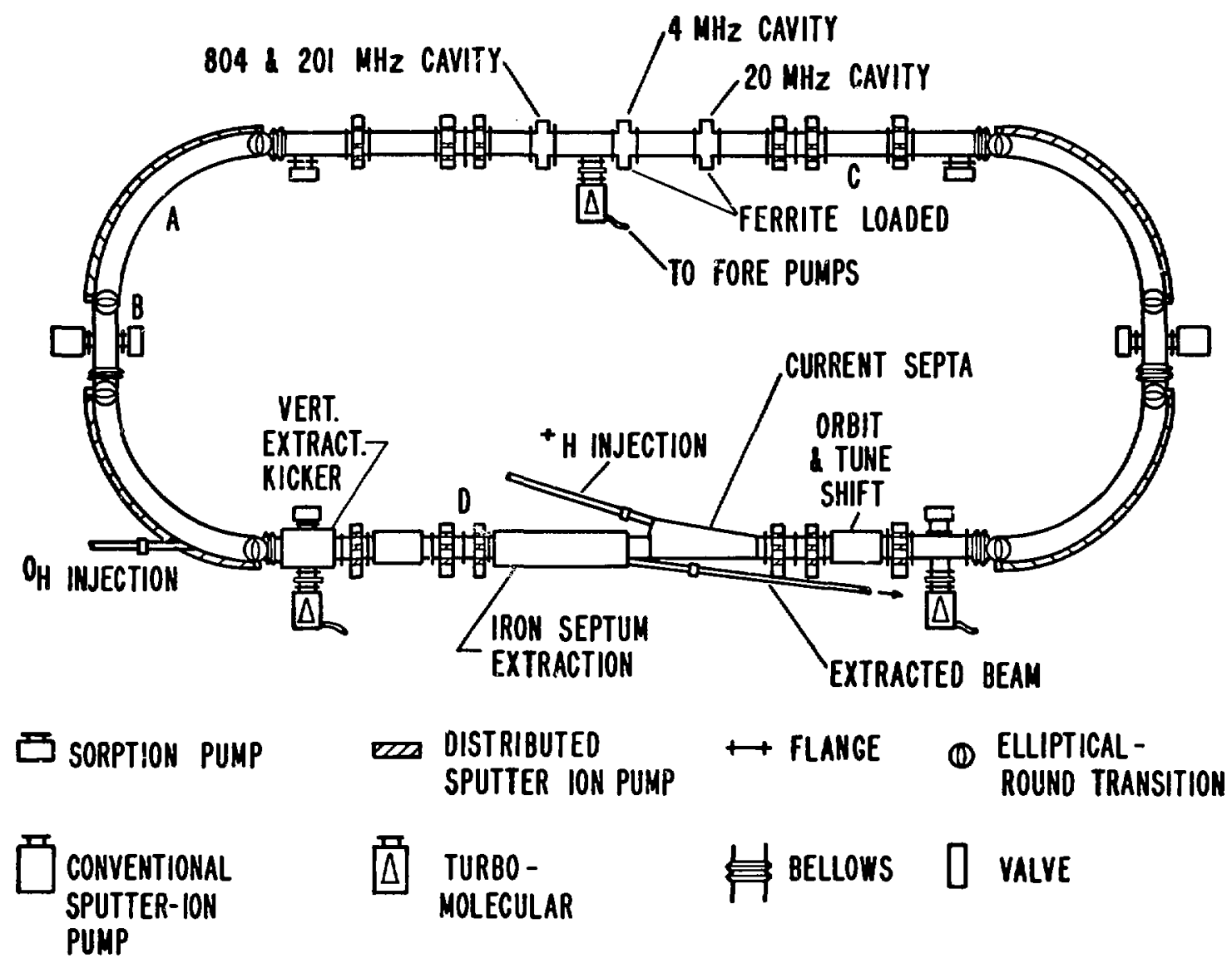

Fig. 45. Vacuum system for the WNR ring.

Dayton $^{71}$ gives an outgassing rate of

$$
q(t)=\frac{a}{t}+b \text {, }
$$

where $t$ is in hours, a is the 1 -h outgassing rati, and $b$ is the uitimate outgassing rate. Using the center of Dennis and Heppel1' $s^{72}$ band of data for aluminum, we find that $a=2 \times 10^{-8}$ Torr $\cdot 11$ ter $\cdot h$ / $\mathrm{sec} \cdot \mathrm{cm}^{2}$ and $b=10^{-9}$ Torr $\cdot$ liter $/ \mathrm{sec} \cdot \mathrm{cm}^{2}$. Then the pressure after a time $t$ is

$$
P(t)=\frac{A}{s} q(t),
$$

where $A$ is the surface-area outgassing and $s$ is the pumping speed. Thus

$P(t)=\frac{61.43 \times 10^{4} \mathrm{~cm}^{2}}{14001 \text { iter } / \mathrm{sec}}\left(\frac{2 \times 10^{-8}}{t}+10^{-9}\right) \frac{\text { Torr.11ter }}{\mathrm{cm}^{2} \cdot \mathrm{sec}}$ $=\frac{8.77 \times 10^{-6}}{t}(1+0.05 t)$.
After $1 \mathrm{~h}$, the pressure is about $8.8 \times 10^{-6}$ Torr; after $4 \mathrm{~h}$, it is $2.63 \times 10^{-6}$ Torr, and baking at $200^{\circ} \mathrm{C}$ begins. During this bake cycle, we assume that the pressure rises by one order of magnitude. After $16 \mathrm{~h}$ of baking, the heat is turned off and the outgassing rate is assumed to be reduced by one order of magnitude $f r$ its value at the start of the baking. The translent outgassing is assumed to be a function of $t i m e^{7 \hat{3}}$ such that

$$
q(t)=\frac{2 \times 10^{-9}}{t^{1.5}}+10^{-10} \text { Torr } \cdot \text { lfter } / \mathrm{cm}^{2} \cdot \mathrm{sec} \text {. }
$$

About $5 \mathrm{~h}$ after baking, hence after considerabl cooling, the distributed sputter-ion pumps are turner on. Assuming the performance of these pumps to be the same as that reported, ${ }^{67}$ the maximum nitrogen speed is 520 liters $/ \mathrm{sec} / \mathrm{v}$. The outer circumference of the bends (A) is $24.2 \mathrm{~m}$, so the pumping speed is 
12,000 1iters/sec. Four sputter-ion pumps are installed in each quadrupole; assuming the above pumping speed, each set of four pumps has a combined pumping speed of 62011 ters/sec. Because there are 12 quadrupoles in the two straight sections, the total pumping speed is 7440 liters/sec to give a combined total of 20,840 liters/sec in the bends, straight sections, and conventional sputter-ion and turbomolecular pumps.

The pressure-time relationship is

$P(t)=\frac{61.43 \times 10^{4} \mathrm{~cm}^{2}}{2 \times 10^{4} 11 \mathrm{ter} / \mathrm{sec}}\left(\frac{2 \times 10^{-9}}{\mathrm{t}^{1.5}}+10^{-10}\right) \frac{\text { Torr } \cdot \text { 1iter }}{\mathrm{cm}^{2} \cdot \mathrm{sec}}$.

This indicates a limiting pressure of $3 \times 10^{-9}$ Torr and a pressure of $6 \times 10^{-9}$ Torr after $1 \mathrm{~h}$. in the above, we have assumed that the pumping impedances are negligible because of the use of distributed pumps.

Reinath and Gunn's and Norgren and Gunn's est1mates did not include the gas load of the last five items in Table XIV, so the pumping speed requirement was lower. Note also that the above estimate does not include the vacuum equipment for delivering the beam to the ring or transporting it away.

\section{F. Alignment, Geodetics, and Errors}

The small apertures assoclated with strongfocusing accelerators usually impose stringent : nnstruction and installation tolerances. Becausf of its large aperture and comparatively small rafius, the WNR ring is not subject to such severe reciuirements as high-energy synchrotrons ilke the AGS or the CERN-PS. Nevertheless, the requirements must be analyzed and criteria must be established.

In the analysis of ihe effect of errors on the closed orbit, errors in megnet placement and magnetic field errors enter similarly. Bruck ${ }^{17}$ integrates the error equation and assumes that the magnet is composed of $M$ units independently aligned and of equal length. Inside the magnet, $B$ is assumed constant, and no correlations between alignment errors and field errors are assumed. With these assumptions, the maxinum closed-orbit displacement where $\beta=B \max$ is

$$
\left\langle y_{F}\right\rangle=\frac{\pi|n| R F^{1 / 2}}{|\sin \pi v| M^{1 / 2} v \rho}
$$

$\sqrt{(\overline{\delta y})^{2}+\frac{\rho^{2}}{n^{2}}\left(\frac{\overline{\delta B}}{B}\right)^{2}+\frac{M(R-\rho)}{M_{s s} \rho}\left(\frac{\delta \bar{B} s s}{B}\right)^{2}}$.

where $M$ is the number of units, $n$ is the field index, $R$ is the equivalent radius, $\rho$ is the magnetic radius, and $M_{s s}$ is the n'mber of straight sections. $B_{s s}$ is the stray ffeld in the straight sections (est $<0.5$ $G)$, and $F$ is the average form factor $\left(F_{f}=1.074\right.$; $\left.F_{d}=1.092\right)$. The remaining numbers are given in Table IV. This gives

$\left\langle y_{f}\right\rangle_{x}=6.478 \sqrt{(\delta y)^{2}+0.078\left(\frac{\delta B}{B}\right)^{2}+8.34\left(\frac{\delta B}{B S}\right)^{2}}$.

This shows that an error in $\delta B / B$ is only about $30 z$ as effective in shifting the equilibrium orbit as is an. error in placement $(\delta y / y)$. It also shows that stray fields in the straight sections produce negligible effects on the beam because of the high operating energy. Assuming that the alignment and magnetic errors are the same: $\delta w^{2}=\delta y^{2}=0.078(\delta B / B)^{2}$, and $\left\langle y_{f}\right\rangle_{x}=9.16 \delta w^{2}$. The beam extent shown in Fig. 27 is $11 \mathrm{~cm}$. If $10 \%$ of this, or $1.1 \mathrm{~cm}$, is considered a negligible beam shift, then $\delta y=0.35 \mathrm{~cm}, \delta \mathrm{B} / \mathrm{B}$ $=1.2 \%$, and $\delta \mathrm{B}=163 \mathrm{~g}$.

Although these tolerances do not require it, Collins' technique ${ }^{17}$ can be used to reduce the closed-orbit excursion. This method has been used at CEA and Hamburg to correct the residual fields at injection. It uses cell-length trim colls dispersed about the ring to compensate errors affecting the closed orbit.

Errors in on of the field index cause deformation of the bear envelope, a change of tune, and expansion of the unstable half-integer tunes into unstable bands. $3 r u c k{ }^{17}$ gives

$$
\begin{aligned}
\left(\frac{\delta y_{e}}{y_{e}}\right)_{e x t r} & = \pm \frac{4}{\pi} \frac{\ln !}{M^{1 / 2}} \frac{R}{v \rho}\left(\frac{\overline{\delta n}}{n}\right)^{2} \\
& = \pm 2.37\left(\frac{\overline{\delta n}}{n}\right)^{2},
\end{aligned}
$$

for the effect of random gradlent errors ou the extremities of the envelope. The CERN-PS has an error of $\left(\overline{\delta_{n}} / n\right) \simeq 1 \%$. If we assume that the WNR ring machining is done equally well, then $\left(\delta y_{e} / y_{e}\right)_{\text {extr }}=$ 
$\pm 2.37 \%$. This seems a bit large and should be investigated further. One big difference, however, is that the WNR ring will be dc instead of pulsed like the CERN-PS. So, tolerance on the gradient probably can be kept much tighter and further reduced with triming coils.

A gradient error can produce a change of tune. Bruck $^{17}$ analyzes this problem for quarter-integer tune such that $2 v=r+1 / 2$ where $r$ is an inzeger. Then

$$
v^{2} \approx v_{0}^{2}-1 / 2 \frac{2 R \sqrt{(\overline{\delta n})^{2}}}{\left(4 v^{2}-r^{2}\right) \mathrm{H}^{1 / 2} \rho}
$$

approximately where a summation over $r$ has been restricted to the $r$ value such that $\left(4 v^{2}-r^{2}\right)$ is minimum $(r=9)$. This gives

$$
\Delta v=0.067 \overline{\delta_{n}} .
$$

Thus for $\overline{\delta \Omega}=0.12, \Delta v=0.0081$.

Errors in in also cause bands of instability centered on integer and half-integer tune values. Bruck $^{17}$ anaiyzes this problem in analogy with the band structure of semiconductors and shows that the full width of the band is approximately

$$
\Delta v=\sqrt{\frac{R}{\rho} \frac{(\overline{\delta n})^{2}}{M}},
$$

or

$$
\Delta v=0.77 \sqrt{\overline{\delta n}} .
$$

Thus for errors of $\overline{\delta_{n}} / \mathrm{n}=0.01, \Delta v=0.28$. This is a signiflcant bandwidth and should be examined further. As stated previously, because the ring is $d c$, it should be possible to trim the magnets so that $\bar{\delta} / \mathrm{n}$ is considerably less than $1 \%$.

Having explored the effects of positioning and magnet errors on the beam, we turn to specif ic alignment techniques, in particular those requiring only distance measurements. Gervaise, 74 and the $200-\mathrm{BeV}$ study ${ }^{75}$ explore various survey techniques and conclude that angular measurements are difficult to make to the accuracy ( $0.1 \mathrm{~mm}$ ) required for highentrgy accelerators. Surveying procedures to deterwine the locations of points on a geometrical figure emplcy redundant technfques. The data are no.mally processed; the method of least squares (with approprlate weights assigned according to the precision of various measurements) to determine the best est 1mate of the desired coordinates. From the relationship between the inferred coordinates or related quantities and the individual measurements, one can determine how much statistically distributed errors: in the measurement will affect the beam characteristics. Laslett and $\mathrm{Smith}^{76}$ have examined how the errors in varlous surveying techniques propagate, and especially how radial errors in the primary survey affect the equilibrium orbit in the horlzontal plane. The effect of these errors is dominated by the Fourier component of the monument error for which the harmonic number is closest to the nacural betatron frequency. In fact, Laslete ${ }^{77}$ has shown that for a 200-BeV synchrotron of the NAL type and a 30-8eV synchrotrun of the AGS type, approximately 907 of the closed-arblt response Is due to one barmonic of the perturbation.

The alignment techmiques developed for highenergy synchrotrons 74,75 are des 1 gned for a cunnel archltecture for which radial measurement to the center of curvature are not possible. It wight appear that tio best vay to survey a torus would be a serles of distance and angle measurements. However, the development of precision distance-measuring equipment using the rime-of-flight of 1 ight has given the superiorfty to distance measurement. This device. called a Mekometer. ${ }^{74,75}$ uses a Kerr cell driven by a precision oscillator to modulate a light beam. By reflecting the beam and determining maxima, distonces can be measured to about $\pm 0.001 \mathrm{in}$. There are no angular measuring instruments that provide comparable accuracy for this purpose. Laslett and Smith ${ }^{76}$ asisume that the azimuthal error is negligible because it is directly determined, and determine the radial position by the perpendicular displacement from the w monument to a chord from the $m-1$ to the mon monments. As the on Index changes to ercomass the $r$ ing, the triangles overlap, resulting in redundant aeasurements. The most probable losation of the benchmarks result from least-squares fitting of all the data.

The Wir ring's comparatively small slze ard racetrack geometry susgest that a much simpler alignment procedure be used. It must be recognized that symetry is all-important.

Figure 46 shows the survey pattern. A single rigid radius vector, possibly made of Invar, sets the equalities $\overline{A D}=\overline{A C}=\overrightarrow{A D}=\overrightarrow{A E}$. The posts on 


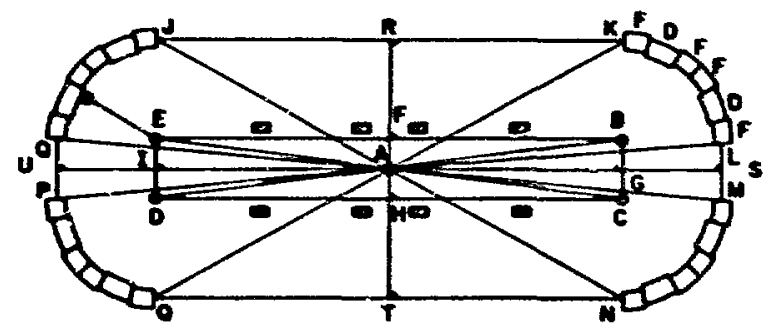

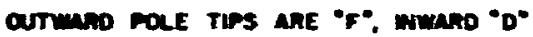
a moor sempoat colunn

7 Penrenoweukan

20

F1g. 46. Survey monument placement for the UAR ring.

zonuaencs B, C, D, and F w1l be equipped with traversal sechanions to pernte action only perpendicular to this radius vector once chis radial distance is fixed. If this device is reallzed using straight yays, chere will be a slight saglete effect. If the wetion of adfustwents is $\pm 1 \mathrm{~cm}$, ehen using a radial length of $8.93 \mathrm{~m}$, one finds a displacesent of \pm $0.007 \mathrm{In}$. It may, therefore, be necessary to lterate on the radial adfustment as the net becoes symeerized.

with the radial distances of $B, C, D$, and $E$ established, the tigure my have a hinge crror near A. Taut wires are stretched from $\overline{B E}$ and $\overline{C D}$, and the perpendicular distances froe these vires co $A$ are nesured and set equal using anocher Invar bar with, possibly, a eraveling miczoscope to sight on the vire. This adjustecnt is perforeed at conseant radius so that upon coapletion $\overline{B E}=\overline{C D}$ and $\overline{B C}=\overline{D F}$. The primary net is now aeasured, possibly using a Mekomeise. 74.75 Tho distances measured are $\overline{A B}, \overline{A C}$. $\bar{N}, \overline{A E}, \overline{B C}, \overline{C D}, \overline{D E}, \overline{E B}$, and the perpendicular chord from A to the segments $\overline{B_{C}}, \overline{C D}, \overline{D E}$, and $\bar{E} \bar{b}$. This r1gld-bar technique should glve 0.001-in. radial symetry with possibly zreater hirge-type error.

The verktcal elevation of the center of curvacure monuments $\mathrm{B}, \mathrm{C}, \mathrm{D}$, and $E$ aust be established. sere again, the absolute value is wataportant, and citen a flane t1le is not significant, but the planartey is all-taportant. The sechod for setting the elevation is that of liqujd levels. ${ }^{75}$ a systete ef tubes connecting vells ar A through $U$ is proposed. If Dercury or vater in 3-in.-deep velle is used, a $1^{\circ} \mathrm{C}$ ceaperature gradient vould cause a $0.0005-\mathrm{in}$. ertor. We ay therefore insulate thit connecting pipes and close the loop so that the fluld can be circulated slovly to average aut gradients. An advantage of mercury over vater as the fluld is the possibility of electically sensing the surface level. Optical metheds probably can be used with vater. so chis advantage may be only apparent. A syscen sieflat to that just desertbed was tested at LBt and appears to be as good as or betcer than opcleai leveling $(* * 0.001 \mathrm{ln}$ ). These vells are used to establist the level of all the wonuments.

With the anuments leveled, a UIld Heerbous Instruments. Ine. T-3 or equivalent cheodolite Is sounted on one of the crect-pf-eurvature posts, say $E$, and adjusted so that it seans a plane Interrecting the levels at $Q$ and $J$. The lower iron poles of the actnet are installed using the leveling screws to bring their upper surfaces to approximately the correct height so that the tap of tha pole tip will be at its design location. The steel is also located in ipproxisately the correct radial location. (Great precision in not requited for the return-lec steel.) One of the lower pole tos is Installed approximately, the lower roturn-steel levellat serma are adfusted so that the pole $\mathrm{i}$ Ip rests evenly on each of the return leg: it ercompasses, and the vertical elcuation is properly adjusted with the theodolize. The skeodollte is renoved, in Envar radits vector and travel ing afcroseope are fintalled on pose $E$, and the pole tip 1 adjusted radially by sthe ine on a fiducial ask achined snce each of lts ends vten le was anufactured. An alternative wethod is to use a machingsts' indfeator on the rudius vector. This metrod accuracely locates wach end of the pole $t \mathrm{p}$. The radius vector 18 rewoved. the theodolite is installed. and the elevation is checked again. Probably leveli it all the lower polt eipz of a sector at once wh lld be wore efficlent. After several perwutations of level ing and radial locating. the lower pole elps of all sectors are located to the desired colerances and rigtdly secured the lower retura lese by bolts. Nomagnetic spacers (Fig. 4!) are installed, and the upper pola clps are wounted on thes: Thus, the accuracy of locating one pole-plece relative to the other is decernined by achining tolerances whlin can be $<0.001 \mathrm{in}$.

-Th1s alignaent procedure is prianrily due to $J$. Gunn. Lat. 
bic have sot mentloned level ing the surface the lower pole tip rests upon. This is necessary because rotation of the pole tif cends so couple verfiral and horizontsl icterton oscillations. levelIng can but tilter by prectsion lezel, such as a Hild Hecrbrus Instruaents, Int. $\mathrm{N}-2$, or by distancec=ansfer blocks. such as Johansen blocks, and sightings taken with the theodolite fros one radial end of the support base to the ocher.

with both pole cips, the vacuv chanber. the upper and lower exefeing coils, and the fserer and cuter rethra sted properly installed. the upper

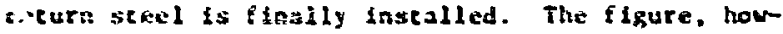
cyot, fs aver-diferefned, and there is no etsurance chat the upper steel will close the box without aif paps. At this point. s meticulous fitting procedure is nece: wry to till the air gap vith steel whose agnetlc sharacteriseles are similar to thes of the pole exp.

As the aghacts are deing asseabled and hence fecting heav ier. the level aust be monftared cont inually with ty thodolfte. Although the alfinment may be correct durtag lnielal asseably. there is no ensurafec chat "oundat fon shffes vill not caust long-cera problems.

The Los Alares Meson Physics factliey is located on a seall =exo called "Mesica de los Alsmos". This ares has exper.tereed volcanic activiey for several allition yeart, eulminatine in che cacaclyoafe eruptlon: that produced the selded tulf of the Bardeller forsation wich will be the foundation for the wa ring. Helced suft is a low-densicy rock someriaes exhlbiting 40)-te high escarpaents, but sofe enough to be cut wh a bulldozer. Yodult of elasticity over 150,000 tsi are comon. A recent 2-!/2-yt atudy of seisefe.dey fndfc yted high stabllfEy compared wth such regfons as southers California. The boulder-eapped cinglomerate pianacles seen In Readija Canger are cfred as evidence of the ground stabilicy.

The lour secters of the tha $r$ lag velgh ily cons and have a $907-\mathrm{ft}^{2}$ botron fare area. Ihis weight is peinarlly bortse by leveling jacks, bat if the foundation (Fig. 39) uniforaly disperses the load, the pressure is 0.2 conife ${ }^{2}$. In teller's excensive study of the ight-beasing character istics of the velded ruff at Mesila de los Alanos. 78 he cites deformat lon chatascerist lcs using aissile-silo counterielghts. He loadings of $4.05 \mathrm{con} / \mathrm{ft}^{2}$, he measures, for the maximum of several experibents, a deformation of $6 \mathrm{cE}, 5 \mathrm{ft}$ from the steel mass and essentally vanishing at $40 \mathrm{ft}$. He observed very Itetc creep during 6 veeks of observation. Some of the experiments showed much less loading deformation. When the load was removed, the potnt of obsezvation roturned to $0.006 \pm 0.006$ of its original location and exhibiced no long-cere creep.

Similar observations vere aude on a water cower located on a nearby eesa. The sater level cyoled, depending upon dezand. and Jeflected the benchwarks, but no long-term deformations vere observed. It therefore secms reasonable that the Mestita de los Alawos provides such a f fra furndation for the wAR ring that frequent realfgivent will be unnecessary.

\section{BEAY STABU.IEY}

A storage ring is a nondissipative mechanical syster and, as such, Is prone to resonances. Indeed. the principal bean-loss aechanisa (neclectint gas scactering) is resionance-bean excitation. In this section, we first explore the resonance structure and chen investigate phenomena known to be capable of shifting the betacron frequency onto one of these resonances. In the following. Sruck's work ${ }^{17}$ is principaliy used.

\section{A. Ffeld Ëror}

In pracifice, the guide fleld contains soue error $j 3_{x}$ (i) or $3 B_{z}(i)$. because of magnetic inperfections or aagnez alsplacenent. These errors way be represented in a Fourier series. When the bean cune coincides with a harmonle of the error, the the effects besta to reinforce, the oscillations grow, and the bean is lost. Analysis of this problew indicates that the beas tune in either plane zust not have incezral values. This is a very serong resonance that noraaliy leads to full beas less.

\section{B. Gradlenz Error}

An error in ffeld gradient way also excite beas resonances. If the error is cxpanded in a Fourfer sertes and inserted In the Kerst-Serber equarion, a Mochieu equacion resules, and, hence. stable oscillations correspond to stable solutions of the Mashiez equartion. Ihis gives rise to the requifewent that $y$ cannot be integer or half-integer. 
When the integer is equal to the number of cells (eighe for the isi ting) or the superpertod (two), the prohibition is espectally strong.

\section{c. Linear-Coupling Error}

If there is coupling between the vertical and radial batatron escillations, as, for example, a tulsted quadrupole, then the two sodes may interact, leading to beam loss. This effect leads to the interdiction against $v_{x}+v_{z}=n$, where $n$ is an inceger.

\section{Nionlirear Resonances}

The trajectory equations are not actually linear, but are made so by the neglect of nonlfnear teros. A driving term any be included to describe the nonlinear coupling by powers of $x$ atud $z$ and include s haranic term having the periodicity of the lattice. This analysia leads to the piohibition of $v=k N / 2$, where $k, f$ are integers and $N$ is the number of lattice cells per revolucion.

All of the various resonances may be sumarized by the prohflution $2 v_{x}+m v_{2}=n ; Q, n, n=0, \pm 1, \pm 2$, $\ldots \ldots$ and $|\&|+|\sigma|=p$. the order of the resonance. For $p>4$, theory and experience indicate that the resonances are weak. Figure 47 sizous the antigipated resonance structure of the whR ring. The classification of the probibitions is indfcated as $(l, m, n)$ where these are the indices used above.

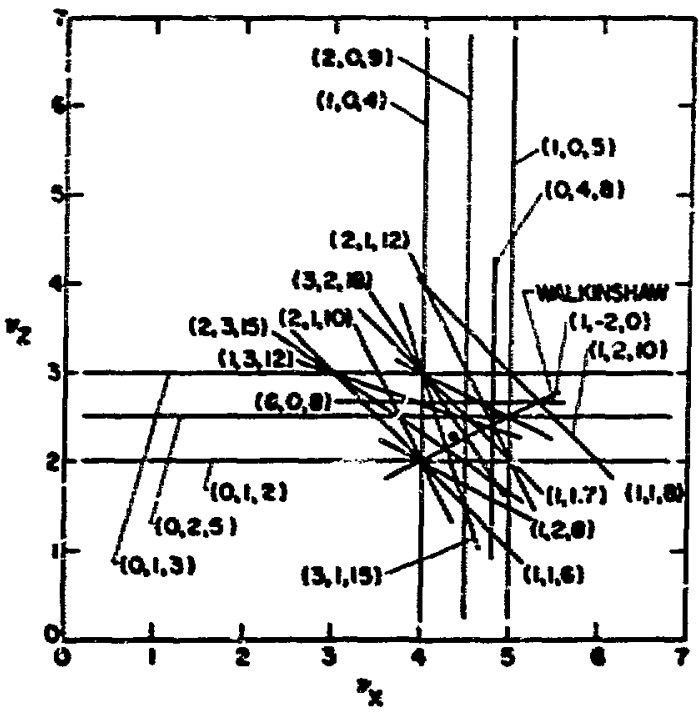

\section{E. Space-Charge Ef fects}

The space-charge forces combine with the magnetic-guide field forces to change the frequency ot betation oscillation. These forces ore brought into the Rerst-Serbor equation as a perturbation on the stiffness cerw resulting from electric and magnet ic forces in the relativistic beam. From these considerations for a round beam, it can be ohown ${ }^{17}$ that

$$
N=\frac{2\left[\delta v \left[\theta^{2} \gamma^{3} A\right.\right.}{r_{p}} .
$$

where $K$ is the cotal number of particles; $\mid \delta v_{i}^{\prime}$, the meximum allowable tune shift, is $1 / 4 ; r_{p}$ is the classical proton radus; and the remaining tems are given in Table IV. Substituting into Eq. (10) and using $(A)=133.9 \mathrm{cr}$ mrad for the admittance; and $N$ $=1.93 \times 10^{15}$ particles for the total charge gives a current of $3000 \mathrm{~A}$ if it is bunched into $100 \mathrm{nsec}$.

Ratl:ce than using a SYNCH-derived value for the admictance, Bruck ${ }^{27}$ gives it as $A=\pi v a^{2} / R F$. Substituting this tnto Eq. (10),

$$
N=\frac{2 \pi u|\delta v| B^{2} r^{3} a^{2}}{r_{p} R E}
$$

where $\mathrm{B}$ is the ring radius, $F$ is the form factur which averaged between the two planes is $\langle F\rangle=4.19$, $v$ averaged is $\langle\nu\rangle=3.31$, and $a^{2}$ is taken to be the sum of the squares of $1-c m$ vertical half-height and s-ca horizontal half-height. This gives $N=1.79 \times$ $10^{14}$ protons and a current of $285 \mathrm{~A}$. The reasun for this auch lower second result is that a beam of the given dimensions is far from filling the ring adrittance:

Equation (10) shows that the maximum urrentholifing capabilities of a ring are a function only of the adoittance and the particle mass and energy. However, when the admittance is considered, the maximin curtent scales with t'ie beam area and inversely with the ring radtus and forn factor.

Laslett ${ }^{79}$ and Laslett and Resegotti ${ }^{80}$ have studied the more realistic problem of a bunched elliptical beam in a perfectly conducting elliptical chamer vith a dipole magnet outside the chamber (Fig. 48). In this analysis, Eq. (11) is nodified to describe tic effect on a single particle as

Fig, 47. HR-ring resonance structure. 


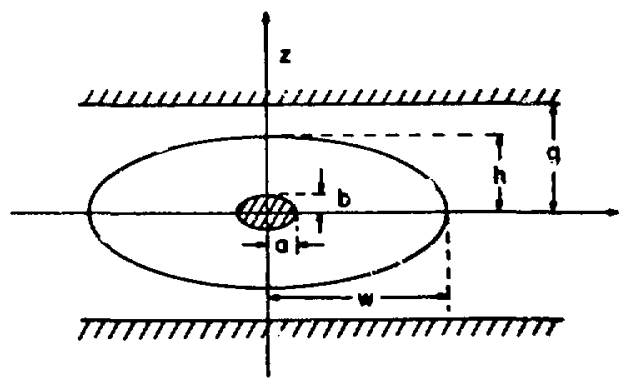

Fig. 48. Elliptical beam in an elliptical vacuum chamber.

$$
\mathrm{N}_{\text {incoh }}=\frac{\pi v|\delta v| B^{2} Y^{3} b(a+b) B}{R_{p} F} \text {, }
$$

where $B$ is the bunching factor and the electrostatic and electromaguetic effects are contained in F.

$F=1-\gamma^{2} n+\frac{b(a+b)}{h^{2}}\left[\varepsilon_{1}\left(1-\eta+B 6^{2} \gamma^{2}\right)+\varepsilon_{2} B B^{2} \gamma^{2}\left(\frac{h^{2}}{g^{2}}\right)\right]$

For the WNR ring, $B=0.4, b=1 \mathrm{~cm}, \mathrm{a}=2 \mathrm{~cm}, \mathrm{~h}=$ $5 \mathrm{~cm}, w=10 \mathrm{~cm}, \mathrm{~g}=7.08 \mathrm{~cm}$, and $\eta$ is the clearing field $(\eta<1)$. For this case, the electrostatic Image factors are $\varepsilon_{1}=0.172$ and $\varepsilon_{2}=0.41$, and the magnetostatic image factor is $\xi=0.6$. As the neutralization factor $\eta \rightarrow 1, F$ goes to zero and even becomes negative, allowing very large currents. Conservatively, we take the case of $\eta=0$. From Eq. (12), $\mathrm{N}_{\text {incoh }}=6.03 \times 10^{14} \mathrm{~B} / \mathrm{F}$. Substituting into Eq. (13), we find that $F=1.04$; that is, the image forces constitute onty $4 \%$ effect on the spacecharge 1init. Using $B=0.4$ gives $\mathrm{N}=2.32 \times 10^{1 \dot{4}}$ protons, or $371 \mathrm{~A}$. This calculation does not consider the nonsinusoidal character of the betatron oscillations. If this is included, $F=4.36$ and $N=5.53 \times 10^{13}$ procons or $88 \mathrm{~A}$, indicating that incomplete neutralization is probably needed to meet the design goals.

\section{F. Negative-Mass Instability}

The charged particles of the beam exert a mutual azimuthal force. If the linear density is not uniform, the particles upstream of the maximum are accelerated and those downstream ai'e decelerated. If rhe heam energy is above the transition energy, an increase in energy is accompanied by reduced angular velocity. Under the action of this density maximum, the particles paradoxically converge on tiis maximum and further increase the current density. This is the qualitative description of the negative-mass instabijity.

In the work of Nielsen, Sessler, and Symon, 81 the Hamiltonian for the azimuthal motion with space charge is formed. This is solved in the linear approximation for a propagating wave of frequency $w$.

$$
w= \pm \omega\left[\frac{g \lambda \mathbf{r} p}{\gamma^{2} B^{2}} \eta+\frac{n^{2}}{4 B^{4}}\left(\frac{\Delta E}{E}\right)^{2}\right]^{\frac{1}{2}} \text {, }
$$

where $\lambda$ is the Ifnear charge density, $g$ is a geometry factor $>1, n=1 / \gamma^{2}-1 / \gamma^{2}$ tr where $\gamma_{t r}$ is the $\gamma$ corresponding to the particle energy at which phase stability is lost, and $w$ is the particle angular frequency. For the wNR ring, $n=0.205$, but the important point is that $\eta>0$ : hence, $\omega$ is real and the solution is harmonic. The beam stabiitty indicated by Eq. (14) for positive $\eta$ values (below $\gamma$ transirion) is in accord with the physical description previously presented.

From this picture of the negative-mass instabi1ity, it seems that for situations below $\gamma$ transition the effect of longitudinal space-charge is to debunch the beam, which does not lead to instability.

\section{Longitudinal kesistiva-Wall Effect*}

Neil and Sessler 82 have applied the concepts of the resistive-wall traveling-wave tube to analys is of longitudinal-beam instabilities such as those observed at MURA. ${ }^{83}$ These longitudinal bunching effects were observed at low energy, below the $\gamma$ transition, and, unill the work of Nell and Sessler, presented a quandary inasmuch as they appeared to be a manifestation of negative-mass instability occurring below transition, which should be impossible.

Their analysis begins with the assumption of a uniform, unbunched beani having a particle-density perturbation of the form $\exp (\operatorname{in} \theta-\omega t)$, where $n$ represents the mode number of the instability. Two cases are considered: a circular beam centered inside a circular vacuum chamber of finite conductivity, and a rlbbon beam of finite extent centered inside a

*The analysis in the next three sections, for which we are grateful, is primarily by V. K. Nell, LLL. 
rectangular vacuum chamber of finite conductivity at top and bottom but with perfectly conducting side walls. In both cases, the chamber curvature is ignored and the longitudinal wavelength of the perturbation is assumed to be much longer than the vacuumchamber dimensions. Here we apply only the first case to the storage ring.

By solving Maxwe11's equations, introducfing the eltstric field into a linearlzed vlasov equation, and assuming that all particles have the same angular momentum, we find an e-folding growth rate of

$$
t_{0}=\frac{b}{B Y}\left\{\frac{2 \sigma E[1+2 \ln (b / a)]}{\operatorname{RNe}^{2} F^{3} \xi}\right\}^{\frac{1}{2}},
$$

where

$$
\begin{aligned}
N= & \text { total number of particics in the ring } \\
& \left(6 \times 10^{13} \text {, low-ducy mode }\right) \\
\mathrm{R}= & \text { equivalent ring radius }(10.03 \mathrm{~m}) \\
F= & \text { particle-circulation frequency }\left(4 \times 10^{6}\right) \\
\sigma= & \text { conductivfty in cgs units }\left(4 \times 10^{17} \mathrm{sec}^{-1}\right. \\
& \text { for aluminum) } \\
a= & \text { beam radius }(1 \mathrm{~cm}) ; b=\text { chamber inner } \\
& \text { radius }(5 \mathrm{~cm}) .
\end{aligned}
$$

The other symbcls have the meanings given in Table IV. This leads to a growth rate of 0.411 sec for $\mathrm{n}=1$ and indicates that the longitudinal resistivewall effect should not be troublesome. Further ref fnements such as including landau damping only tend to siow this growth time.

The longitudinal instabiifties, even if they occur, do not liead to catastrophic consequences; they only produce local densities in excess of the space-charge limit and hence some particle loss. However, before investigating the transverst iscistive-wall effect, we will investigate anocher longitudinal effect.

H. Beam-Cavity Interaction

As the beam circulates through rf cavilira or other electrical inserts in the vacuum system, density fluctuations may excite electrical oscillations that interact with the beam to produce more bunching and posstbly lead to longttudinal instabtlity. In the ISR design, 84 the shunt Impedance of each cavity was held to $6.5 \Omega$ at $10 \mathrm{MHz}$. Because there are six cavities, the total impedance is $39 \Omega$, less than the estimated $50 \Omega$ needed. ${ }^{8}$ In the ISR, this is achieved by nearly class-A operation of the final power tubes using strong negative feedback. Faltens et a1. ${ }^{85}$ giv a method for measuring this coupling impedance with a given structure. However, we use Laslett, Nefl, and Sessler's stabflity criteria ${ }^{86}$ here to estimate the maximum accumulated impedance of the frserts. They consider the problem of a rectangular vacuum chamber with an undriven cavity and find

$$
z_{c}<\frac{z_{o}^{n c n}}{r_{p} N F r B^{2}}\left(\frac{\Delta E}{E_{o}}\right)^{2} \text {, }
$$

where $Z_{0}=377 \Omega$, the impedance of free space, and the other terms are conventional or as given in Table IV. The criterion is

$$
z_{c}<47 n\left(\frac{\Delta E}{E_{0}}\right)^{2} M \Omega \text {. }
$$

For the $2.2 \%$ energy spread needed to miss the stripper, the cavity impedance, $Z_{c}$ is less than $23 \mathrm{k} \Omega$, which should not be difficult to satisfy for cavities or other inserts such as ciearing electrodes.

\section{Transverse Resistive-Wa11 Instability}

In the MURA 50 MeV electron accelerator, transverse beam oscillations with a frequency $f=(n-v) f_{c}$ were observed, where $\mathrm{n}$ is an integer $>\nu, \nu$ is the tune, and $f_{c}$ is the circulation frequency. The effect can be understood in terms of a traveling wave in a resistive wall interacting with the beam to cause beam translational oscillations. Conceptually, we see that if the particle velocity is greater ' an the pirase velocity, the effect is capacituve; the force is $90^{\circ}$ out of phase, and the work cone on the particles is zero. If, however, the wall conductivity is finite, the charges $1 \mathrm{lag}$ and work is done on the beam.

This problem was analyzed by Laslett, Neil, and Sessler 87 for cylindrfical and slab geometry. In cylindrical geometry, they find that the vertical oscillations grow exponentially with a time constant

$$
t_{g}=\frac{4 \pi^{2} v_{z} \gamma b^{3} \sqrt{\left(n-v_{z}\right) f_{o} \sigma}}{r_{p} c^{2} N \beta},
$$

where $n>v_{\mathrm{z}}$. Using $\sigma \times 4 \times 10^{17} / \mathrm{sec}$ as the 
conductivity of aluminum, $\mathrm{N}=6 \times 10^{13}$ and $\mathrm{n}=3$ gives $t_{g}=1.15 \times 10^{-5} \mathrm{~b}^{3} \mathrm{sec}$. The value of $\mathrm{b}$ in the sectors is least at $5 \mathrm{~cm}$, giving $1.43-\mathrm{msec}$

growth time.

They also analyze a ribbon beam of width $\Delta$ in a rectangular chamber of width $w$ and height $h$ having a growth time of

$$
t_{B}=\frac{6 v_{z} \gamma h^{3} F_{3}(h / w, \Delta / h) \sqrt{\left(n-v_{z}\right) f_{o} \sigma}}{r_{p} c^{2} N E} .
$$

For the values $h / w=1 / 2$ and $\Delta / h=1 / 2, F i g .5$ of Ref. 87 gives $F_{3}=0.95$. For $\mathrm{N}=6 \times 10^{13}$, the growth time is 3.72 msec.

The vertical instabilities due to the transverse resistivi-wall effect were stabilized in the 50-MeV MURA electron accelerator by feedback. Narrow-band feedback had been used previously to stabilize the Cosmotron, but with an unbunched beam, wide bandwidth feedback is needed. Pruett, Otte, and $M i 11 s^{88}$ present an analysis Indicating that an odd number of betatron quarter-wavelengths should separate the beam positicn-sensing electrodes and the correcting electrodes. Furthermore, the time delay in transultting the correction signal should be an integral multiple of the beam transit time between these locatious. The technique used at MURA and at Argonne ${ }^{89}$ was to use parallel-piate beamelevation sensors operating differentially to reject the intense common-riode pulse from a bunched beam. This was amplifled by a wide-band chain amplifier in the former case and by a more conventional compensated amplifier in the latter case. The maximum signal delivered to the electrostatic currection plates was $1.5 \mathrm{~V}$ at MURA and $20 \mathrm{~V}$ at Argonne tc stabilize growth rates of milliseconds. The problem at Argonne was made difficult by the need to correct during the acceleration cycle when the particle velocity is not constant. In tue wNR ring, this problem will not arise; however, the need for feedback beam stabilization is indicated.

The amount of syster gain needed to give stabilization has been 100-1000. In Richter' $s^{90}$ analysis of the problem for SLAC-SPEAR, he arrives at a gain of 1000 and points out the need for servolng the vertical position on the medla plane. Very slight shifts of the average beam elevation will saturate the sensing system unless ac coupling, which may have detrimental effects on the phase shift, is used.

The bandwidth for the WNR ring does not seem to Impose serious requirements. In the low-duty case for which the previous transverse resistive-wall calculations were made, only one $100-n s e c$ bunch is planned. This seems to require only a $10-\mathrm{MHz}$ bandwidth. If the instability should, however, be an interbunch instability, such as the head-tail, then wider bandwidth would be necessary.

\section{J. Head-Ta1l Instability}

The interaction of a beam of charged particles with its environment produces an electronagnetic wave that can inceract witin the beam. This wave's decay rate deternines whether the interaction occurs from one revolution $i$ in the next, as for the transverse resistive-wall effect, or has decayed by the next revolution. In the latter case, the head of the bunch of particles produces an electromagnetic wake that affects the tall of the bunch symmetr1cally or antisymmetrically. If the bunch were rigid, this would change only the restoring forces and hence the tune; however, the bunch is not rigid and particles circulate within it. Pellegrini 91,92 and Sands ${ }^{93}$ consider a magnetic-wake field produced by charge displacement by betatron oscillations which causes a radial displacement force on the tall of the bunch. Sanda applied Robinson's analysis ${ }^{94}$ of the electromagnetic wake in a cylindrical, resistivewall vacuum chamber to the head-tail instabllity. 95 zotter $^{96}$ applied Sands' analysis to the ISR proton-storage ring by numerically evaluating the wake integraj. instead of using the power-series expansion that is valid for electron storage rings. The following analysis for the WNR ring is for the low-duty mode, $6 \times 10^{13}$ protons in a single 100-nsec bunch. Two cases are considered: Case $I$, conserved phase density for which the energy spread, $\Delta E / E_{0}$, is $6.25 \times 10^{-4}$; and Case II, diluted ptsase density for which $\Delta E / E_{0}$ is $7.75 \times 10^{-3}$.

The variable that determines whether the wake integral can be expanded or numerical integration is. needed is

$$
x=\frac{2 \operatorname{Aff}_{0} \xi}{\alpha}
$$


where $A$ is the synchrotron amplitude in time units

$$
A=\frac{\alpha \Delta E_{\text {max }}}{\gamma E_{0} \omega_{s}},
$$

and the synchrotron frequency is

$$
\omega_{s}=2 \pi f_{\circ}\left(\frac{h \eta V}{\beta^{2} 2 \pi \gamma E_{o}}\right)^{\frac{1}{2}}
$$

The rotational frequency is $f_{0} ; \nu$ is the average tune; $\xi$ is the chromaticity, $(\mathrm{d} v / v) /(\mathrm{d} E / E) ; \alpha$ is the dispersion, $-\eta / \beta^{2}$; and the bunching voltage (see Sec. IV) is $84 \mathrm{~V}$ for Case I and $13 \mathrm{kV}$ for Case II. The other values are given in Table IV, except for the chromaticity which is assumed to be $-1 / 2$. When this is used with an $\alpha$ of -0.0864 , because the energy is below transition, positive $x$ values result.

The chromaticity is varied readily using sextupole magnets; hence, it may have positive or negative values. Changing the sign of the chromaticity changes from growing to damping instability modes, and vice versa. It may be desirable to desig:. for zero chromaticity.

Following Zotter's notation, the exponential growth rate is

$$
\beta_{m}=-0.0808\left(\frac{r_{o} c}{b^{3} \sqrt{\mu \sigma}}\right)\left(\frac{N \xi \sqrt{A}}{\alpha r}\right) \quad F_{m}(x),
$$

where the first parenthesis is $5.35 \times 10^{-7} \mathrm{sec}^{-3 / 2}$ assuming an aluminum wall of radius $b=5 \mathrm{~cm}$, and $F_{m}(x)=2 \int_{0}^{\pi} d \psi \cos \psi\left\{\frac{\pi}{\sqrt{2 x \sin (\psi / 2)}} \sin [x \sin (\psi / 2)]-2\right.$

$$
\begin{aligned}
& \int_{0}^{x \sin (\psi / 2)} \frac{d u}{\sqrt{x \sin (\psi / 2)+u}} \\
& \cdot\left[\cos u-\frac{\sin u}{2\left(x \sin \frac{\psi}{2}+u\right)}\right] \tan ^{-1} \sqrt{\frac{u}{x \sin \left(\frac{\psi}{2}\right)-u}}
\end{aligned}
$$

was numerically evaluated for the Case I and II $\mathbf{x}$ values. The growth rates are summarized in Table XV. These growth or damping times are of the order of a millisecond, so further consideration should

\begin{tabular}{|c|c|c|}
\hline Mode Number & Case I $\left(\mathrm{sec}^{-1}\right)$ & Case II $\left(\sec ^{-1}\right)$ \\
\hline $\begin{array}{l}0 \\
1 \\
2\end{array}$ & $\begin{array}{r}-129.8 \\
+351.4 \\
+798.1\end{array}$ & $\begin{array}{l}+838.8 \\
+1091.0 \\
+1178.0\end{array}$ \\
\hline
\end{tabular}
be given to suppressing this head-tail effect. This is most easily done using sextupole fields.
TABLE XV

HEAD-TAIL GROWTH RATES FOR THE WNR RING

\section{K. Resistive-Ha11 Effect for a Bunched Beam}

We conclude this section on instabilities by calling attention to Courant and Sessler's paper 97 on resistive-wall effect on bunched beams. This paper assumes that the bunches are rigid and obtains the rule that for a single bunch, the tune $v$ should be $N<V<N+1 / 2$ where $N$ is an integer. This rule, which is the reason for the tune selection in the WNR ring, is without experimental confirmation. In fact, the ACO and Adone storage-ring experience is fust the opposite. It is generally held that the assumption of rigid bunches is not true and so this ruie should not be applied. Probably a more successful approach would be to allow freedom of tune manipulation and explore the most favorable tunes experimentally.

IV. BUNCHING

The WNR-ring design involves various requirements for debunching, energy shifting, and bunching. These concepts are not frozen, but we should estimate the problems involved.

\section{A. Capture and Adiabatic Debunching}

The beam from LAMPF is designed to have a momentum spread of $\pm 0.2 \%$ averaged over a micropulse and leaving the accelerator with a phase-angular spread of $36^{\circ}$. For bunching ratios of 10 , excessively large bunching voltages are required. If the beam is just injected into the ring, the beam ellipse will shear and there will be large phase dilution just as for a beam in a drift region. What is required is a method to preserve the phase density while distorting the ellipse to occupy $360^{\circ}$ of phase space (Fig. 49). Upright ellipses represent the injected beam that is modulated at $201 \mathrm{MHz}$, and flattened ellipses represent the desired deformation. The shear lines show what would happen if the bunches were not captured. 


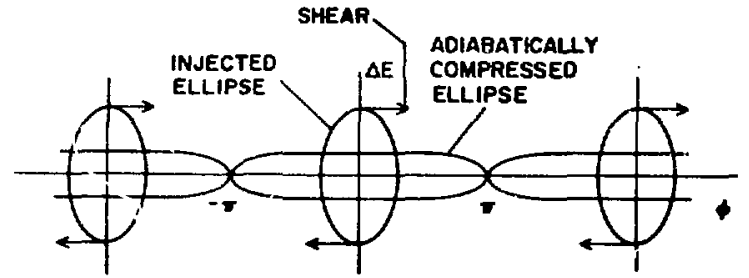

Fig. 49. Synchrotron-space beam ell1pse and adiabatic deformation.

Symon and Sessler ${ }^{98}$ give a general discussion of $\mathrm{r} f$ beam mantpulation. They cast the acceleration equations in a Hamilton tan form so that phase-space density is corserved during adiabatic deformation (Liouville's theorem). The area occupied by the injected beam will be $A_{1}=\Delta \theta_{1} \Delta E_{1} / f_{1}$ where $\Delta \theta_{1}$ is the phase angular spread, $\Delta \mathrm{E}_{1}$ is the energy spread, and $f_{1}$ is the circulation frequency. The LAMPF microstructure bunch width is $0.12 \mathrm{nsec}$, which, following a 500-ft transport line, is broadened to $0.4 \mathrm{nsec}$ or $\Delta \theta=(0.08) 2 \pi$. This number is probably an upper limit because the energy spread in a single bunch is probably much less than average. If we now assume that phase area is conserved as $\Delta \theta+2 \pi$, the resulting energy spread is

$$
\frac{\Delta E_{2}}{E_{0}}=\frac{(2 \pi)(0.08) \Delta E_{1}}{(2 \pi) E_{0}}= \pm 0.025 \% \text {. }
$$

The provlem is to devise a procedure to bring about this erergy homogenization. The voltage required to contain a bunch whose maximum angular extent (the separatrix) $\phi$, relative to the $r f$, is

$$
V=\frac{2 \pi h \gamma E_{g} \eta}{\beta^{2}}\left[\frac{\left(E_{m}-E_{s}\right) / \gamma E_{o}}{2 \sin \phi / 2}\right]^{2},
$$

where $h$ is the number of buckets around the clrcumference, $E_{\mathrm{In}}$ is the maximum particle energy, $E_{s}$ is the synchronous energy, and $E_{0}$ is the rest energy. Equation (21) for the WNR ring is written as

$$
V=196.2 h\left(\Delta E / E_{o}\right)^{2} \frac{1}{\sin ^{2} \phi / 2}(M V),
$$

where $\Delta E=E_{m}-E_{s^{*}}$.

For adsabatic damping, the bucket catching the pulse must not be completely filled, but if the bucket is too empty, excessive capture voltages will be required. We will capture the beam with an 804-MHz cavity; hence, $\phi 1$ is $116^{\circ}$ and $h$ is 4 . Thus the capture voltage is $10.5 \mathrm{kV}$. This voltage is lowered unt 11 the separatrix is $\pi$, the energy spread is reduced by 3.1 to $0.1 \%$, and the capture voltage is $7.54 \mathrm{kV}$. If the voltage were further reduced, the particles would escape and the ellipse would shear.

At this point the 201-MHz cavity is turned on to capture the bunch on the fundamental. Hence $h$ is 1 and $\phi$ is $\pi / 2$, giving a capture voltage of $393 \mathrm{~V}$. This is lowered to zero, and, presumably, the energy spread is $\pm 0.025 \%$, a lower limit (assumıng LAMPF beam values). For stability, it may be desirable to keep the spread broader. This can be done at any time by simply turning of the voltage used for a adiabatic damping and allowing the ellipse to shear.

\section{B. Energy Shifting}

In the discussion of the stripper design, we indicated a need tc shift the beam energy by $1.44 \%$ ia $7.73 \mathrm{msec}$ so that the previously infected beam would miss the stripper on the next injection cycle. This requires an energy shift of $573 \mathrm{~V}$ per turn, which allows no time for adiabatic damping (unless it continues concurrently). W- will therefore assume that the time interval is broken into thirds so that $2.58 \mathrm{msec}$ and $1720 \mathrm{~V}$ per turn are allowed for energy shifting. This is added to the capture voltage to give $40.2 \mathrm{kV}$, and the synchronous phase angle is $2.45^{\circ}$. Substituting into Bruck's $\mathrm{s}^{17} \mathrm{Eq}$. (16.32) gives $\Delta E / E= \pm 0.34 \%$, ind fcating that the assumed bucket is somewhat deeper than need be, but st111 reasonable.

The fractional cavity-frequency shift needed to provide this energy gain is $\mathrm{df} / \mathrm{f}=(\mathrm{dE} / \mathrm{E})\left(\mathrm{n} / \mathrm{B}^{2}\right)=$ $0.289 \Delta E / E=0.416 \%$. The fractional bandwidth of $a$ cavity is approximately $1 / Q$, so the $Q$ need be no greater thar 240 to accommodate this frequency shift. This seems to place a severe restriction on the cavity and to cause excessive power loss, but on this time sca?e it is quite possible to modulate the cavity mechanically.

\section{Bunching}

There are many combinations of pulse widths and repetition rates, but we will consider only two, the low-duty and high-duty modes. 
1. Low-Duty Mode. This mode requires the beam to be a single 100-nsec bunch. This can be done in two steps, bunching with the fundamental, followed by the second harmonic. However, it is more conservative to consider only fundamental bunching.

Assuming that the homogenized beam $\left(\Delta \mathrm{E} / \mathrm{E}_{0}=\right.$ $2.5 \times 10^{-4}$ ) is increased in energy spread by the bunchlang factor (2.5), h=1, and $\phi=144^{\circ}$, Eq. (22) gives $85 \mathrm{~V}$ for bunching at $4 \mathrm{MHz}$.

2. High-Duty Node. This mode requires five 5-nsec bunches. Here the bunching factor is 10 ; hence, $\Delta E / E_{0}=2.5 \times 10^{-3}, h=1$, and $\phi=36^{\circ}$, and we find a bunching voltage of $12.8 \mathrm{kV}$ at $20 \mathrm{MHz}$. This voltage could be considerably reduced by only partially bunching on the fundamental and finfshing on the second or higher harmonic.

In the prevtous example, If phase density had not been preserved (there was no adlabatlc damping), 2 MV of bunching voltage would have been required.

\section{An Alternative to Debunching}

Equation (21) shows that the voltage needed for bunching or debunching depends on $\eta=1 / \gamma^{2}-1 / \gamma_{t r}^{2}$ which has teen a free parameter in the design of the WNR ring except for the requirement that it be positive to avoid the negative mass instability. If $\delta=$ $\gamma_{\text {t.r }}-Y$, then a power series expansion gives

$$
n=2 \delta / \gamma_{t r}^{3}+3 \delta^{2} / Y_{t r}^{4}
$$

Present1y, $\gamma_{\mathrm{tr}}=3.402$ and $\eta=0.205$. If $\gamma_{\mathrm{tr}}=2$, then $\eta=0.047$, a reduction of 4.34 in the bunchingvoltage requirements.

It seems that this could be an alternative to debunching and would allow the bunching to take place with the present LAMPF nergy spread (increased by the bunching factor). We do not know what difficulties ${ }^{99}$ may be encountered as $\eta+0$, but the freedom of this parameter should be kept in mind

\section{MEDIUM-ENERGY PROTON-STORAGE RING APPLICATIONS}

All previous work with storage rings has been with colliding beams; the use of a storage ring as a duty-cycle manipulator is a new application. Here we outline various possible usages but do not develop them in depth.

\section{A. Defense Applications}

A storage ring used in conjunction with a neutron-chain multiplying target should be capable of total neutron output epproaching $10^{17} \mathrm{n}$. This is roughly the output of a bare critical reactor (Godiva), but our interest is in the fact that the burst duration is only several tenths of microseconds. Thus, the first applications to come to mind are those for which Godivas have bee.. used in the past. Some uses have been suggested in conference proceedings 100,101 ; however, probably the most extensive use has been in the investigation of transient radiation effects of electronics (TREES) as a result of neutron and secondary-gamma irradiation. The advantages afforded by the storage ring are:

(1) The pulse is of much shorter duration than is possible with a supercritical multiplier. (2) The irradiation volume is larger because the target is only a multiplier and does not go critical. A target study involving a $7-\mathrm{cm}-\mathrm{d}$ iam by $10-\mathrm{cm}-10 n$ central cavity in $238_{U}$ predicted a neutron fluence of 0.063 $\mathrm{n} / \mathrm{cul}^{2}$ proton. For $6 \times 10^{13}$ incident protons and a target multiplication of 20 through the use of ${ }^{235} \mathrm{U}$, a fluence of $\approx 7 \times 10^{13} \mathrm{n} / \mathrm{cm}^{2}$ will result. The hollow beam for this design could be achieved by a pulsedwire septum or a high-frequency rotating field.

The hard neutron spectrum and smail gamma production provide a good simulation of degraded nuclear weapon spectra. It should be superior in total output to Gulf General Atomics' EPFA, ${ }^{100}$ an electron-11nacpulsed supercritical assembly $\left(4 \times 10^{13} \mathrm{n}\right)$ and in reduced gama production. For experiments requiring a high neutron production rate, the proton-storage ring booster rate of $3 \times 10^{23} \mathrm{n} / \mathrm{sec}$ is significantly greater than EPFA's $4 \times 10^{18} \mathrm{n} / \mathrm{sec}$.

In achieving these high production rates, severe booster mechanical-design problems are anticipated. The total neutron output is comparable to a Godiva, but the pulse is so short that shock waves will be produced throughout the material. This seems to indicate that a soldd-metal booster would crack under the rarifaction wave, and some other design is needed. One concept is to make the fuel in the form of very small pellets held together in a container. A second thought along the same line is to use a uranyl-sulphate solution in the KING concept. 100 This approach is particularly interesting because much of the energy goes into the heat of 
vaporization, not into translational motion. Unfortunately, uranyl-sulphate tends to be a comparatively slow reactor because of the hydrogen in the water; an alternative might be condensed uranylhexafluoride.

The very fact that booster damage is anticipated suggests that the storage ring could be used For the study of material properties under extreme conditions. This and many other defense-related applications are discussed elsewhere. ${ }^{102}$

\section{b. Neutron-Pulse Radiolysis}

Pulse radiolysis is a technique for direct study of transient, radiation-produced chemical and biological species. These metastable molecules are detected by fast-responding optical or spectrophotometric time analyses of the species population.

Neutron radiolysis is an interesting approach because its linear-energy transfer (LET) is about $4 \mathrm{eV} / \mathrm{A}$ in typical tissue as compared with the LET of $0.02 \mathrm{eV} / \mathrm{A}$ for $1-\mathrm{MeV}$ electrons. ${ }^{100}$ This high LET for neutrons resulting from the proton recoll is sufficient to dissociate the hydrogen-oxygen bond along the path it traverses. Further, the energy is sufficient to ionize one molecule of each patr along the path. The result is a cylindrical volume contalning closely spaced 1ons, electrons, and free radicals. The recoll of nuclet of oxygen, carbon, and other atras will produce tracks of even higher Ionization density.

As an aside, it may be possible to study the recombination of the transient species resulting from $\pi^{-}$-produced stars in tissue and thereby gatn some fundamental insight into the basis of pion cancer therapy.

The lack of neutron sources of sufficlent intensity and short duration hasi prevented investigations of this scrt. Some investigations were performed using the APFA putsed-neuticon source; however, the storage ring and subcritical booster could provide a neutron-source increase of 1000 times the total neutron output and nearly 5 orders of magnitude in the production rate.

It seems that a special booster design would be necessary to accommodate the spectrophotometer beam, but this does not seem difficult. Depending upon the progress of the work, it might be desirable not to use a booster because of the fairly long time response, but to use a nonmultiplying target with the storage ring in the high-duty 5-nsec burst mode. Then we could study short-lived specles.

\section{Polarized Proton-Storage Ring}

Polarization experiments have been significant in physics for distinguishing between competing theorles, stimulating new research, determinating nuclear spin and parity, testing invariance princi$\Gamma^{l e s,}$ and measuring off-diagonal elements of the $S$ matrix.

The fact that protons are contained in a storage ring for some time suggests that operations such as beam polarization by multiple target traversals are possible. Csonka ${ }^{103}$ considers this problem particularly for the CERN-ISR for the purpose of colliding polarized proton beams. He suggests three methods for polarizing the beam in each ring:

Polarization by beam transmission through a polarized proton target. In this case, if the total cross section for scattering a proton beam polarized along the target-polarization vector differs for parallel and antiparallel spin orientation, the net result is a beam whose polarization increases with target traversals. (2) Introducing an unpolarized hydrogen target into the beam so that particles scattered to the right and left are captured in separate satellite orbits, causes the two beams to have opposite polarization. This approach depends upon the ability of the lattice to hold three separate orbits. (3) Introducing a pola:ized hydroges target, but capturing scattered protons withi.1 the acceptance of the storage ring, results in a beam of scattered and original protons of gradually increasing polarization.

We will not try here to design the experiment, only to point out its possibility. If direct comparisons with the ISR were possible, then using Csonka's numbers and the fact that the WNR ring has 40 times more circulation frequency, the beam should be $10 \%$ polarized in $45 \mathrm{sec}$ and $30 \%$ polarized in 2.25 min. This, combined with the ring's capabilities for long or short extraction and the abillty to raduce the energy spread below that of LAMPF, could make this a valuable experimental tool. 


\section{Counting Experiments}

A storage ring may be considered a duty-cycle manipulator. We have been interested mostly in pulse compression, but it can also be used with slow beam extraction to provide a practically dc beam. This is espectally true if charge-exchange injection is used, for then it is possible to inject and extract at the same time. The micropulses, as well as the macropulses, would be smoothed. Thus, if the micrustructure is $0.4 \mathrm{nsec}$ after traveling $500 \mathrm{ft}$ this microduty is $8 \%$. The macroduty is $6 \%$. So, in this sense, the LAMPF duty is $0.5 \%$. This is probably overly severe because in most experiments the microduty would be smeared in the secondary beam line.

Suppose an experiment has an accidental counting rate of

$$
T=2 \tau \frac{R^{2}}{D^{2}},
$$

where $\tau$ is the resolving time, $R$ is the true counting rate, and $D$ is the beam duty. Then if we wish that the fraction of accidentals be $10 \%$ or less,

$$
\frac{\mathrm{R}-\mathrm{T}}{\mathrm{R}}=0.1=1-\frac{2 \tau \mathrm{R}}{\mathrm{D}^{2}} \text {. }
$$

Hence,

$$
R=\frac{0.1 D^{2}}{2 \tau}
$$

For this situation in which the counting rate is limited by accidentals, the data rate could be increased 278 times by smoothing the macrostructure or 40,000 times by smoothing bcth the micro- and macrostruc.ures.

Admitcedly these advantages are realized for only some experiments but for those, the rewards of slow extraction from a storage ring are great indeed.

\section{E. Pulsed Source for an Unstable Particle-Storage}

1. Muon-Storage Ring. One of the fundamental unknowns in physics today is the difference between an electron and a muon. The precision measurement of the difference between the observed magnetic moment of a Fermion and the Dirac predicted value of 2 (the so-called $g-2$ experimeut) is very important. Because the interaction should be purely electromagnecic, an alternative way of viewing the experiment is to search for a coupling to another field that would explain the muon-electron mass difference.

One method for this measurement is a counting experiment involving measurement of the precesston frequency in a precise, well-known, magnet.tc field. 104 This technique could profitably use the storage ring In a slow-spill mode to improve the counting rate.

Another, perhaps potentially more accurate, method uses a muon storage ring. 105 The weak-focusing storage ring operated at CERN is $5 \mathrm{~m}$ in diameter. The muons are infected into the ring as a result of the decay of pions formed by proton bombardment of an internal target. The muons are formed polarized by the forward decay of the pions, and the polartzation diuction as a function of time is determined by recording the electrons emitted in muon decay. The experiment consists of comparing the frequency of muon revolution to the spin-precession frequency in the ring's magretic fleld. Because of radiative corrections, the muon spin precesses faster than the state of polarization and this gives a direct measurement of the $\mathrm{g}-2$ factor.

Tise CERN-PS proton pulse for forming the muons consists of three 10-nsec microstructure pulses, $105 \mathrm{nsec}$ apart. Therefore, about $10^{11}$ protons are injected every $3 \mathrm{sec}$. The WNR ring in the high-duty mode would inject $6 \times 10^{11}$ protons 600 times a second. Thus, on the basis of imcident-particle flux, the WNR ring should be about 1800 times better than the CERN-PS for this purpose. In actual fact, the energies are so $d i f f e r e n t$ that they do not compete, but supplement eacl other. The short (5-nsec) proton-burst width will implement the turn-coumcing method of measurement.

One mighe wonder if the muons could be formed and circulate in the WNR ring itself. This point has not been investlgated, but, off hani, it seems that a strong focusing storage ring is not suitable. However, because of the long drift distances, the period of rotation may be relitively independent of momentum and could be useful.

\section{Colliding Unstable-Particle Storage Ring.} Macek and Maglic 106 have proposed a weak-focusing, superconducting storage ring in which unstable particles such as plons and muons would precess and interact with each other. This "Precetron" requires 
very intense proton bursts of short duration compared with the pion lifetime. Using their Table I, we conclude that the WNR ring using the full LAMPF $\mathrm{H}^{-}$bean, i.e., the low-duty mode but at a 10-pps repetition rate, could drive the Precetron to produce about 100 iriceractions per hour. This is a very low counting rate, and perhaps future improvements in the Precetron design, such as strong focusIng, could increase the interact lon efficiency.

\section{F. Beam Dynamics}

Advancement of the understanding of beam dynamics comes with each advanced accelerator or storage ring, and this will be true for the WNR ring. The results of this study will be used to improve the performance of the WNR ring and assist in future circular-accelerator designs. In the design of the WNR ring, there are new concepts and applications of theoretical principles not experimentally tested. Particular interest is in the advantages of operatIng below the transition energy of the storage ring.

From the instability studies in this report, we see that the head-tail and trancyersi resistive-wall effects are most likely to be troublisome. Both effects result from the interaction $\sigma^{*}$ a beam with Its environment which can be changed : o affect the electromagnetic field. Thus, Sessle; and Vaccaro 107 suggest the use of a helical insert (like that used in raveling-wave tubes) to slow the wave. Briggs 108 and Briggs and Neil 109 suggest the use of dielectric wall coatings. Inductive or Iris-loading of the walls, like that used in linear microwave accelerators, or Impedance matching of the walls to absorb the radiation ${ }^{110}$ may be future develupnents that couid be explored with the WNR riag.

Besides these passive techniques, there are active approaches to stabilizing the beam at high currents. We have already referred to the wide-hand feedback stabilization systems used at MURA and on the zGS. Another active technique used at Cacbridge Involved $\mathrm{rf}$ quadrupoles to cause different parts of a bunch to have different tunes.

An electron-storage ring pruperty that would be advantageous for proton-storage rings is radiation damping of the betation oscillations. A methed proposed to accomplish this is to mix electrons of similar velocity with the protons so that electron-proton
Coulomb interactions occur. The electrons talse up some of the proton energy, thus cooling the protons. Budker, ${ }^{111}$ a strong exponent of this technique, has calculated the relativistic case for equal proton and electron velocity. Maurer has calculated both the nonrelativist $1 c^{112}$ and relativistic ${ }^{113}$ cases for dissimilar particle velocities. Using Hereward' Debye length technique, 114 we find a damping time of $2.7 \mathrm{sec}$ using $1 \mathrm{~A}$ of electrons in the interaction region if the beam has a 27 momentum spread.

Use of electron cooling in conjunction with adiabatic compression of the energy spread could produce extremely high-density beams. This would be useful for storage-ring applicarions and would improve the ring performance through the use of many stacked, high-density orbits.

\section{Neutron Time-of-Flight Spectrometer}

Neutron resonance spectroscopy is the oldest application of pulsed-neutron research. The literature is voluminous, and a recent survey is recommeno ed. 115

The WNR ring in the high-duty mode would const 1 tute the best neutron time-of-flight spectrometer in thr? world. In terms of neutron intensity, the Columbia Universicy Improved Nevis Cyclotron is the closest competition. The higher repetition rate and greater target flexibility give the WNR ring advantages that in practice yle:d much higher counting rates than are reflected in the direct-intensity comparison. 1

\section{GLOSSARY OF SPECIALIZED TERMS}

Admittance: the maximum emittance an accelerator or storage ring can accept.

B: the magneic field intensity, unless stated otherwise, in units of kilogauss.

Betatron Space: the phase ispace representing radial and vertical oscillations.

Bucket: a bounded region of synchrotrun space in which particles can be held.

Cell: a repeating element.

Charge Exchange: the removal of one or more electrons from an ion.

Chromaticity: the variation of tune with momentum: pdu/vdp. 
Closed orbit: the orblt for which the restoring torces are zero, f.e., the orbit for which the betatron amplitude is zero; thence, the equilibrius orbil.

Dispezsion: the iractional variation of period with momentug, $p d T / T d p=1 / c b-1 / \gamma^{2}$.

Eritcance: the srea of canonical phase space that represents the beam. Practically, the emittance is the product of the beam diameres and the angular divergence in that plane.

Field Index: the ratio of the logaritholc derivacive of the magnetic fleid with radius $n=$ $-\mathrm{RdB} / \mathrm{BdR}$.

Insert: a separation in a latice. A matched insert would have a unit transfer natrix.

Kicker: a fast-rusponse deflection element.

Lattice: the configuration of elements that provides the beam-restoring forces for a circular accelerator or storage ring.

Llouville's Theorem: the statement that the area representing a collection of particles in phase space is preserved if the energy is constant.

Morentur Compaction: see $\alpha$.

Ph. se Advance: the change of phase angle of a particle traversing an accelerator element $\mu=\int \mathrm{ds} / \mathrm{B}(\mathrm{s})$.

Profile Parameter: $1 / B(d B / d R)=-n / R$.

Rigicity: the product of magnetic field times radius of curvature.

Sector Magnets: those magnets used to bend a part 1cle through sone angle. They may also provide restoring forces, in which case they are called combined-function magnets.

Septum: a thin element located close to a heam for injection or extraction.

Shock Line: a delay line having ronlinear properties.

stripper: an element used to remove electrons from ions.

Strong Focusing: the use or restoring forces so great that convergence in both planes cannot be achicved simultaneously.

Synchrotron Space: energy phase space.

Tune: the number of betatron ascillations per turn.

Weak focusing: focusing in two plane simultaneously. It is characterized by $0<n<1$ for magnetic forces.

$x_{e q}$ : the shift of orbit radius with momentum $=\alpha R$.

$\alpha$ : momentum compaction factor, $\alpha=R d p / p d R=1 / Y_{t r}^{2}$.
E: ratio of partficle velocity to that of 1 ight.

S-iunction: upper right-hand element of the Triss matrix. The average heta cunction is the betatron wavelength.

$y$ the ratio of the particle cotal energy to its rest energy.

$Y_{t F}$ : the $Y$ of a particle in a storage rlag or circular accelerstor having no phase stabiliry: l.e., $\eta=0$.

$\eta=1 / \gamma^{2}-1 / Y_{t r}^{2}$

\section{REFEREMES}

1. R. R. Fullwood, J. Cramer, R. Haurman, R. Forrest, and R. Schrandt, "Neutron Production by MediumEnergy Potons on Heavy Metal Targets", Los Alamos Scientif ic Laboratory report $L A-4789$ (1972).

2. G. K. U'Neill, "Storage Ring Synchrotron: Device For High Energy Physics Research", Phys. Rev. 102, 1468 (1956).

3. D. W. Kerst, F. T. Cole, H. R, Crane, L. W. Jones, L. J. Laslett, T. Ohkawa, A. M. Sessler, R. R. Symon, K. M. Terwilliger, and N. Vogt-Nilsen, "Atcainment of Very High Energy by Means of Interacting Beams of Par:icles". Phys, Rev. 102, 590 (1956).

4. L. W. Alvarez, "Energy Doubling in dc Accelerators", Rev. Sc1. Instr. 22, 705 (1951).

5. G. I. Budker, "Accelerator Developments at Novosibirsk", Proc. Sth Int. Conf. High Energy Accelerators, Frascati, Italy (1965), pp. 399402 .

6. F. T. Howard, "High Energ̈y Accelerators 1967", Cambridge Accelerator Conferanze', rambridge, MA (1967).

7. P. F. Meads, Jr., "An Invisible Long Straight Sect. in for Synchrotrons", Nucl, linstr. and Meth. 96, 351 (1971).

8. CERN Study Group in New Accelerators, "The Design Study of Intersecting Storage Rings (ISR) for the CERN Proton Synchrotron", CERN laboratory Report AR/Int. SG/64-9 (1964).

9. A. A. Garren and A. S. Kenney, "A Computer System for Synchrotron Design and 0rbit Analysis", Lawrence Berkeley Laboratory report in preparation.

10. P. F. Meads, Jr., "I. The Theory of Aberrations of Quadrupole Focusing Arrays"; "II. Ion Optical DesIgn of HIgh-Quality Extracted Synchrotron Beams with Applications to the Bevatron", University of Califirnia, Lawrence Radiation Laboratory report UCRL-10807, PhD thesis (1963). 
11. P. F. Meads, Ir., "An thy 7994 Bean, Quadrupole Abersation Progra". Suel. Instr, and Meth. GO, 166 (1966).

12. K. L. Brokm and Sam K. Houry, "Transpore/360 C Compucer Progran for Designing Cinarged Part:cle Bean Transpore jysizms". Stanford Linear Accelerator Cencer report SLAC-91 (1970).

13. T. L. Coliins, "Long Siregght Sections for A. C. Synchrotrons", Cambridge Electron Accelerator zepor: CEA-86 (1961).

14. A. A. Garren, "onstruction of a $\pi$-Phase $\lambda$ dvance Straight Section", Lawrence Padiation Laboratory report, iCLD-101SS (1965).

15. A. A. Garren, "Compensation of " Straight Sections with Bend Ing Magnets", Lawreace Radiation Laboratory report UCLD-10129 (1964).

16. A. A. Garzen, "Design of Long Straight Sections for Synchrotrons", Proc. 5th Int. Conf. High Energy Aicelerators, Frascat1, Italy (1965). p. 22 .

17. Henri jruck, "Acćelérateurs Circulaires de Particules", Institut National das Sciences et Techniques Nucleatrea, Saclay (S.-et. O.) (1966), Translaced by R. R. Fullwood, Los Alames Scientific Laboracory report LA-72-TR-10 (:972).

18. K. Halbach (LBL) private commenication to R. R. Fullwood.

19. E. A. Crosbie, "Negativa Hydrogen Ion Infection inte the ZGS", Argonne National Laboratory internal report EAC-11 (Sept. 11, 1970), also appearing in the CERN Courier $\underline{9}$ (Aug. 1969).

20. "Plon Facility - a High Energy Cyclotron for Negative Ions", University of California report TID-20822 (1964).

21. H. C. Bryant, C. P. Leavitt, B. D. Dieterle, A. Paxton, and P. Lovo1, "Solitary Micropulses by Photodetachment of the $\mathrm{H}^{-}$Beam", Los Alamos Meson Physics Facility proposal $\log$ No. 52 (April 1, 1971).

22. P. W. Allison and C. R. Emigh, "On the Feasibility of $\mathrm{H}^{-}$Ion Acceleration by LAMPF", LoS Alamos Scientific Laboratory Group MP-4 interna1 meinorandum MP-4/PWA, CRE-1 (1968).

23. G. M. Stinsen, W, C. Olsen, W. J. McDonald, P. Ford, D. Ax $n$, and E. W. Blackmore, "Electric Dissociat ion of $\mathrm{H}^{-}$Ions by Mapuetic Fields", Nuc1. Insiz. and Merh. 74, 333 (1969).

24. S, K. Allison, "Experimental Results on ChargeChanging Collisions of Hydrogen and Helium Atoms and Ions at Kinetic Erergies above 0.2 kev", Rev. Mod. Phys. 10, 1137 (1958).

25. S. K. Allison and M. Garcia-Munoz, "Electron Capture and Loss at High Energies", in Atomics and Molecular Processes, P. R. Sdtes, Ed. (Academic P.ess, N.Y., 1962), PP. 721-782.
26. R. Saythe and J.W. Toeus, "Collistonal Electron Detacimene fron tydregen Acons and Negative Hydrogen Ioris Between \& and 18 MeV". Phys. Rev. 139. $+15(1905)$.

27. Private comantcation F. H. Allison to $R$. R. Ful lwood, Los Alamos Seientific Laboratory, Dec. 21, 1971 .

28. H. A. Thiessen, "Stripping Cross Section at $800 \mathrm{MeV} j$ Design of Stripper for $800 \mathrm{MeV}$ ". Los Alamos Scient fif Laboratory Group MPM internai memorandun to P. W. Mllison (Oct. 12, 1970).

29. Bruno Ressi, High Energy Particles (PrenticeHall, In..., N.Y., 1952).

30. B. T. Wright, "On the Acceleration of Negative Ions in a Cyclotron", Arch. Math. Naturvidenskab 54, 1 (1957).

31. Private comonication from J. L. McKibben to R. R. Fullwood, Los Alamos Sciertific LaboraEcry (Dec. 22, 1971).

32. Handtook of Chemistry and Physics, 47th Edition The Chemical Rubber Pullishing Co., Cleveland, ohio, (967).

33. W. H. Barkas and M. J. Berger, "Tables of Energy Losses and Ranges of Heavy Charged Particles". Natinnai Aeronautics and Spac? Administration report NASA SP-3013 (1964).

34. R. M. Sternheimer, "Interaction of Radiation with Matter" in Methods of Experivencal Physics, Vo1. SA (Academic Press, N.Y., 1961), p. 73.

35. Private comenunfatien: L. C. Northeliffe (Texas A\&M University) to L. E. Agnew, Jr. ('ASL) (Sept. 14, 1970). Subject: "On Negativa-ion Stripping within the Acceleratcr as a Heans of Producing Bi-energetic Beams".

36. G. Mackenzie, "Cyclotron Stripping Folls and Target5", Tri-Uni"ersity Meson Facility Design Note TRI-DN-69-15 (April 11, 1969).

37. J. McDermott, "High-Voltage Ionic Discharges Ptovide Silent, Efficient Cooling", Electronic Design 19, 22 (1971).

38. Direct Energy Conversion, G. W. Sutton, Ed. (McGraw-Hill Book Co., N.Y., 1966), P. 242.

39. Smi hsonian Physical Tables, Ninth Revised Edition, Smithsonian Institute, washington, D.C. (1959), pp. 364-367,

40. Sodium Jet Beam Desector, CERN Courier 11, 324 (1971).

41. B. A. D'yachkov, "Production of High Energy Neutral Atoms by Transformation of $\mathrm{H}_{1}^{-}, \mathrm{H}_{2}^{-}$, and $\mathrm{H}_{3}$ Ions in a Supersonic Lithium Vapor Jet", zh. Tekh. Fiz (USSR) 38, 1259 (1968). Eng1ish trans: Soviet Phys. Tech. Phys. (LSA) 13, 1036 (1969).

42. H, R. Smith, Jr., "Application of Dry-Pumped Systems Operating Above $10^{-5}$ Torr", J. Vac. Sci. Tech. 8, 285 (1971). 
43. A. A. Kolomensky and A. N. Lebeder, Theory of Cyclic Accelerators. transiated from the Russian by H. Barbier (CERN) (North-Holland Pub. Co.. Amsterdan, 1966).

44. J, J. Livingood, Principles of Cyclic Barticle Accelerators (D. Van Nostrand Co., Inc., Princeton, N.J., 1961 ).

45. Handbuch Jer Physik, Vol. XLIv "Nuclear Instrumentation $I^{\prime \prime}$, S. Flügge, Ed. (Springer Verlag, Berl1n, 1959), p. 332 et. seq.

46. "The Oanitron - A Nuleipurpose Accelerator", Lavrence Radiation Laboratory report UCRL-16828 (JuIy 1966).

47. "A Proposal for Increasing the Intensity of the Alternating-Gradient Synchrotron at the Brcokheven National Laboratory", Brookhaven Naticnal Laboratory report BNL-7956 (May 1964).

48. R. T. Avery, "LASl. Storage Ring Injection Septun Magnct Concepcual Design", Lawrence Radiation Laboratory Mechanical Engineering Note $M 4488$ (Dec. 9. 1971).

49. A. A. Lake, "Design and Fabrication of the Septum Coil of the Bevatron Extraction Magnet Ml Mark 4". Particle Accelerators 1. 137 (1970).

50. K. H. Reich, "Beam Extraction Techniquus for Synchrotrons", Section III of Progress in Nuclear Tuchniques and Instrumentation, Vol. II, F.J.M. Farley, Ed. (North-Holland Pub. Co., Ansterdan, 1959).

51. E. B. Forsyth and M. Fruitman, "Fast Kiciers", Particle Accelerators 1, 27 (1970).

52. A, Brückner, "Kicking Prctons, Fast and Cheap", IEEE Trans. on Nucl. Sci. NS=18, 976 (1971).

53. "Specification Pour la Fabrication des Pieces Mechaniques Constituant L'knsemble des Hodules Formant le "Kicker"," CERN/SI/Int. MAE/69-12 (1968).

54. P. Bolin, F. Tse, W. Bell, and M. Mulcahy, "Review of Dielectric Media-Vacuun Insulation", Insulation Circuits 16, 59 (1970).

55. J. Fud:an, English Electric San Francisco Represeatative, in private communication with $R$. $L$. Avery, LBL (Dec. 1971).

56. H. O'Hanlon and J. P. Zodasco, "A High Voltage Thyracron Switch for the Fast Inflector of the ISR", CERN Internal Report ISR-BT/67-55 (1967).

57. I. G. Katayev, Electromagnetic Shued Waves, Translated by Scripta Technica Ltd., D. L. Jones, Ed. (Iliffe Buoks, Itd., London, 1966).

58. A. Falcens (LBL) private communication to R. L. Avery (LBL), Dec, 1971.

59. G. N. Glasoe and J. V. Lebacqz, Pulse Generators (Dover Pub., Inc., N.Y., 1948), p. 327 et seq.
60. K. Halbach. "A Progran for Inversion of System Analysis and Its Application to the Design of Magnets", Lawrence Radiation Laboratory report UCRL-17436 (1967).

61. H. F. Vogel and R. Yound, "Magnetic Fielà Computations for 8QN16 and 1IQN15 - Comparison of LINDA and POISSON", Los Alamos Scientific Laboratory Group MP-7 Internal memorandun MP-? $=40$ (Nov. 1972).

62. P. Haloschek, "Storage Rings with Colliding Beams", Kerntechnik 12, 525 (2970).

63. E. D. Courant, "Revision of Gas Scattering Thno:y", Rev. Sei. Instr, 24, 836 (1953).

64. H. Hereward, P. Morton, and K. Schind1, "The Effect of Ions on the Sywmetrical Throbbing Beam Mode", CERN report MPS-SI//Int. DL/68-6 (1958).

65. A. Roth, Vacuum Sealing Techpigues, (Pergamon Press, N. Y., 1966).

66. C. L. Ha11, "Vacuum Joint", U. S. Patent $3,305,250(1964)$.

67. v. Cumings, N. Dean, F. Johnson, J. Jurow, and J. Voss, "Vacum System for Stanford Stovage Ring, SPEAR", J, Vac. Sci. Tech. 8, 348 (1971).

68. P. M. Danielsen, "A Demountable, Stainless Steel to Aluminum Transition Seal for Ultrahigh Vacuum", Vacuun 19, 365 (1970).

69. Proceedings of the Meeting of the High Pressure Technology Assoctation on "Use of Explosives in Forming, Kelding and Compaction", held at the Department of Mechanizal Engineesing of the Queen's University at Belfast, March 19, 1968, J. D. Williams and B. Crossland, Eds.

70. J. Gunn (LBL) private communication to R. R. Fullwood (LASL) Nov. 1971.

71. Handbook of Vacuum Physics, Vol. I, A. H. Beck, Ed. (The Macaillan Co., N.Y., 1966), p. 17.

32. N.T.H. Dennis and T. A. Heppe11, Vacuum System Design. (Chapman and Hall, London, 1968), P. 127.

73. F. S. Reinath, "Proposal and Cos: Estimate for Vacuum System for LASL-LANPF Neutron Facility", Lawrence Berkeley Laboratory ifechanical Engineering Note (March 22, 1971).

74. J. Gervaise, "Positioning the CERN Intersecting Storage Rings: The Geodetic Approack", CERN report CERN 70-18 (1970).

75. "200 BeV Accelerator Design Study", Latrence Radiation Laboratory report UCRL-16000 (June 1965).

76. L. J. Lexicte and 2. Smith, "Analysis of Surveying Procedures That Only Eaploy Distance Measurewents and the Effect of Surveying Errors on the Closed Orbic", Lawrence Radiation Laboratory Internal Repore UCID-10162 (1965). 
77. 1. J. Laslett, "On the Harmonic Response of the Closed Orbit in an Alternating-Gradieni Synchrotron", Lawrence Radiation Laboratory Internal Report UCID-10157 (19E5).

78. M. Dean Keller (compiler), "Geologic Studies and Material Properties Investigations of Mesita de los Alamos", Los Alamos Scientific Laboratory report 'A-3728 (1968).

79. L. J. Laslett, "On Intensity Limitations Imposed by Transverse Space-Charge Effects in Circular Particle Accelerators", Proc. 1963 Sunmer Study on Storage Rings etc., Brookhaven National Laboratory report BNL-7534 (1963), p. 324.

80. L. J. Laslett and L. Resegotti, "The SpaceCharge Limit Imposed by Coherent Oscillation of a Bunched Synchrotron Beam", Proc. 6th Int. Conf. High-Energy Acceleration, Cambridge, MA (1967), pp. 150-152.

81. C. E. Neilsen, A. M. Sessler, and K. R. Symon, "Longitudinal Instabilities In Intense Relativistic Beams", Proc. Int. Conf. High-Energy Accelerators, Geneva, Switzerland (1959), pF. 239-253.

82. V. K. Neil and A. M. Sessler, "Longitudinal Resistive Instabilities of Intense Coasting Beans in Particle Accelerators", Rev. Sci. Instr. 36: 425 (1965).

83. F. T. Cole, G. Parzen, C. H. Pruett, W. A. Wallenmeyer, and D. E. Young, "MURA 50-MeV Electron Accelerator", Rev. Sci. Instr. 35, 1393 (1964).

84. "Intersecting Storage Rings", CERN Technical Booklet No. 5 (May 1969), p. 15.

85. A. Faltens, E. C. Hartwig, D. Mob1, and A. M. Sessler, "An Analog Method for Measuring the Longltudinal Coupling Impedance of a Relativistic Particle Beam with its Environment", Proc. 8 th Int. Conf. High-Energy Accelerators, CERN (1971).

86. I. J. Laslett, V. K. Neil, and A. M. Sessler, "Coherent Electromagnetic Effects in High Current Particle Accelerators: Ií. Electromagnetic Coupling Instabilities in a coasting Beam", Rev. Sci. Instr. 32, 276 (1961).

87. L. J. Laslett, V. K. Neil, and A. M. Sessler, "Transverse Resistive Instabilities of Intense Coasting Beams in Particle Accelerators", Rev. Sci. Instr. 36,436 (1965).

88. C. H. Pruett, R. A. Otte, and F. E. Mills, "Diagnostics and Control or a Coherent Instability in the MURA $50 \mathrm{MeV}$ Electron Accelerator", Proc. 5th Int. Conf. High-Energy Accelerators, Frascati, Italy (Sept. 1965), p. 343.

89. J. H. Martin, R. A. Winje, R. H. Hilden, and F. E. Mills, "Damping of the Coherent Vertica1 Beam Instability in the Argonne ZGS", Proc. 5th Int. Conf. High-Energy Accelerator's, Frascati, Italy (Sept. 1965), p. 347.
90. B. Richter, "Feec'back System for Stabilization of Coherent Oscillations in SFEAR", SLAC-SPEAR Internal Report SPEAR-65 (March 1970).

91. C. Pellegrini, Coherent Instabilities in Electron-Positron Storage Rings, Proc. Intern. School of Physics - Enrico lermi Course XLVI, B. Touschek, Ed. (Academic Press, N.X. 1971), p. 221 .

92. C. Pellegrini, "On a New Instability in ElectronPositron Storage Rings (The Head-Tail Effect)", I1 Nuovo Cimento 64A, 447 (1969).

93. M. Sands, "The Head-Tail Effect: An Instability Mechanism in Storage Rings", Stanford Linear Accelerator Laboratory Internal Report SLAC-TN69-8 (1969).

94. K. W. Robinson, "The Wake Flelds of a Charged Particle Traveling in a Vacuum Chamber with Resistive Walls", Stanford Linear Accelerator Center Report SLAC-49 (1965), P. 32.

95. M. Sands, "Head-Ta1l Effect II: From a Resistive-Wall Wake", Stanford Linear Accelerator Laboratory Internal Report SLAC-TN-69-10 (1969).

96. B. Zotter, "The Influence of Various Beam Profiles on the Transverse Resistive Wa11 Instability", CERN Internal Report ISR-TH/68-5I (1968).

97. E. D. Courant and A. M. Sessler, "Transverse Coherent Resistive Instabilities of Azimuthally Bunched Beams in Particle Accelerators", Rev. Sci. Instr. 37, 1579 (1966).

98. K. R. Symon and A. M. Sessler, "Methods of Radio Frequency Acceleration in Fixed Fie1d Accelerators with Applications to High Current and Intersecting Beam Accelerators", Intern. Accelerator Conf., CERN (1956), p. 44.

99. A. M. Sessler (LBL) to R. R. Fullwood (LASL), private communication, March 17, 1972.

100. "Fast Burst Reactors", Proc. Nat1. Topical Meeting on Fast Burst Reactors, University of New Mexico, Jan. 28-30, 1969. U.S. Atomic Energy Commission AEC-15 (1969).

101. "Neutron Sources and Applications", Proc. Nucl. Soc. Nat1. Topical Meeting, April 19-21, 1971, Augusta, Georgia. Savanna k kver Laboratory report CONF-710402.

102. Los Alamos Sclentific Laboratory Form 44 Proposal for an Intense Proton Storage Ring, 1972 (SRD).

103. P. L. Csonka, "Could We Build Polarized Proton Storage Rings", Nucl. Instr. Meth. 63, 247 (1968).

104. J. F. Hague, J. E. Rothberg, A. Schenck, D. L. Williams, R. W. Willianls, K. K. Young, and K. M. Crowe, "Precision Measurement of the Magnetic Moment of the Muon", Phys. Rev "Letters $\underline{25}, 628$ (1970). 
105. J. Bailey and E. Picasso, "The Anomalous Magnetic Moment of the Muon and Relaced Topics", Prog. Nuc1. Phys. 12, 43 (1970).

106. R. Macek and B. Mag1ic, "The Principle of SelfColliding Orbits and Its Possible Application to $\pi-\pi$ and $\mu-\mu$ Collisions", Particle Accelerators 1,121 (1970).

107. A. M. Sessler and V. G. Vaccaro. "Passive Compensation of Longitudinal Space Charge Effects in Circular Accelerators: The Helical Insert", CERN 68-1, Geneva (1968).

108. R. J. Briggs, "Dielectric Wall Stabilization of Intense Charged Particle Beams", U.S. Patent $3,324,325$ (1965).

109. R. J. Briggs and V. K. Neil, "Stabilization of Intense Coasting Beains in Particle Accelerators by Means of Induction Walls", Plasma Phys. $\underline{8}$, 255 (1966).

110. Y. S. Derbenev, N. S. Dikanskii, "Damping of Coherent Beam Oscillations in a Storage Ring", SLAC-Trans-106 (1969).
111. G. J. Budker, "Relativistic Stabilized Electron Beams. Part I, Physical Principles and Theory", and "Part II (with A. A. Naumov), Brief Review of Experimental work", CERN Symposium on High Energy Accelerators, Geneva (June 11-23, 1956).

112. W. Maurer, "Proton Beam Cooling with Electrons in the Nonrelativistic Case", IEEE Trans. Nuc1. Sci. NS-1E, 281 (1969).

113. W. Maurer, "Proton Beam Cooling with Electrons in the Relativistic Case", Institut fur Experimente1le Kernphysik Kernforschungzentrum Karlsruhe Internal Report (no date).

114. H. G. Hereward, "Artificial Damping in the CERN Proton Storage Ring", Symposium International sur les Anneaux de Collisions a Electrons et Positrons, Saclay, France, VIII-3-1 (1966).

115. Experimental Neutron Resonance Spectroscopy, J. A. Harvey, Ed. (Academic Press, N.Y., 1970). 